
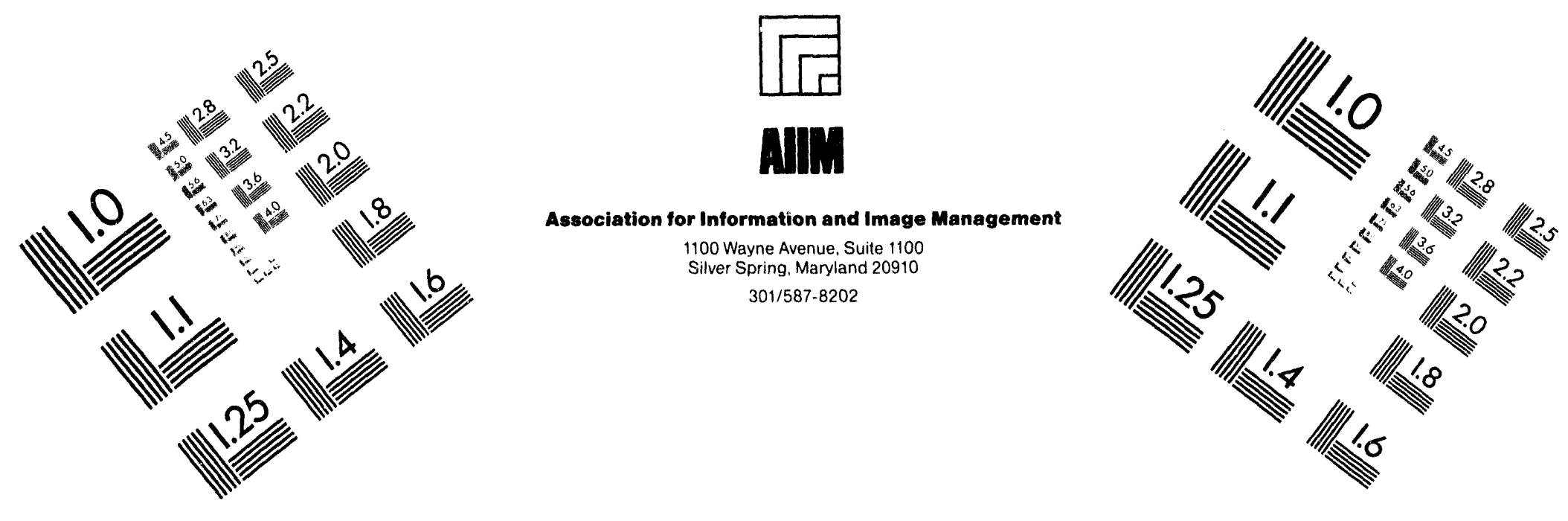

\title{
Centimeter
}

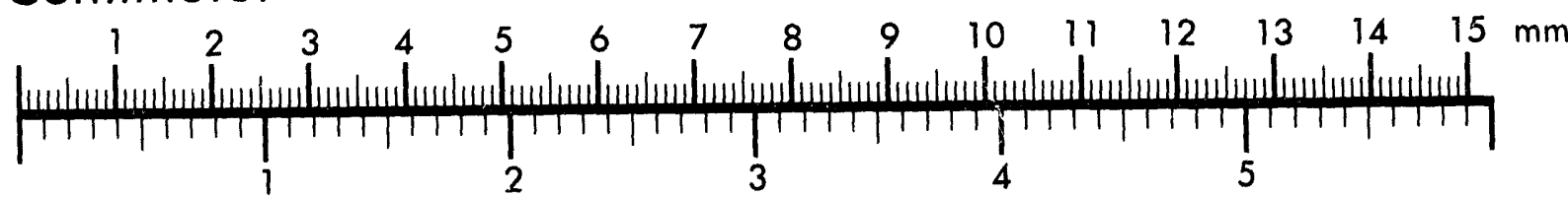

Inches

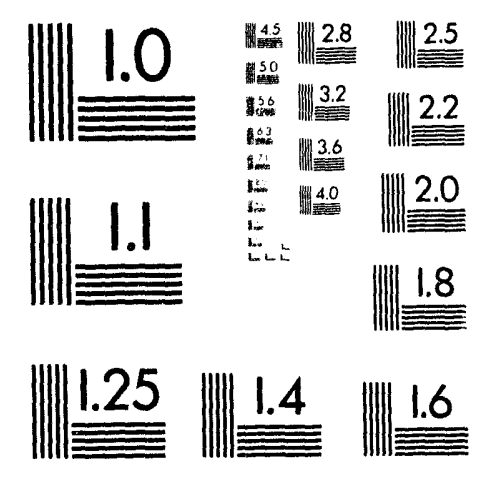

$-$

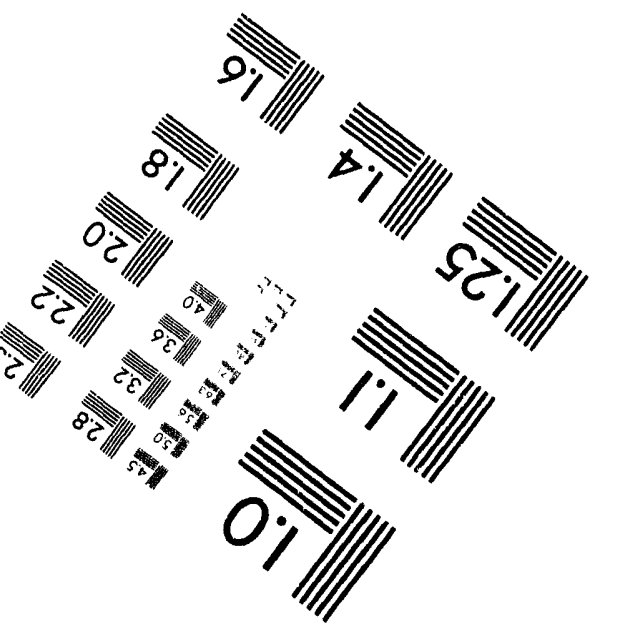

MANUFACTURED TO AIIM STANDARDS BY APPLIED IMAGE, INC.

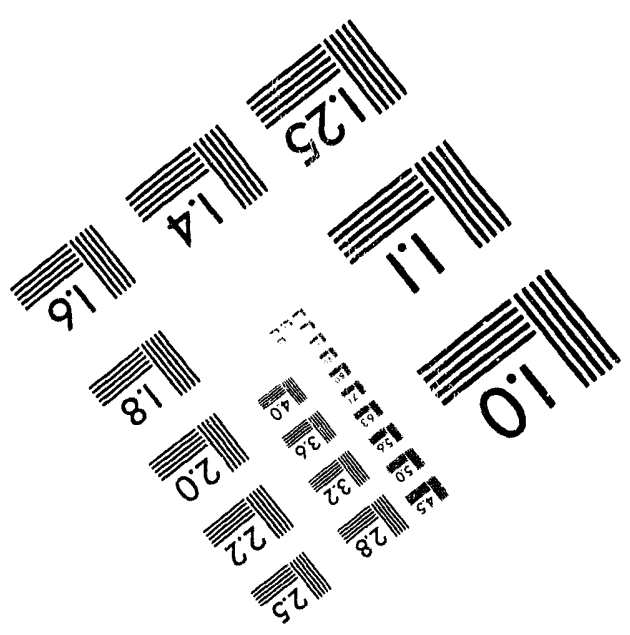



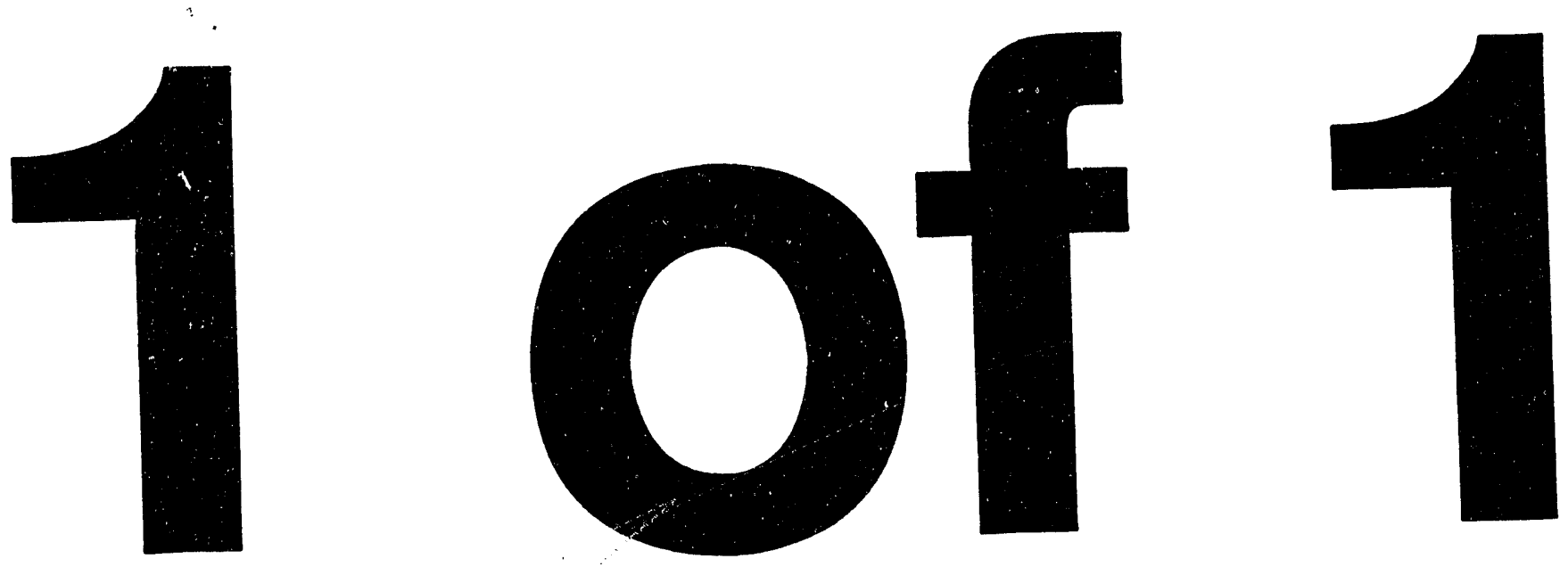
Distribution Category:

High-Level Radioactive Waste Disposal in Tuff

(UC-814)

\title{
ARGONNE NATIONAL LABORATORY \\ Chemical Technology Division \\ 9700 South Cass Avenue \\ Argonne, Illinois 60439
}

\section{CRITICAL REVIEW OF GLASS PERFORMANCE MODELING}

\author{
by \\ William L. Bourcier \\ Earth Sciences Division \\ Lawrence Livermore National Laboratory \\ Livermore, California
}

July 1994

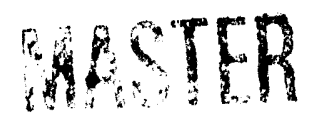


TABLE OF CONTENTS

Page

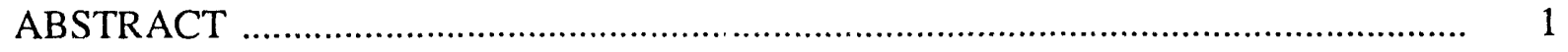

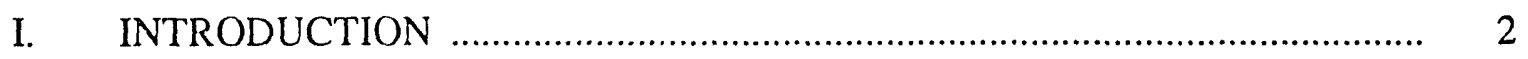

II. BACKGROUND INFORMAT!ON ....................................................... 4

A. Overview of Glass Dissolution Processes ........................................... 4

B. Experimental Database for Glass Dissolution Modeling …..................... 8

III. GLASS DISSOLUTION MODELS _..................................................... 13

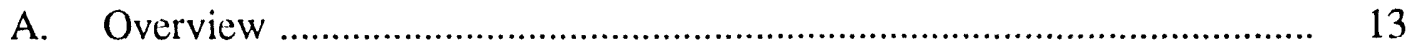

B. Solid-State Diffusion Models .............................................................. 13

C. Nonkinetic Reaction Path Models .................................................... 13

D. Kinetic Reaction Path Models .......................................................... 14

1. The Rate Law ............................................................................. 17

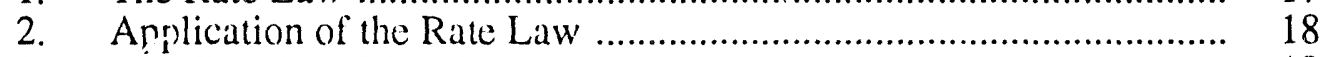

3. The Grambow Model ................................................................. 19

4. Curti's Critique of the Grambow Model .......................................... 21

5. Other Kinetic Reaction Path Models ............................................ 22

E. Hydration Theory for Estimating Glass Durability ............................... 25

F. Parametric Modeling Studies of Glass Dissolution ................................ 29

1. Effects of Glass Composition ....................................................... 29

2. Effects of Temperature ........................................................ 31

3. Effect of $\mathrm{pH}$....................................................................... 31

4. Effects of Secondary Phases ...................................................... 32

5. Effects of Radiolysis ............................................................... 33

6. Effects of Surface Chemistry .................................................... 33

G. Model Applications …............................................................... 35

1. Results from Applying the Grambow Model ............................... 35

2. Modeling Unsaturated Test Results .................................................. $\quad 35$

3. Modeling Accelerated Rates .................................................... 37

4. Interactions with Other Repository Materials ................................ 39

5. Application of Glass Dissolution Models to Natural Analogues ...... 39

6. Modeling the Release of Actinides ................................................. 40

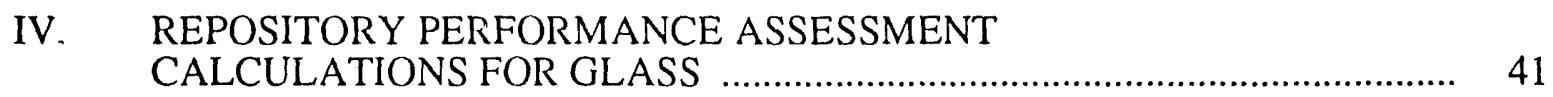

V. SUMMARY AND CONCLUSIONS ..................................................... 42

A. Outstanding Problems .................................................................. 42

B. Recommended Future Experimental and Modeling Work .................... 43

1. Issues Needing Investigation ..................................................... 43

2. Types of Experiments Needed …................................................... 44

VI. ACKNOWLEDGMENTS _.................................................................. 47

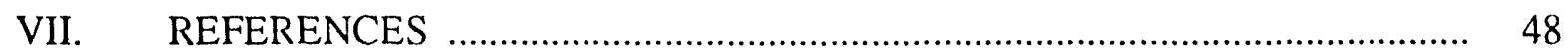




\section{LIST OF FIGURES}

No.

Title

Page

1. Glass Dissolution Mechanism ................................................................ 5

2. Cross Section through Typical Alteration Layer Forming on

Borosilicate Glass Surface during Early Stages of Dissolution

3. Normalized Elemental Release from SRL 165 Glass Reacted

in 0.003 molal $\mathrm{NaHCO}_{3}$ at $150^{\circ} \mathrm{C}$ with a Surface Area-to-

Volume Ratio of $0.01 \mathrm{~cm}^{-1}$

4. Silica Release Data for SRL 165 Glass

5. The pH Dependence of Silica Release Rate from SRL 165 and

Five-Component Analogue (CSG) Glasses, as Measured in

Open-System Tests

6. Results from Nonkinetic Reaction Path Modeling of the

Reaction at $90^{\circ} \mathrm{C}$ of SRL 165 Glass with J-13 Groundwater

from the Proposed Yucca Mountain Repository Site

7. Experimental Data from Ebert et al. Showing Accelerated

Dissolution Rate for SRL 202 Glass Reacted in EJ-13 Water

at $90{ }^{\circ} \mathrm{C}$ with a Surface Area-to-Volume Ratio of $20,00\left(0 \mathrm{~m}^{-1}\right.$

8. Model Simulation Results and Experimental Data for

Closed-System Dissolution Tests of SRL 165 Glass in

(0.003 molal $\mathrm{NaHCO}_{3}$ Solution at 15()$^{\circ} \mathrm{C}$, with a Surface

Area-to-Volume Ratio of $0.01 \mathrm{~cm}^{-1}$

9. Relation between the Normalized Mass Loss of Silicon Measured

in an MCC-1 Test and the Calculated Free Energy of Hydration

for a Variety of Glass Compositions

10. Types of Surface Complexes Potentially Present at Glass-

Solution Interface

11. Comparison of Experimental and Calculated Normalized

Solution Data for Elements Released from R7T7 Glass at $90^{\circ} \mathrm{C}$

12. Results of Simulations of Interactions of SRL 2(12 Glass with

EJ-13 Water in Unsaturated Test

13. Proposed Microscopic Structure of Glass-Solution Interface 


\section{LIST OF TABLES}

No. $\quad$ Title $\quad \underline{\text { Page }}$

1. Compositions of Glasses by Weight Percent of Oxides ................................... 4

2. Free Energies of Hydration for Glass Components ......................................... 27 


\title{
CRITICAL REVIEW OF GLASS PERFORMANCE MODELING
}

\author{
by \\ William L. Bourcier \\ Earth Sciences Division \\ Lawrence Livermore National Laboratory \\ Livermore, California
}

\begin{abstract}
Borosilicate glass is to be used for permanent disposal of high-level nuclear waste in a geologic repository. Mechanistic chemical models are used to predict the rate at which radionuclides will be released from the glass under repository conditions. The most successful and useful of these models link reaction path geochemical modeling programs with a glass dissolution rate law that is consistent with transition state theory. These models have been used to simulate several types of short-term laboratory tests of glass dissolution and to predict the long-term performance of the glass in a repository. Although mechanistically tased, the current models are limited by a lack of unambiguous experimental support for some of their assumptions. The most severe problem of this type is the lack of an existing validated mechanism that controls long-term glass dissolution rates. Current models can be improved by performing carefully designed experiments and using the experimental results to validate the rate-controlling mechanisms implicit in the models. These models should be supported with long-term experiments to be used for model validation. The mechanistic basis of the models should be explored by using modern molecular simulations such as molecular orbital and molecular dynamics to investigate both the glass structure and its dissolution process.
\end{abstract}




\section{INTRODUCTION}

The purpose of this report is to provide a critical summary of current work on the development of chemical models for borosilicate glass dissolution. When these models have been sufficiently refined, they will be used to predict the rate of release of radionuclicies from borosilicate glass waste form stored in a high-level nuclear waste repository over long time periods (10,000 years or longer). The models will also be used to determine whether the calculated release rates are less than the maximum allowable release rates specified by U.S. Nuclear Regulatory Commission Regulation 10 CFR 60. Experiments alone are insufficient to satisfy these requirements because they cannot be performed over the extended time period (up to tens of thousands of years) over which radionuclides will be released, and they cannot be performed for the numerous sets of possible conditions anticipated for the repository site. Simple extrapolations of short-term test results according to an empirical rule are not sufficient. Although the identification of the important chemical processes taking place during glass dissolution is best achieved through carefully designed experiments, an understanding of the interactions and coupling of these processes is best achieved through modeling.

Successful extrapolation of experimental data to conditions outside the range of what can be measured demands a quantitative, mechanistic understanding of the complex chemical processes taking place during glass dissolution. This is the fundamental reason why chemical modeling is needed in the performance assessment of nuclear waste repositories. The mechanistic chemical model for glass dissolution is also needed so that waste glass performance can be coupled with the hehavior of other repository materials also undergoing degradation by reaction with groundwater. All these reactions are coupled by the interaction of a common reservoir of water with each type of repository material. A mechanistically based glass performance model is therefore essential for interfacing a glass dissolution model with repository performance assessment models.

Glass dissolution models will also be used to link short-term tests of glass durability (performed as a quality control check on giass melter production) and long-term behavior of the glass under repository conditions. By providing this link, such models will help resolve fundamental problems that currently exist in our development of high-level waste forms: no validated methodology exists that allows short-term performance tests to be used to predict long-term glass performance. In fact, glasses of differing compositions may show one order of durability in one type of performance test, but a different order of durability in an alternate test. Currently, we cannot directly relate any durability test to the suitability of the glass waste form for use in a repository. In fact, a glass composition that is optimum for one repository may not be optimum for an alternate repository. Therefore, in developing glass waste forms and optimizing them for any proposed repository, we should base predictions of their long-term performance on both site-specific experiments and models of those experiments.

This report is one in a series of critical reviews of the literature on nuclear waste glass performance. Together, these reviews will provide a sound data base to support the qualification of nuclear waste glass for disposal. In this report, we first briefly summarize what is known about the processes taking place during glass dissolution (Section II). Much of this material is described in more detail in other reports in this critical review series. In this section we only attempt to identify and define the important processes to which we refer later in the discussions of model applications. We include in Section II an evaluation of the types of experiments used in the development and application of glass dissolution models. The current database of experimental results is lacking in some key areas. Most significantly, much of the reported data is incomplete. in order to interpret experiments in terms of rates and mechanisms and incorporate the results into a mechanistic model, the experiment must be fully characterized, including solution, glass, and alteration layers. Too often, only a partial examination of the test 
is reported. Further model development is highly dependent on carefully examined glass reaction tests, and in particular on detailed analysis of the reacted glass surface layers.

In Section III, we review the major glass dissolution models. We discuss how several of these models are applied to glass waste form dissolution tests. As will be shown, the models most useful for predicting long-term glass dissolution in a repository environment share a methodology. We discuss the assumptions behind this methodology and point out conditions under which the models cannot be expected to perform well. We also describe some examples of the application of mechanistic models to both waste glasses and natural glasses, and we describe how factors such as glass composition, temperature, $\mathrm{pH}$, radiolysis, unsaturated hydrologic conditions, and secondary phase formation have been treated in the models.

Section IV provides a critical summary of work performed to date on performance assessment calculations of borosilicate glass in potential high-level nuclear waste repositories. We discuss current limitations of the various approaches and make recommendations as to how the models can be improved.

We conclude in Section V with a summary of the current status of glass dissolution modeling and a summary of recommendations for future work. This is work we believe will be most effective in increasing our understanding of borosilicate glass dissolution and therefore improving our ability to make long-term predictions of radionuclide release rates from a repository. 


\section{BACKGROUND INFORMATION}

More information on the details of the glass dissolution process are given in other reports in this critical review series (see ANL-91/17 and ANL-93/45). The description here is aimed at identifying the important features and processes which must be accounted for in chemical modeling of glass dissolution. The compositions of glasses referred to throughout the text are listed in Table 1.

\section{A. Qverview of Glass Dissolution Processes}

Glasses are metastable solids which over time and in contact with water will partially dissolve, forming crystalline and noncrystalline secondary solids and releasing some elements into solution. Fortunately, in most aqueous systems, the transformation rates are not large. In closed systems, the dissolution rate slows with time; as the concentration of glass constituents in solution increases, the affinity for dissolution decreases. In addition, the buildup of a hydrated and less reactive surface layer may protect the glass and partially inhibit further reaction.

Table 1. Compositions of Glasses by Weight Percent of Oxides

\begin{tabular}{|c|c|c|c|c|c|c|c|c|}
\hline Oxide & SRL 165 & JSS-A & PNL 76-68 & SRL 131 & SRL 202 & R7T7 & CSG & $\begin{array}{l}\text { Basalt } \\
\text { Glass } \\
\end{array}$ \\
\hline $\mathrm{Al}_{2} \mathrm{O}_{3}$ & 4.08 & 4.9 & 0.7 & 3.1 & 3.8 & 4.9 & 11.7 & 14 \\
\hline $\mathrm{B}_{2} \mathrm{O}_{3}$ & 6.76 & 14.4 & 9.3 & 9.9 & 8.0 & 14.0 & 8.43 & -- \\
\hline $\mathrm{BaO}$ & 0.06 & .. & ().5 & 0.1 & 0.22 & 0.6 & -- & -- \\
\hline $\mathrm{CaO}$ & 1.62 & 4.0 & 2.4 & 1.0 & 1.2 & 4.0 & 6.0 & 11 \\
\hline $\mathrm{CeO}_{2}$ & -- & 0.9 & 0.9 & 0.2 & -- & 0.93 & -- & -- \\
\hline $\mathrm{Cs}_{2} \mathrm{O}$ & 0.07 & 1.4 & 0.9 & 0.3 & -- & 1.4 & -- & -- \\
\hline $\mathrm{Fe}_{2} \mathrm{O}_{3}$ & 11.3 & 2.9 & 9.3 & 14.3 & 11.4 & 2.9 & -- & 4 \\
\hline $\mathrm{FeO}$ & 0.35 & -. & -- & -- & -- & -- & -- & 8 \\
\hline $\mathrm{K}_{2} \mathrm{O}$ & -- & -- & -. & ().1 & 3.7 & -- & -- & 0.2 \\
\hline $\mathrm{La}_{2} \mathrm{O}_{3}$ & -- & 0.9 & 4.1 & 0.3 & -- & 0.90 & -- & -- \\
\hline $\mathrm{Li}_{2} \mathrm{O}$ & 4.18 & 2.0 & -- & 3.9 & 4.2 & 2.0 & -- & -- \\
\hline $\mathrm{MgO}$ & 0.70 & -. & -- & 1.2 & 1.3 & -- & -- & 7 \\
\hline $\mathrm{MnO}$ & 2.27 & -- & 0.04 & 4.2 & 2.2 & ().30 & -- & 0.2 \\
\hline $\mathrm{MoO}_{3}$ & -- & 1.7 & 1.9 & -- & 0.05 & 1.7 & $-\cdots$ & -- \\
\hline $\mathrm{Na}_{2} \mathrm{O}$ & 10.8 & 9.8 & 13.9 & 14.8 & 8.9 & 9.9 & 18.2 & 2.5 \\
\hline $\mathrm{NiO}$ & 0.85 & -- & -- & 1.5 & 0.82 & 0.73 & -- & -- \\
\hline $\mathrm{SiO}_{2}$ & 52.8 & 45.2 & 41.5 & 38.6 & 49.0 & 45.5 & 55.7 & 51 \\
\hline $\mathrm{SrO}$ & 0.11 & -. & 0.4 & 0.1 & 0.03 & 0.33 & -- & -- \\
\hline $\mathrm{TiO}_{2}$ & 0.14 & -- & 3.0 & 0.8 & 0.91 & -- & -. & 2 \\
\hline $\mathrm{ZnO}$ & 0.04 & 2.5 & 4.6 & -- & 0.02 & 2.5 & -- & -. \\
\hline $\mathrm{ZrO}_{2}$ & 0.66 & 2.6 & 1.8 & 0.3 & 0.10 & 1.7 & -. & -- \\
\hline $\mathrm{U}_{3} \mathrm{O}_{8}$ & 0.96 & 0.5 & -. & 1.6 & 1.9 & 0.54 & - & -- \\
\hline $\mathrm{P}_{2} \mathrm{O}_{5}$ & 0.29 & -- & 0.7 & 0.1 & - & 0.28 & - & 0.1 \\
\hline Reference & {$[125]$} & {$[81]$} & {$[70]$} & {$[70]$} & {$[24]$} & [23] & {$[24]$} & {$[10]$} \\
\hline
\end{tabular}


Glass reactions in aqueous environments are complex and depend on both glass composition and solution chemistry. Many different glass dissolution tests have been performed and a seemingly unlimited number of reaction mechanisms inferred. However, although the reaction products and reaction rates are much different for glasses reacted under different conditions, it appears that the same chemical processes are taking place under all conditions. Differences in the appearance of reacted glasses are due to changes in the relative rates of a common set of processes.

Figure 1 illustrates the major processes taking place during glass dissolution. The reaction begins with water diffusion into the glass and alkali ion exchange. Evidence for water diffusion comes from secondary ion mass spectroscopy (SIMS) and ion-probe profiling of reacted glasses. The profiles show penetration of water in a surface zone generally less than $1 \mu \mathrm{m}$ thick $[1,2]$. Ion exchange is indicated by the early, rapid release of aikalis relative to other glass components that is commonly observed in glass dissolution tests [3]. A typical ionexchange reaction is

$$
\mathrm{Na}^{+} \text {(glass) }+\mathrm{H}^{+} \leftrightarrow \mathrm{Na}^{+}+\mathrm{H}^{+} \text {(glass) }
$$

in which $\mathrm{Na}^{+}$in the glass is released and replaced with $\mathrm{H}^{+}$. Hydration and ion exchange result in the formation of two layers on the glass surface: an inner "diffusion layer," where concentration gradients for alkalis and water are observed, and an outer, hydrated "gel layer," where network hydrolysis (breakage of Si-O-Si bonds) takes place (Fig. 2). The gel layer is depleted in alkalis and horon and enriched in insoluble elements such as $\mathrm{Al}, \mathrm{Ca}, \mathrm{Mg}$, and heavy metals (e.g., actinides). The cations enriched in this layer tend to be those that form the most insoluble oxide or silicate phases in the leachate. The combined thickness of the gel layer and diffusion layer is commonly in the range of a few tenths of a micron to tens of microns, depending mainly upon the duration, temperature, and $\mathrm{pH}$ of reaction.

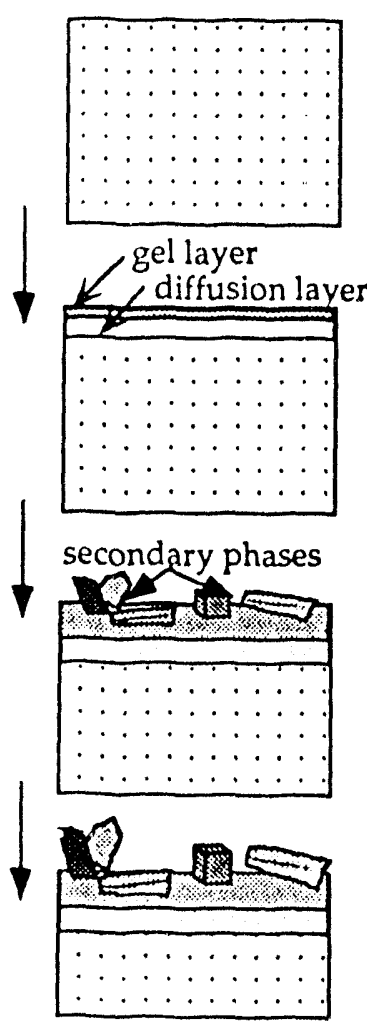

\author{
Glass begins to \\ react with water \\ Hydration and ion \\ exchange at the \\ surface.
}

Fig. 1.

Diffusion layer thickens until rate of diffusion of alkalis equals rate of network dissolution.

Diffusion layer maintains constant thickness as glass dissolves at steady state. Secondary phases continue to grow. 


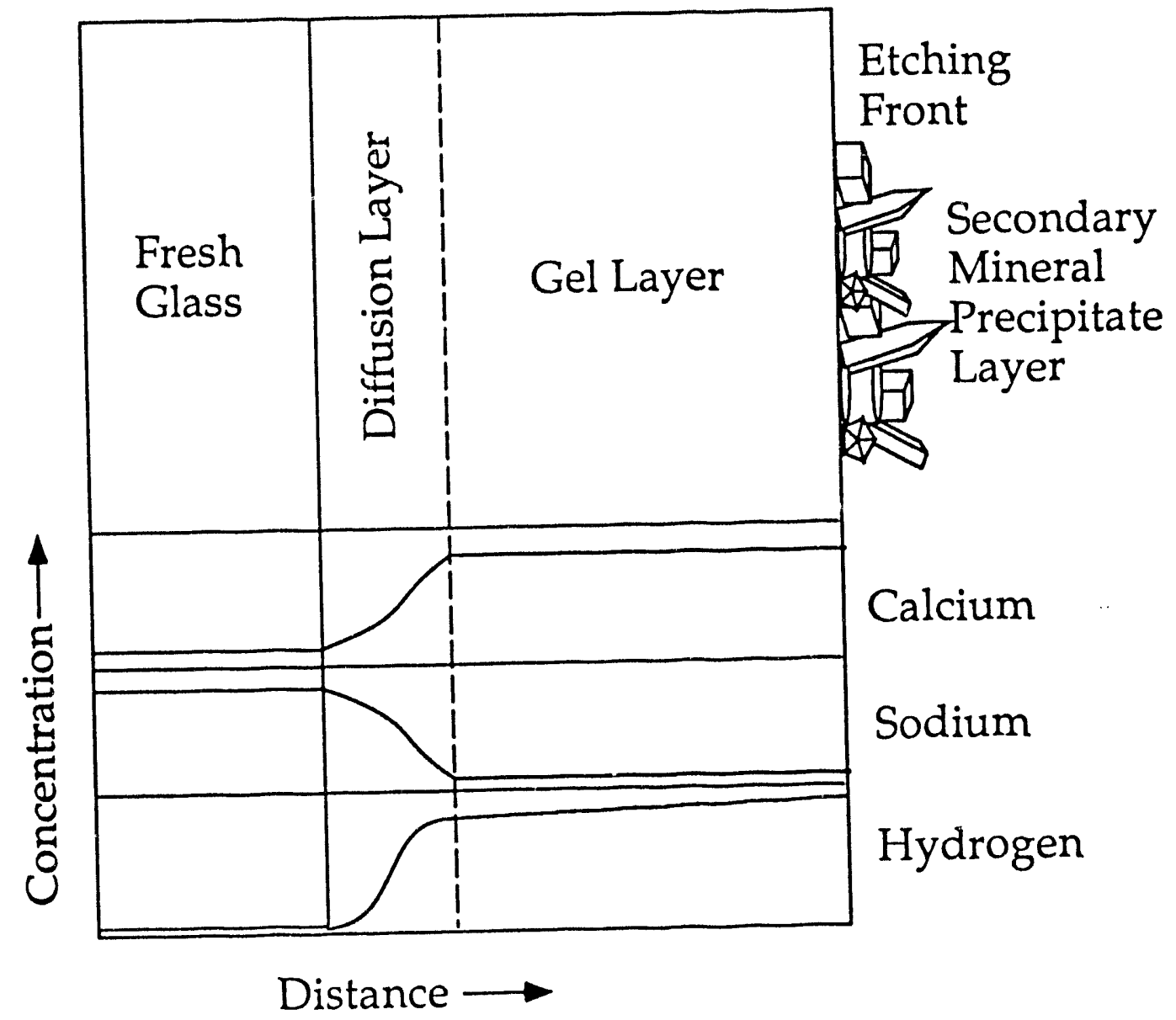

Fig. 2. Cross Section through Typical Alteration Layer Forming on Borosilicate Glass Surface during Early Stages of Dissolution

With time, some elements released into solution reprecipitate on the hydrated glass surface and elsewhere as a variety of secondary phases. Water allows glass to react and transform into a set of crystalline phases that are thermodynamically more stable. These phases are commonly clays, zeolites, and metal oxides/hydroxides [4]. Water acts as a flux and allows the glass to react at a measurable rate. Under anhydrous conditions, even glass compositions that are relatively nondurable in water are stable for up to billions of years $[5,6]$.

Either of the two primary processes of glass dissolution, network dissolution and ion exchange, may be rate-limiting for the o verall glass dissolution process. Note that in the discussion of glass dissolution, the term "rate of ion exchange" refers to the rate at which the species undergoing ion exchange diffuse through the altered glass surface layers. The ionexchange process itself is rapid. Evidence for diffusion of ions during ion exchange includes the observed diffusion profiles of ions in the diffusion layer and the nonstoichiometric release of ions in the early stages of leach tests [1]. Dissolution at the gel layer-solution interface is indicated by the observable migration of the surface layer into the fresh glass $[7,8]$ and by massbalance calculations combined with surface analyses [1]. 
Steady-state conditions are commonly observed during glass dissolution. Under these conditions, the rates of water diffusion and ion exchange are equal to the rate at which the glass network dissolves, and the diffusion layer remains approximately constant in thickness while the glass dissolves away. The steady state is a consequence of positive feedback between the rates of diffusion and the rate of network dissolution at the glass surface. For example, if the network dissolution rate increases, then the diffusion gradients increase, causing the diffusion rate to increase as well. A similar positive feedback exists to counter changes in the diffusion rate or diffusion layer thickness.

Under steady-state conditions, the mass of secondary phases increrses with time [9]. In open-sysiem (flow-through) 6 :xperiments, the rate of release of most elements is approximately constant or slowly decreases with time. In closed-system experiments, the release rates decrease more rapidly with time because of "saturation" effects, i.e., the buildup of dissolved glass species in solution (Fig. 3). Elemental releases from glasses in closed-system tests also show nonstoichiometric behavi or; some elements are released much more rapidly than others (Fig. 3). Most of this nonstoichiometry is due to the precipitation of the less soluble glass components as secondary mineral phases, altiough a small part of it is accounted for by the formation of alteration layers.

Nuclear magnetic resonance (NMR) spectroscopy shows that the network dissolution reactions taking place in the gel layer are complex. Experiments on glass doped with ${ }^{17} \mathrm{O}$ show that $\mathrm{Si}-\mathrm{O}-\mathrm{Si}$ lirikages are both breaking and reforming [12]. Hydrolysis of the highly stressed glass structure allows relaxation and removal of incompatible elements. The original glass is transformed into a hydrous, silica-rich phase interspersed with local areas enriched in transition and other heavy metals, such as actinides. The metals in these areas eventually crystallize into a varicty of solid phases or are released into solution. In some open-system glass dissolution

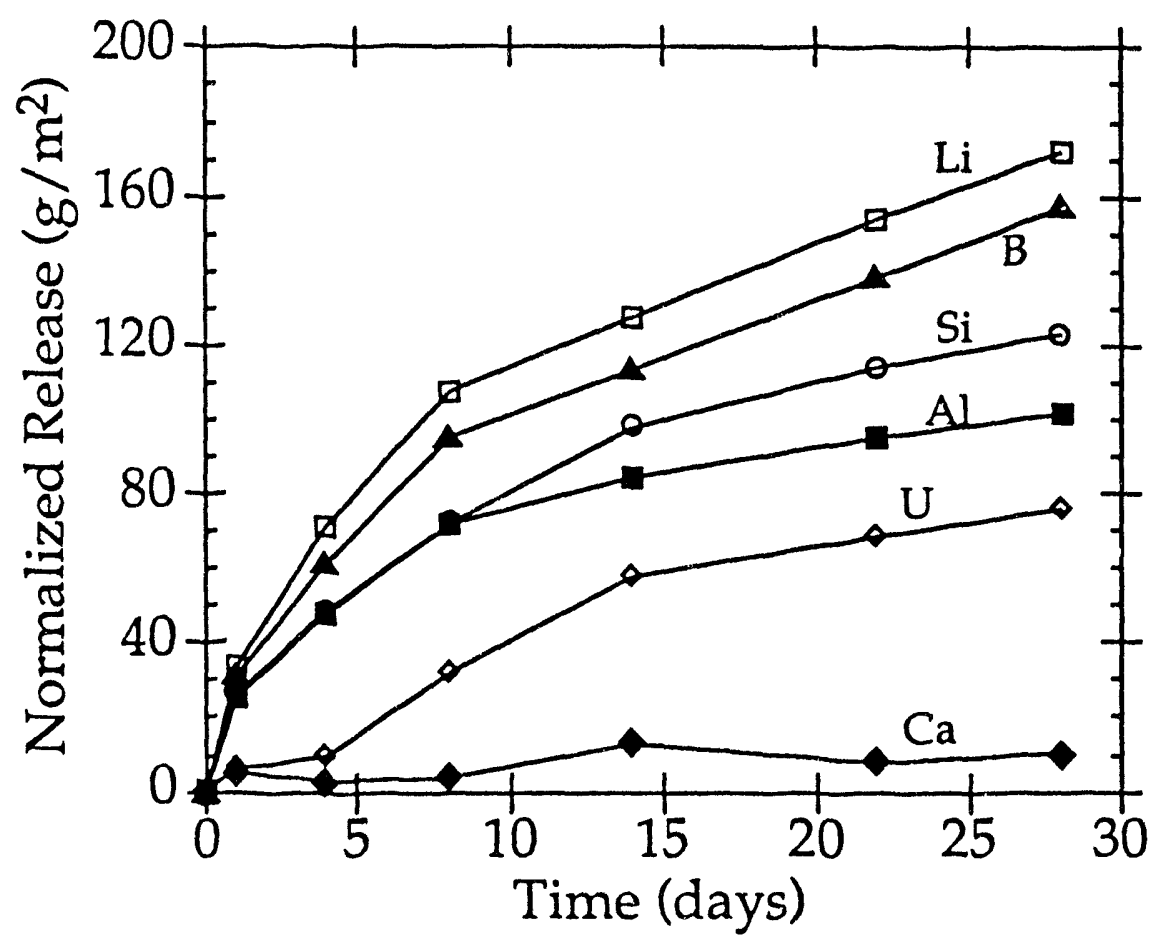

Fig. 3. Normalized Elemental Release (NL) from SRL 165 Glass Reacted in 0.003 molal $\mathrm{NaHCO}_{3}$ at $150^{\circ} \mathrm{C}$ with a Surface Area-to-Volume Ratio of $0.01 \mathrm{~cm}^{-1}[10,11]$ 
tests, the gel layer appears to serve as a transport barrier that limits the overall dissolution rate [13]. However, in most closed-system experiments, elemental release data and electron microscopic examination of the surface layers show that the overall reaction rate is not controlled by diffusion of elements through the alteration layers [14-17]. Note, however, that some recent Product Consistency Test (PCT) data [17] show a significant effect of surface layer formation and possible diffusional rate control for some simple borosilicate glass compositions.

Recent NMR data have also shown that boron in waste glasses is clustered into boronrich regions [18]. Boron occurs in both three- and four-fold coordination with alkalis in a sodium diborate-type structure. The high reactivity and solubility of these zones gives rise to the relatively rapid release of boron from borosilicate glasses in leach tests.

There is a consensus that long-term glass dissolution rates are controlled primarily by silica concentration in solution $[13,15]$. However, other dissolved species also affect glass dissolution rates $[7,19-25]$. For example, the dissolution rates of silicate glasses are strongly decreased in the presence of dissolved $\mathrm{Mg}, \mathrm{Pb}$, and $\mathrm{Zn}$ and strongly enhanced, under some conditions, by cissolved Fe (see Section III.G.4). Likewise, anions such as phosphate and sulfide are known to affect mineral dissolution rates and may likewise affect glass dissolution rates. The effects of metals may be attributable to several processes depending upon the metal, including the formation of surface complexes, the precipitation of a surface layer providing a transport barrier, and the reaction of dissolved glass species with the dissolved metals causing the precipitation of colloids or secondary phases that affect the glass dissolution affinity [22]. Other mechanisms are also possible. These types of effects are potentially important in repository environments, where a variety of dissolved species will be present from other repository materials. What remains unclear is whether dissolved species affect the reaction rate through surface complexation, precipitation of secondary phases, saturation effects, or a combination of effects.

In summary, a model for borosilicate glass dissolution must account for the following processes: (1) kinetically controlled network dissolution, (2) precipitation of secondary phases, (3) ion exchange of selected elements, (4) in some cases, rate-limiting diffusive transport through a hydrous surface reaction layer, and (5) specific interactions between the glass surface and dissolved cations and anions. A model that adequately represents this set of coupled processes shculd be able to quantitatively predict observations of glass dissolution, including the saturation effect (glass dissolution rates slows as dissolved glass species build up in solution); the increase in $\mathrm{pH}$ that accompanies glass dissolution in closed-system tests; the variation of glass dissolution rate as a function of glass composition; and rate-affecting interactions between the glass surface and dissolved cations and anions. We will first look at examples of how the five processes are incorporated into current models (Section III.D) and then critically review modeling results from a representative set of applications (Section III.G).

\section{B. Experimental Database for Glass Dissolution Modeling}

Before experiments can be used to isolate and measure the parameters needed as input into a glass dissolution model, certain information must be obtained. The same is true when site-specific glass dissolution tests are to be used to validate a model. If all the key information has not been collected, the tests cannot be used in model development or validation. To define those needs, we first explain some chemical characteristics of the glass dissolution process. We then show how this information can be used to identify the most important experimental measurements for the purpose of developing a quantitative dissolution model. 
In closed-system tests, soluble elements typically show parabolic release trends, i.e., the release rate is initially high, then decreases and becomes approximately linear with time (Fig. 4). This result has often been used as evidence for diffusion control of the reaction rate. Although the early parabolic behavior may be due to initial rapid ion exchange and associated diffusion of ions and water through a continuously forming diffusion layer [26], the later linear leaching behavior is due to a surface dissolution reaction. Equations describing the two types of rate control, diffusion control and reaction affinity control, were regressed on the silicon release data shown in Fig. 4. The regressions show that the two mechanisms explain the release data equally well [27]. For most glasses, the initial rate-limiting reaction is diffusion, which changes after a few hours or weeks (depending on test conditions and glass composition) to surface reaction control. Figure 4 clearly indicates that resolving this changeover will be difficult or impossible and that curve-fitting of observed leaching trends to distinguish between the two mechanisms is not conclusive.

The change in $\mathrm{pH}$ with time during leach tests reflects the complexity of the dissolution process. In leach tests of simulated waste glasses with $\mathrm{J}-13$ well water, ${ }^{*}$ ion exchange of $\mathrm{H}^{+}$in solution for alkalis in the glass initially causes the $\mathrm{pH}$ to rise. Dissolution of the alkali and alkaline earth components of the glass also causes the $\mathrm{pH}$ to increase, as a result of reactions such as

$$
\mathrm{CaO}_{\text {(component in glass) }}+2 \mathrm{H}^{+}=\mathrm{Ca}^{2+}+\mathrm{H}_{2} \mathrm{O} \text {. }
$$

However, for components such as alumina, the $\mathrm{pH}$ is decreased through the reaction

$$
\mathrm{Al}_{2} \mathrm{O}_{3 \text { (component in glass) }}+5 \mathrm{H}_{2} \mathrm{O}=2 \mathrm{Al}(\mathrm{OH})_{4}{ }^{-}+2 \mathrm{H}^{+} \text {. }
$$

Precipitation of secondary phases also increases or decreases the $\mathrm{pH}$ of the solution, depending on whether the precipitation reaction consumes or releases acid. These dissolution and precipitation processes give rise to a complex change of $\mathrm{pH}$ with time for unbuffered glasswater systems. Generally, the $\mathrm{pH}$ increases steadily throughout the reaction, rising more quickly at first.

This $\mathrm{pH}$ effect is important because open-system tests of borosilicate glasses have shown that the glass dissolution rate is highly dependent on $\mathrm{pH}$ (Fig. 5). Therefore, it is critical to take into account the $\mathrm{pH}$ of the leachate solution when comparing dissolution rates of different glasses. This is particularly a problem when one tries to compare the relative durability of two glasses in the same initial solution. Although relative durabilities can be determined for the specific test conditions, the glass compositional effect cannot be clearly separated from the effect of differences in solution chemistry that arise as the tests proceed. Reaction of the glass generally raises the $\mathrm{pH}$. Unless the $\mathrm{pH}$ is held constant or somehow controlled in the two tests, comparison of the relative durabilities of the two glasses under those differing conditions is not straightforward.

\footnotetext{
* J-13 water is a representative groundwater from the proposed Yucca Mountain, Nevada, repository site.
} 


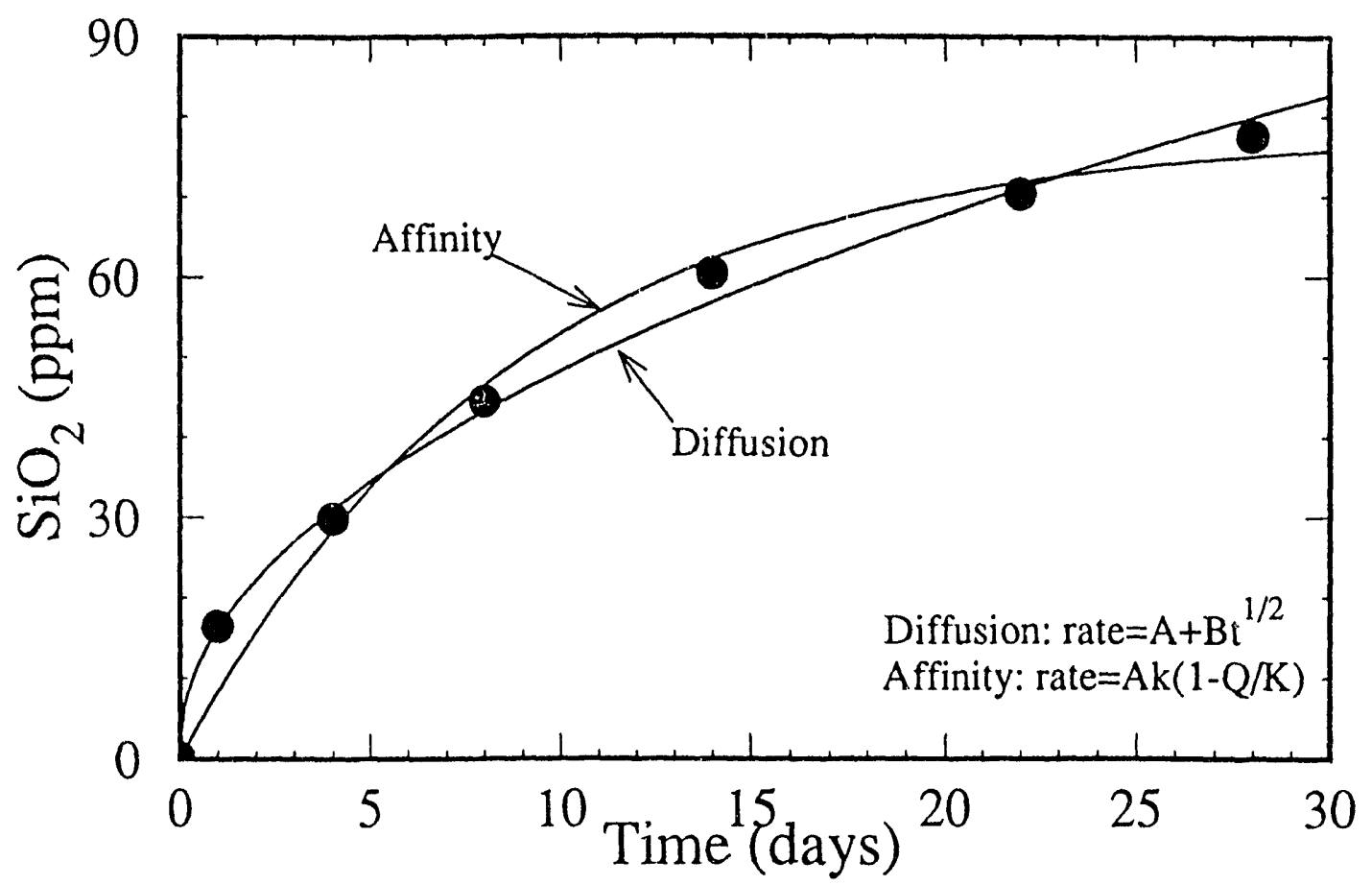

Fig. 4. Silica Release Data for SRL 165 Glass. The two curves are model results for glass dissolution controlled by (a) diffusion rate and (b) matrix dissolution (affinity) rate [27].

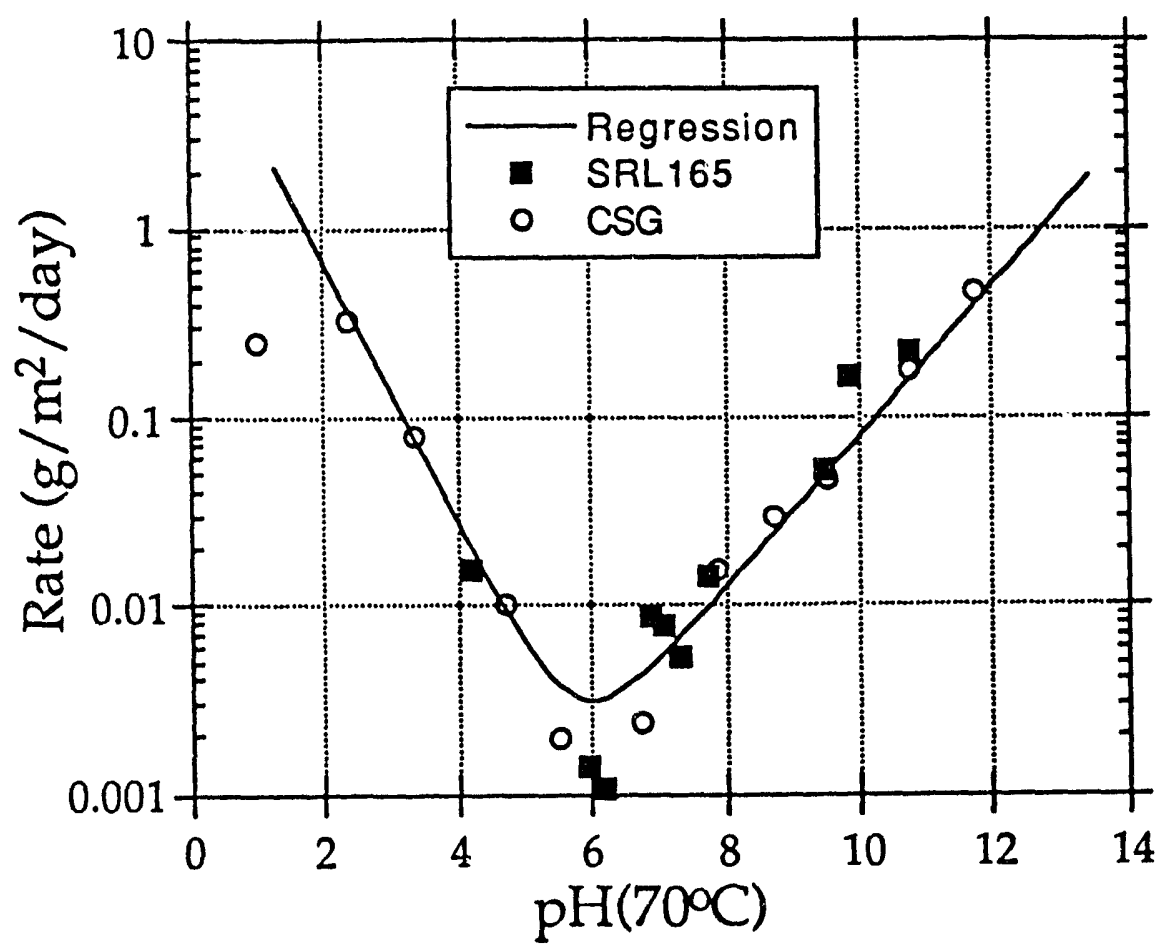

Fig. 5. The pH Dependence of Silica Release Rate from SRL 165 and Five-Component Analogue (CSG) Glasses, as Measured in Open-System Tests 
The $\mathrm{pH}$ issue is a problem for glasses tested under the conditions required by Materials Characterization Center Test 1 (MCC-1) or PCT-type tests. For example, consider two glasses having significantly different alkali contents that are being leached in distilled water. The alkali-rich glass will undergo rapid ion exchange and raise the $\mathrm{pH}$ of the solution to a higher value than will the alkali-poor glass. Because the intrinsic rate of reaction increases with increasing $\mathrm{pH}$ under alkaline conditions (see Fig. 5), the rate of glass dissolution will increase for the alkali-rich glass. Thus, the dissolution rates of the two glasses are being compared under conditions in which the effect of the solution composition on the glass dissolution rate cannot be separated from the effect of glass composition. Moreover, in a repository environment, the $\mathrm{pH}$ of the reacting solution may not be controlled by interactions with the glass waste form. Instead, it may be controlled by the interactions of the groundwater with other repository materials and the host rock. Under those conditions, the alkali-rich glass may be more durable than the alkali-poor glass. Therefore, these simple types of glass dissolution tests cannot be used alone to determine the necessary durability information and cannot be directly used in model development, but they provide useful information regarding glass reaction mechanisms.

Good experimental data are clearly needed to refine the kinetic model of glass dissolution and provide more fundamental information on the important chemical processes taking place. With such information, it should be possible to project test results to repository conditions by using a model. Site-specific experiments, i.e., those designed to simulate as closely as possible the actual repository conditions, do not ceadily allow examination of the key processes occurring during dissolution that give rise to the measured release rates of glass components. Such experiments are too complicated, involve too many coupled processes, and are subject to greater variations in results than more simple tests that allow direct input to model development. However, site-specific tests are necessary for model validation.

The $\mathrm{pH}$ of the leachate is obviously a critical variable. A matrix of tests in which one or more glass formulations are reacted under controlled $\mathrm{pH}$ conditions is preferable for model development compared to tests where the $\mathrm{pH}$ is allowed to drift, i.e., to assume a value that depends on test conditions such as surface area-to-volume ratio and glass composition. Systematic data that isolate the effect of $\mathrm{pH}$ on dissolution rate can readily be used to constrain glass performance in a repository.

Several aspects of the way the common leach tests (MCC-1 and PCT) are designed and performed may be responsible for the variability in the test results that makes modeling more difficult. The systems are not buffered in $\mathrm{pH}$ or Eh. As the glass dissolves, the $\mathrm{pH}$ and Eh are allowed to drift and are controlled by the oxidizing atmosphere inside the vessel and dissolution/precipitation reactions involving both glass and container materials. Unbuffered solutions are particularly susceptible to relatively small amounts of accessory reactions, such as corrosion. The influence of these reactions on the test results may obscure the more important processes that will actually control glass dissolution in the repository. For example, modeling of the dissolution of the stainless steel container [11] shows that oxygen fugacity will drop from a value of 0.2 bars (atmospheric) to $10^{-60}$ bars with the reaction of only $20 \mathrm{mg}$ of iron. The change is large because the system is so poorly buffered in the redox state. Components that have Eh-dependent dissolution reactions will be drastically affected by Eh changes of this degree.

The standard MCC-1 static leach test [28] should require that in situ solution samples be taken. As the procedure is written, test vessels aer to be removed from the oven and allowed to begin to cool before samples are withdrawn. Quenching effects, including degassing (especially of $\mathrm{CO}_{2}$ and the consequent $\mathrm{pH}$ change), and precipitation or dissolution of secondary phases may occur. These changes are probably partly responsible for the high degree of variation in the concentrations measured and for the fact that the tests of this nature show only poor 
reproducibility $[3,29]$. To avoid these problems, samples should be filtered and taken at temperature (without any cooling and degassing) from corrosion-resistant containers such as gold, Teflon, or titanium [30]. To understand the changing composition of the fluid phase during leaching of the glass, it is essential to have accurate information on the concentrations of all dissolved species which are actually present as aqueous species during the experiment. The fluid sample must not include particulate, colloidal, adsorbed materials, or materials leached from the container, gasket, or secondary precipitates dissolved during acidification. These phases must eventually be accounted for in the total glass reaction process.

Another factor that must be considered in predicting glass performance is the chemical conditions in the repository. Much of the available experimental data on glass corrosion is not adequate in this regard, because these experiments focused on measurements of product consistency, not glass performance in a repository. The chemical conditions in a potential repository must be identified before glass performance can be predicted. However, these conditions are dependent on the types of materials that will be present in the repository, and those materials will be chosen depending on how they react with waste forms, such as glass. The problem is clearly an iterative one and cannot be solved in a direct manner. The solution requires a process where repository attributes are optimized concurrently with waste form composition to maximize overall repository performance. 


\section{GLASS DISSOLUTION MODELS}

\section{A. Overview}

The long history of studies of glass/water reactions has yielded a massive amount of data on all types of giass compositions, and many modeling approaches have been designed to interpret these results. This section discusses the similarities among many of the more successful approaches to the problem of predicting long-term glass dissolution rates in repository environments.

The most : videly used approach to modeling the dissolution of waste borosilicate glass assumes a surface reaction control for the dissolution process and explicitly accounts for the formation of alteration and secondary phases with feedback from the evolving solution composition. Although diffusion takes place, it is assumed to not be rate-limiting and is therefore not explicitly included in the model. This approach better accounts for the chemical processes which dominate the long-term leaching of real waste glasses and is discussed in greater detail in Section III.C.

\section{B. Solid-State Diffusion Models}

One category of glass dissolution model involves the solution of the diffusion equations for a moving boundary layer, where the rate of reaction is controlled by water diffusion [31-34] or ion exchange [35-38]. This approach originated in studies of dissolution of simple, relatively nondurable glasses over short periods during which reaction rates are diffusion-limited and unaffected by saturation effects. However, the dissolution rates of glasses with durabilities typical of nuclear waste glasses are not well described by this type of model [31].

Another similar approach combines rate control by transport or ion exchange with a term to account for the effect of a growing surface layer that provides a diffusion barrier for subsequent reaction [39-42]. Still other approaches use various combinations of the above processes to account for flow conditions and glass saturation effects as well [35,43-45].

Although these models may be applicable to some glass compositions, definitive experiments $[15,46]$ showed that glass dissolution rates for more durable borosilicate waste glasses are essentially independent of alteration layer thickness. The alteration layer therefore does not provide a rate-limiting transport barrier. Rather, the glass dissolution rates are controlled almost entirely by solution composition, in particular, by dissolved silica concentration and $\mathrm{pH}$.

The diffusion models of glass dissolution are most applicable for modeling the earliest stages of dissolution, when the surface diffusion layer is developing. They are also useful for modeling nondurable glasses, such as alkali silicate glasses, in which the ion-exchange process takes place quickly and proceeds to completion. However, although these reactions take place during reaction of more durable borosilicate waste glasses, they are not the dominant processes and do not control the long-term dissolution rates. They also do not provide for the formation of secondary phases, which is the most important sink for most elements being removed from the dissolving glass. These models will not be considered any further in this review.

\section{Nonkinetic Reaction Path Models}

Modeling of glass dissolution has also been performed by using reaction path modeling codes such as EQ3/6 [47-49], PHREEQE [50], and SOLMNEQ [51] (see work described by Strachan, Bruton, Ebert, and Savage [29,52-55]). In the following examples, no explicit 
provision was made for glass dissolution kinetics. In these modeling simliautions, glass reacts with an aqueous solution at an arbitrary rate, and mineral precipitation/dissolution reactions are evaluated during the reaction. The models do not predict the rate of glass-water reaction; it is specified as input. The results predict the solubility-limited concentrations for elements that form relatively insoluble secondary phases, such as the actinides.

As an example, EQ3/6 was used to simulate the reaction of SRL 165 glass with J-13 water [52]. A total of $10 \mathrm{~g}$ of glass was assumed to dissolve stoichiometrically into $1 \mathrm{~kg}$ of J-13 water in a closed system. The simulation results predict the concentrations of dissolved species (Fig. 6a) and the types and amounts of secondary phases that form (Fig. 6b) as a result of the reaction. Radionuclides and other glass components precipitate predominantly in the form of oxides and hydroxides, together with carbonates, silicates, and phosphates. All known secondary phases for which there is available thermodynamic data were considered in these simulations. The database of minerals used was not restricted.

In contrast, in similar nonkinetic simulations [55] executed by using PHREEQE, the treatment of minerals was constrained: PHREEQE used data from dissolution tests of SRL 131 glass to evaluate the saturation indices of all available mineral phases. In these simulations, equilibrium solubility control is indicated by a close agreement between measured solution concentrations and a calculated saturation state close to zero. For example, measured zinc concentrations in solution are predicted well by assuming the solid $\beta-\mathrm{Zn}(\mathrm{OH})_{2}$ exists in equilibrium with the system. A set of phases is chosen on the basis of this type of analysis and used to constrain the reaction path simulation. This simulation applies to a relatively short-term experiment. Long-term solubilities of released elements may be lower than the simulation results because more stable secondary phases will nucleate and grow from metastable precursors. For most scenarios, this type of simulation should provide solubility-limited concentrations and conservative maximum release rates of solubility-controlled radionuclides.

However, such models are not appropriate for soluble radionuclides because they do not directly consider kinetics. Release rates for soluble radionuclides must be estimated by using a kinetic model. These nonkinetic models are also limited by a current lack of knowledge as to what secondary phases are likely to form over the long term. This information is not available from short-term experiments: long-term or accelerated laboratory experiments and data from natural analogues are needed.

The formation of more stabie secondary phases, which is expected to occur at longer times, would have two opposing effects on release rates of radionuclides. The transformation to more stable phases lowers the concentrations of species in equilibrium with the solids. This should decrease radionuclide concentrations. However, lowering the concentrations of species in solution, especially silica, will increase the dissolution rate of the glass waste form (see Section III.D). This phenomenon has already been observed in some laboratory experiments [56], where the disso!ution rate has been observed to increase by more than an order of magnitude after a year of reaction (Fig. 7). The formation of new types of secondary phases has a complex effect on solution chemistry, such as the effects on solution $\mathrm{pH}$. Careful experimental and modeling work are needed to quantify predictions of this effect on the longterm performance of glass waste forms.

\section{Kinctic Reaction Path Models}

Currently, the most successful long-term dissolution models for borosilicate glass employ a rate equation consistent with transition state theory. The rate equation is embodied in a geochemical reaction-path modeling program that calculates aqueous phase speciation and 

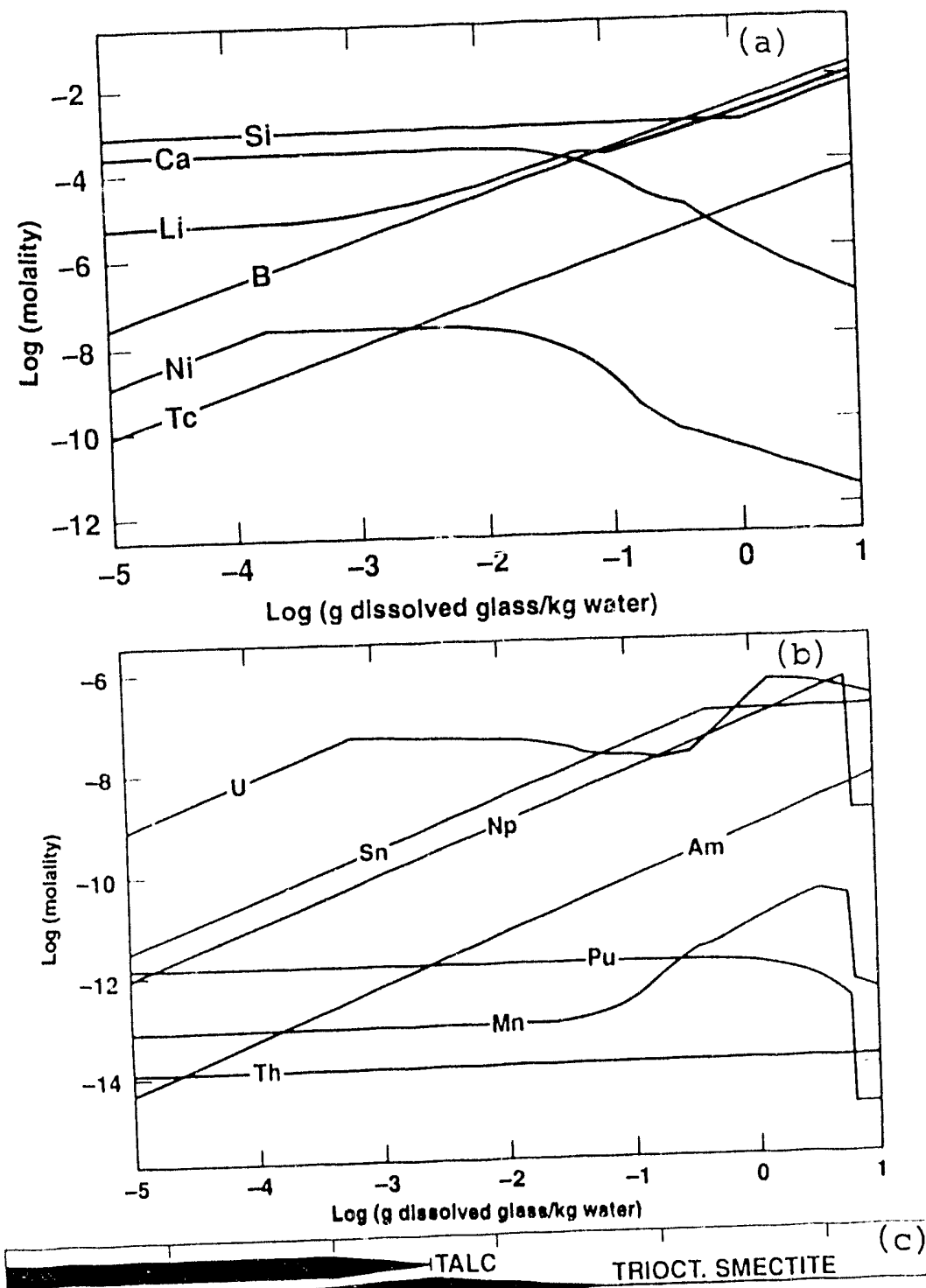

DIOCT. SMECTITE

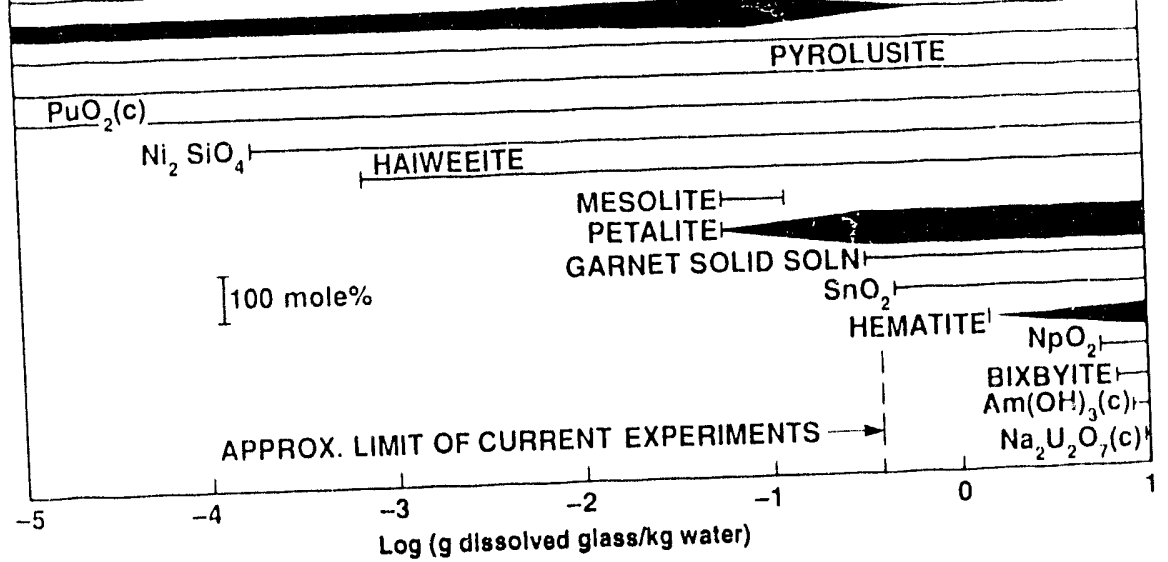

Fig. 6. Results from Nonkinetic Reaction Path Modeling of the Reaction at $90^{\circ} \mathrm{C}$ of SRL 165 Glass with J-13 Groundwater from the Proposed Yucca Mountain Repository Site: (a \& b) Predicted Concentrations of Dissolved Elements and (c) Predicted Sequence of Secondary Solid Phases [52]. 


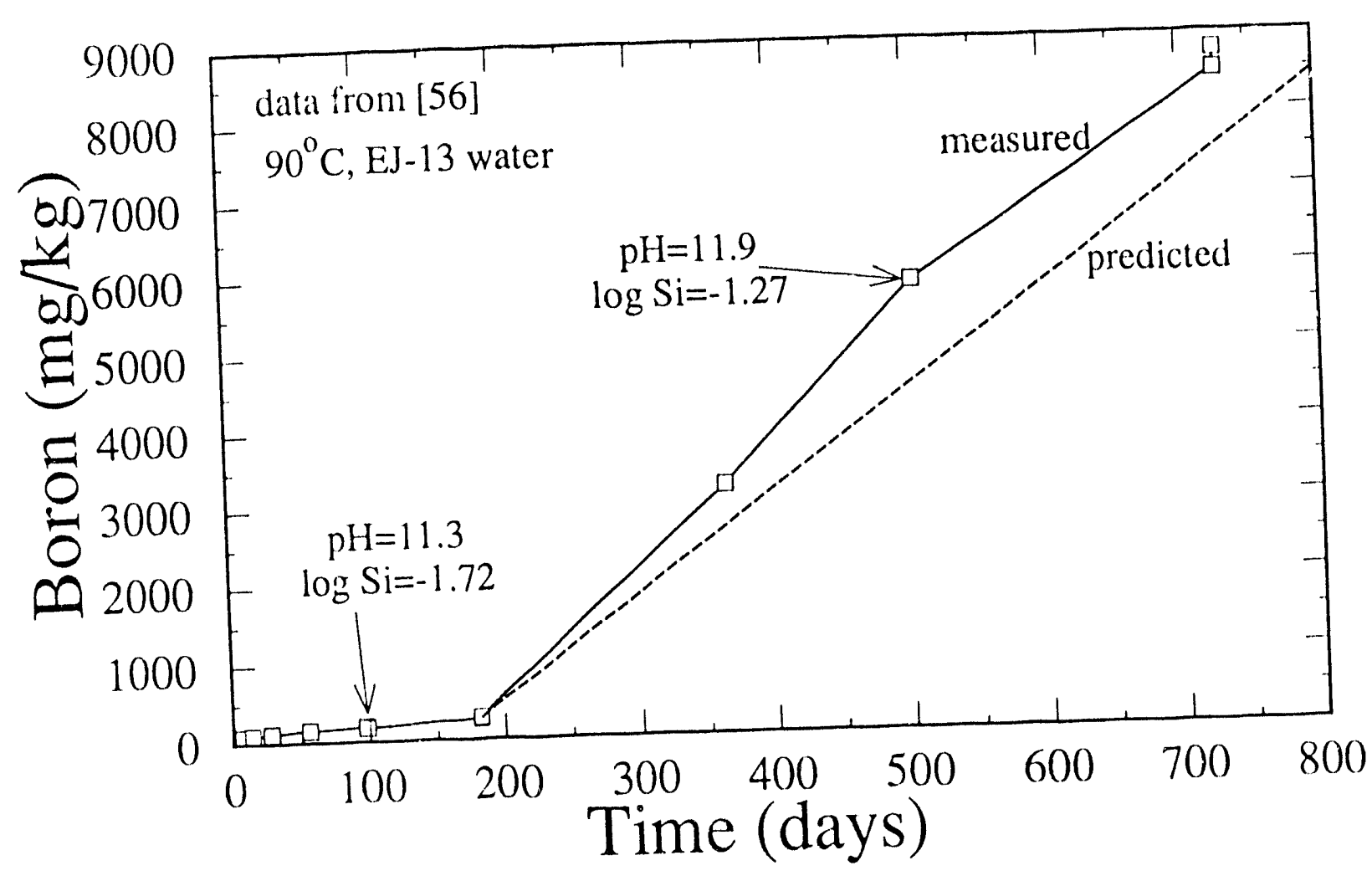

Fig. 7. Experimental Data from Ebert et al. [56] Showing Accelerated Dissolution Rate for SRL 202 Glass Reacted in EJ-13 Water at $90^{\circ} \mathrm{C}$ with a Surface Area-to-Volume Ratio of $20,(0)() \mathrm{m}^{-1}$. Dotted line shows predicted increase in rate based on solution analyses at days 182 and $5(24$.

mineral precipitation and dissolution. Early versions of these models ignore early, diffusioncontrolled dissolution behavior, which, for borosilicate waste glasses, is important only in the very early stages of reaction. (It is more important for less durable glass compositions such as alkali-silicates.) Diffusion in this case refers to solid-state diffusion of ions $\left(\mathrm{H}^{+}\right.$, alkalis) through the partially hydrated diffusion layer, not diffusion of aqueous species through the more hydrated and restructured gel layer.

The primary two features of glass dissolution that must be taken into account in models are: (1) the change in reaction rate with time and (2) the nonstoichiometric release of elements to solution (Fig. 3). As discussed above (Section II.A), the primary reason for nonstoichiometric release is the precipitation of secondary phases or retention of elements or phases within the gel layers. These phases selectively incorporate the less soluble glass constituents, which therefore do not show up in solution analyses. The basis of the reaction path model (such as PHREEQE, EQ3/6, etc.) is shown in Fig. 1. The glass begins to react through ion exchange and hydration. A steady state is quickly reached in which the diffusion layer maintains a nearly constant thickness and network dissolution controls the overall dissolution rate. The mass of secondary phases and alteration products continues to increase with time. Glass dissolution is stoichiometric from this point on, but the measured concentrations of elements in solution will not appear to be stoichiometric. Concentrations will not normalize to a constant value but will instead reflect the fact that precipitation of secondary phases affects 
some elements more than others. The reaction path codes are used to compute the aqueous solution speciation and mineral saturation states. Supersaturated phases are allowed to precipitate and maintain equilibrium between aqueous solution and precipitating solids. Instantaneous precipitation is currently an artifact of the reaction path code, and a full treatment of nucleation of phases and its effect on rate is currently not part of the codes.

\section{The Rate Law}

The rate law commonly used to model network hydrolysis, the assumed to control the rate of glass dissolution, has the general form $[57,58]$

$$
\frac{d n_{i}}{d t}=A v_{i} k_{r} \prod_{j} a_{j}^{-n}\left(1-e^{\left(-\frac{A_{f}}{\sigma R T}\right)}\right),
$$

where $\quad n_{i}=$ number of moles of species $i$ in solution released from the glass,

$t=$ time,

$A=$ reactive surface area of glass,

$v_{i}=$ concentration of species $i$ in the glass,

$\mathrm{k}_{\mathrm{r}}=$ rate coefficient for the rate-limiting reaction for glass dissolution,

$\prod_{j} a_{j}^{-n}=$ product of the activities (concentrations) of dissolved aqueous species which

contributes to the activated complex of the rate-limiting microscopic dissolution reaction,

$A_{f}=$ reaction affinity, defined as $R T \ln (Q / K)$, where $Q$ is the activity product and $\mathrm{K}$ the equilibrium constant for the rate-determining glass dissolution reaction,

$\sigma=$ a stoichiometric factor that relates the rate-controlling microscopic reaction to the overall solid dissolution reaction (usually it is assumed $\sigma=1$ ),

$\mathrm{R}=$ gas constant, and

$\mathrm{T}=$ temperature in kelvins.

The form of Eqn. 4 predicts that the dissolution rates of solids will have the following characteristics: (1) the amount of solid dissolved will be proportional to exposed surface area, (2) the dissolution rate will slow as the solution approaches saturation, and (3) the dissolution rate will be constant under conditions far from saturation $(\mathrm{Q} / \mathrm{K} \ll<1)$. An expression having this general form is currently used in all of the major glass modeling computer codes (e.g., PHREEQE/GLASSOL [13,50], EQ3/6 [47-49], DISSOL [59], REACT [60], LIXIVER [61]).

This rate law implies that at equilibrium there is a reversible microscopic dissolution reaction that is rate-limiting. However, because glass is thermodynamically unstable and cannot reach saturation, the overall glass dissolution reaction is clearly not reversible. Therefore, when this rate law is applied to glass dissolution, it must be applied not to the overall reaction, but to some rate-limiting microscopic reversible reaction. 


\section{Application of the Rate Law}

In the glass dissolution process, Eqn. 4 describes the rates of molecular reactions between silanol groups ( $\mathrm{Si}-\mathrm{OH})$ on the glass surface and aqueous species. At alkaline $\mathrm{pH}$ values, the rate-controlling reaction probably involves hydrolysis of surface $\mathrm{Si}-\mathrm{O}$ bonds by hydroxide ions [62]:

$$
>\mathrm{Si}-\mathrm{O}-\mathrm{Si}(\mathrm{OH})_{3}+\mathrm{OH}^{-}=>\mathrm{Si}-\mathrm{O}^{-}+\mathrm{Si}(\mathrm{OH})_{4}
$$

At neutral $\mathrm{pH}$, when hydroxide ions are much less abundant, the rate-controlling reactant is most likely water:

$$
>\mathrm{Si}-\mathrm{O}-\mathrm{Si}(\mathrm{OH})_{3}+\mathrm{H}_{2} \mathrm{O}=>\mathrm{Si}-\mathrm{OH}^{+}+\mathrm{Si}(\mathrm{OH})_{4}
$$

and at acidic $\mathrm{pH}$ values the hydronium ion $\left(\mathrm{H}_{3} \mathrm{O}^{+}\right)$.

The u-shaped dependence of glass reaction rate on $\mathrm{pH}$ (Fig. 5) may be explained in terms of these reactions. At low and high $\mathrm{pH}$ values, $\mathrm{H}_{3} \mathrm{O}^{+}$and $\mathrm{OH}^{-}$are actively hydrolyzing surface Si-O bonds. At neutral $\mathrm{pH}$, where $\mathrm{H}_{2} \mathrm{O}$ is the reacting species, rates are lower because the rate of attack by uncharged water is slower than that of the charged hydroxide and hydronium species.

Many of the parameters in Eyn. 4 are not known either from theory or from experiments, so that in practice the rate equation is simplified to

$$
\frac{\mathrm{dn} n_{i}}{d t}=A v_{i} k(p H)\left(1-\left(\frac{Q}{K}\right)^{r}\right)^{\sigma} \text {, }
$$

where the product term $\prod_{j} a_{j}^{-n}$ has heen reduced to i.xclude only the $\mathrm{pH}$ dependence of the rate coefficient, and the affinity expression is simplified and reexpressed in terms of the saturation index $(\mathrm{Q} / \mathrm{K})$ of the dissolving solid and the fitting parameters $r$ and $\sigma$. This form of rate law is commonly used as an expression to which experimental elemental release data are fitted; i.e., the values of $k, K, r$, and $\sigma$ are determined by regression of experimental data.

Current modeling codes may further simplify Eqn. 7. GLASSOL (see next section) assumes no solution compositional dependence of $\mathrm{k}$, which is assumed to vary only with temperature. DISSOL, EQ3/6, LIXIVER, and REACT treat $\mathrm{k}$ as a function of both $\mathrm{pH}$ and $T$. No models account for any further dependencies of $k$ on solution composition as indicated in Eqn. 7 above.

To use Eqn. 7 to predict glass dissolution rates, the $\mathrm{Q} / \mathrm{K}$ term must be evaluated, and to do that, an assumption must be made as to what phase becomes saturated. Several phases have been tried, ranging from the initial unreacted glass composition $[11,59]$ to the composition of the alkali-depleted surface layer [63] to simple hypothetical silica phases $[13,23,64,65]$. It is clear from these modeling studies that using the unreacted glass composition gives results that deviate from experimental ebservations (see Section III.E). However, the other two approaches give comparable agreement with experiments (see Section III.F.1). 
Equation 7 has been used successfully to model the dissolution kinetics of aluminosilicate phases $[57,66]$ and some synthetic silicate glasses [67]. This rate equation predicts that the dissolution rate will be a function of the surface area-to-volume ratio (SA/V), a $\mathrm{pH}$-dependent rate constant, and an affinity term, which decreases in size as the system approaches equilibrium. The models incorporate the rate equation (Eqn. 7) into a general reaction path program that provides for speciation of the aqueous phases, and precipitation of secondary phases as they hecome saturated. Thus, the model accounts for both the control of rate-limiting reactions on dissolution, and the efiects of surface layer formation on solution chemistry. Glass is allowed to dissolve stoichiometrically into solution at the rate determined by the rate of matrix dissolution. Nonstoichiometry of release is accounted for by the incorporation of elements into secondary phases and amorphous precipitates.

\section{The Grambow Model}

The borosilicate glass dissolution model introduced by Bernd Grambo'v is the most developed and widely used model for borosilicate glass dissolution. The model has evolyed and improved with time and has been described in several publications $[13,68-70]$. The model is based nn a simplified version of Eqn. 7 that includes only silica in the affinity term. That is, the reaction affinity for glass dissolution is calculated by using only dissolved silica as the value for $Q$, and $K$ corresponds to a silica "saturation" value for a particular glass composition at some temperature and $\mathrm{pH}$. The actual rate equation used is

$$
\mathrm{R}_{\mathrm{m}}=\mathrm{k}_{+}\left(1-\frac{\mathrm{a}_{\mathrm{SiO}_{2}(\mathrm{aq})}}{\mathrm{K}}\right)+\mathrm{R}_{\mathrm{final}},
$$

where $\mathrm{R}_{\mathrm{m}}$ is the rate of matrix dissolution, $\mathrm{k}_{+}$is the rate coefficient, $\mathrm{aSiO}_{2}(\mathrm{aq})$ is the activity of aqueous silica at the reacting surface, $K$ is the glass saturation silica activity, and $R_{\text {final }}$ is the final residual rate after silica saturation is achieved. The parameters $k_{+}$and $K$ are usually regressed from a set of experimental glass dissolution data. Both $\mathrm{k}+$ and $\mathrm{K}$ vary with glass composition, solution composition, and temperature. As yet, there is no methodology to extrapolate these parameters to other glasses or test conditions significantly different from those from which $\mathrm{k}+$ and $\mathrm{K}$ were regressed

During glass dissolution, the concentration of silica in solution is fixed by a balance between the rate at which silica is released from the glass and the rate at which silica is incorporated into glass alteration layers and secondary phases. Glass dissolution rates increase as dissolved silica decreases. Precipitation rates of silica-containing secondary phases increase as dissolved silica increases. Positive feedback between these processes causes the dissolved silica concentration to reach a plateau at which dissolved silica is nearly constant with time. Grambow has termed this plateau region the "silica saturation" level for the glass. It is clear that the silica saturation level may be a function not only of glass composition, but also other environmental parameters and in particular $\mathrm{pH}$.

Experimental evidence suggests that under certain open-system test conditions, the dissolution rate of some glasses is controlled by transport. In these tests, the dissolution rate exhibits a maximum after a few days, which probably results from the formation of an alteration layer that limits the overall rate of release of silica to solution. Under some conditions, transport of dissolved silica through this layer is suggested as the mechanism controlling the overall rate of glass dissolution. Grambow [13] has hypothesized that it is the transport of silica through the surface alteration layers that is rate-limiting. The transport-limited rate is modeled by a simple diffusion law: 


$$
r_{t}=\frac{D}{L}\left(a_{s}-a_{b}\right)+r_{\text {final }}
$$

where $r_{t}$ is the dissolution rate, $D$ is the diffusion constant, $L$ is the thickness of the hydrous alteration layer, $\left(a_{s}-a_{h}\right)$ is the dissolved silica concentration gradient across the layer from the surface (s) to the bulk solution (b), and $r_{\text {final }}$ is the "final rate," an experimentally estimated empirical parameter to account for the observed finite rate of glass reaction even at "saturation," at which Eqn. 7 would predict a reaction rate of zero.

The dissolved silica rate control (Eqn. 8) is combined with this simple diffusion rate control in the GLASSOL model [13]:

$$
r_{m}=k_{+}\left(\frac{\frac{D}{L} \times\left(K-a_{\text {bulk }}\right)+r_{f i n}}{\frac{D}{L} \times K+k_{+}}\right) .
$$

The model tests for whether the rate is controlled by transport or surface reaction and makes the appropriate calculation.

These rate equations are embodied in the computer code GLASSOL. Aqueous speciation and mineral saturation states are provided by an interface between GLASSOL and the program PHREEQE [50]. The model can therefore account for secondary phase precipitation/dissolution reactions as well as calculation of glass dissolution rates as the reaction proceeds.

In closed-system tests, glass dissolution is rapid initially but slows with time as the glass dissolves and dissolved glass species build up in solution. The early rate has been called the "forward rate" and the later slower rate has been called the "long-term rate" by Grambow. The forward rate corresponds to the rate when the affinity term $(1-Q / K)$ has a magnitude near ne, so that the rate does not slow as silica and other glass species build up in solution. The long-term rate corresponcis to the rate at longer time periods, when the affinity term is much smaller than one. The physical mechanism that determines the magnitude of the long-term rate, which will presumably limit the rate of release of radionuclides to the environment, is less well defined. This is one of the outstanding problems in models of glass dissolution.

The Grambow model has been applied to numerous closed- and open-system dissolution tests of a variety of glass compositions, including both waste glasses and natural glasses, with varying degrees of success $[13,23,59,68-85]$. In most cases, the model predicts measured trends and agrees with measured solution compositions to within a factor of two or three. However, the model uses data obtained from the tests being modeled to determine the values of fitting parameters in the model, such as the rate constant, final rate constant, silica saturation value, and diffusion constant for silica through the surface layer. Fairly good agreement is expected under these conditions, in which modeling parameters are obtained from the experiment being modeled. All model parameters must, therefore, be determined for each glass composition.

The Grambow model has also been extended to model glass dissolution in saline brines [78,86]. The model has been incorporated into the EQ3/6 code [47] and uses Pitzer's equations for calculating speciation in brines [87]. Calculations of solution $\mathrm{pH}$ and mineral saturation indices are difficult in brines because of the limitations of current methods for 
calculating thermodynamic properties of brines, in particular, $\mathrm{pH}$. The results of glass dissolution tests in $\mathrm{Mg}$-rich brines are interesting because in contrast to dilute solutions, the $\mathrm{pH}$ values in these tests decrease from around seven to values less than four. In dilute solutions the $\mathrm{pH}$ rises. The model is successfully able to reproduce this trend. The $\mu \mathrm{H}$ decreases as a result of the precipitation of $\mathrm{Mg}$-rich alteration phases such as saponite and $\mathrm{Mg}$-zeolites [78].

\section{Curti's Critique of the Grambow Model}

Recently, Curti [72] has used the Grambow model to model dissolution of the British MW glass in order to critically evaluate the model for use in performance assessment of the Swiss high-level waste repository. Curti [72, p. 3] concludes that the model is not yet suitable for safety analysis for the following reasons: "(1) the model neglects the potential effects of diffusive transport and silica sorption in a bentonite backfill on the glass dissolution kinetics; (2) the release of radionuclides can only be modeled assuming congruent dissolution; and (3) the magnitude of the final rates of dissolution, the parameter defining the maximal lifetime of the glass matrix, is still not known with sufficient precision."

Curti's first criticism has to do with the observation that the British MW glass reacts to form a thick, silica-rich layer on the surface, unlike other glasses for which the model was developed and applied. Without accounti: $g$ for this silica layer, the model predicts "silica saturation" much earlier than it actually occurs in experiments, and the model incorrectly predicts a much slower dissolution rate than observed in experiments [72]. It was necessary to add a fictitious silica phase to the PHREEQE database to account for this silica layer. The basic problem is that the Grambow model has no capability to model the effects of glass composition on the dissolution process. Early versions of Grambow's model used hydration theory to predict glass composition effects [68], but that element was later dropped from the model because of lack of success. Without some mechanistic basis to predict the type of alteration layer that will be formed, one cannot expect the model to predict dissolution effects that depend on properties of the glass alteration layer (see discussion of third criticism).

The second criticism is that the model makes the conservative assumption that the rate of release of radionuclides will be limited by the overall rate of glass dissolution. Although the assumption is valid in its conservatism, the model ignores that some radionuclide leachate concentrations will likely be limited by low solubilities and will not be released at the relatively high rate of glass network dissolution. It is conceivable that the geochemical model PHREEQE could account for their lowered release rates, provided adequate thermodynamic data were available for the solids into which they are incorporated. Current programs are in place in several countries to obtain the necessary data. This criticism is valid for all glass dissolution models, not just the Grambow model.

Of the three criticisms, the most significant is the third. The Grambow model (and in fact all current glass dissolution models) do not provide a mechanistic basis tor predicting the long-term dissolution rate of glasses. In the Grambow model, the long-term rate is a fitting parameter regressed to short-term, high SA/V test results (the high SA/V presumably accelerates tests to equivalent long times). The model has no capability to predict how the longterm rate may change as environmental parameters change during the lifetime of the repository. The concept of "residual chemical affinity," an ad hoc term used by Grambow to justify adding the long-term rate parameter $\left(R_{\text {final }}\right.$ in Eqn. 8) to his rate equation, has also been criticized [88] by Petit et al. In their experiments, both powdered and monolithic glass samples were reacted in a common vessel and showed a continuous slowdown in rate past the point where silica saturation should have occurred and the rate should have remained constant. Petit et al. [88] 
conclude that the mechanism controlling the long-term rate is affected by other environmental parameters and that the mechanism must include alkali concentrations as well as silica concentration to explain their data.

\section{Qther Kinetic Reaction Path Models}

A variation of the Grambow model was proposed by Bourcier et al. $[11,63]$. The model differs from Grambow's mainly in that the rate of reaction is assumed to be controlled by the dissolution affinity of the gel layer on the reacted glass. This replaces the simple silica saturation concept of Grambow's model. The composition of the surface layer, determined from SIMS or some other surface analytical method, is used to determine thermodynamic properties of the layer. The layer is commonly depleted in alkalis and boron and fairly high in silica content. Thus, the model is similar to Grambow's in that dissolved silica has a predominant effect on the saturation state (and therefore glass dissolution rate) of the surface layer. However, the model predicts other components of the alteration layer, such as aluminum and iron, can also affect glass dissolution rates. The model is incorporated into the EQ3/6 geochemical modeling code [47]. Results of using this model to predict short-term dissolution rates of SRL 165 glass are shown in Fig. 8.

The thermodynamic properties of the surface layer are calculated on the basis of a solid solution of amorphous and hydrous phases whose net composition is that measured for the alteration layer. Phases such as amorphous silica, amorphous ferric hydroxide, and amorphous aluminum hydroxide are used as components in the solid solution model for the alteration layer. The free energy of the alteration layer, as determined by using the solid solution model, provides the value of $\mathrm{K}$ in Eqn. 7. The advantage of this model is that it provides a mechanistic basis to the calculation of "silica saturation" that is not available in the Grambow model. The model can be tested by comparing measured glass dissolution rates with the composition of the alteration layer to see if the model predicts the correct sequence of dissolution rates. The model can therefore be used to make predictions of long-term dissolution rates. Because compositions of alteration layers must be known to apply the model, some assumptions must be made about how their composition may change with time. For all applications reported to date, the composition is assumed to remain constant and identical to the composition determined in short-term tests. Analyses of compositions from glasses in natural systems could also be used to constrain the composition expected over long periods.

The gel layer model of Bourcier et al. [11] also uses a pH-dependent short-term rate constant derived in independent open-system tests. Thus, neither the "forward rate" or "long-term rate" as employed by Grambow are retrieved from the data to be modeled; they are determined independently. The model can therefore be used to predict glass dissolution rates without requiring any parameters to be generated from the experiment being modeled. The only input needed is the composition of the alteration layer and a way to narrow the suite of secondary phases that form in long-term reaction. This semiselection of phases is required because the data base for phase stability and formation is not refined to the point where it can successfully predict which phases will form.

Another model used to simulate the dissolution of borosilicate waste glass is the DISSOL model [89], which is conceptually similar to the Grambow model in that it couples a reaction-path geochemical modeling code to a first-order kinetics rate law. The model incorporates a complex clay solid solution model, "CISSFIT" [90], to model the formation of the abundant clay alteration phases that commonly form during glass dissolution. 

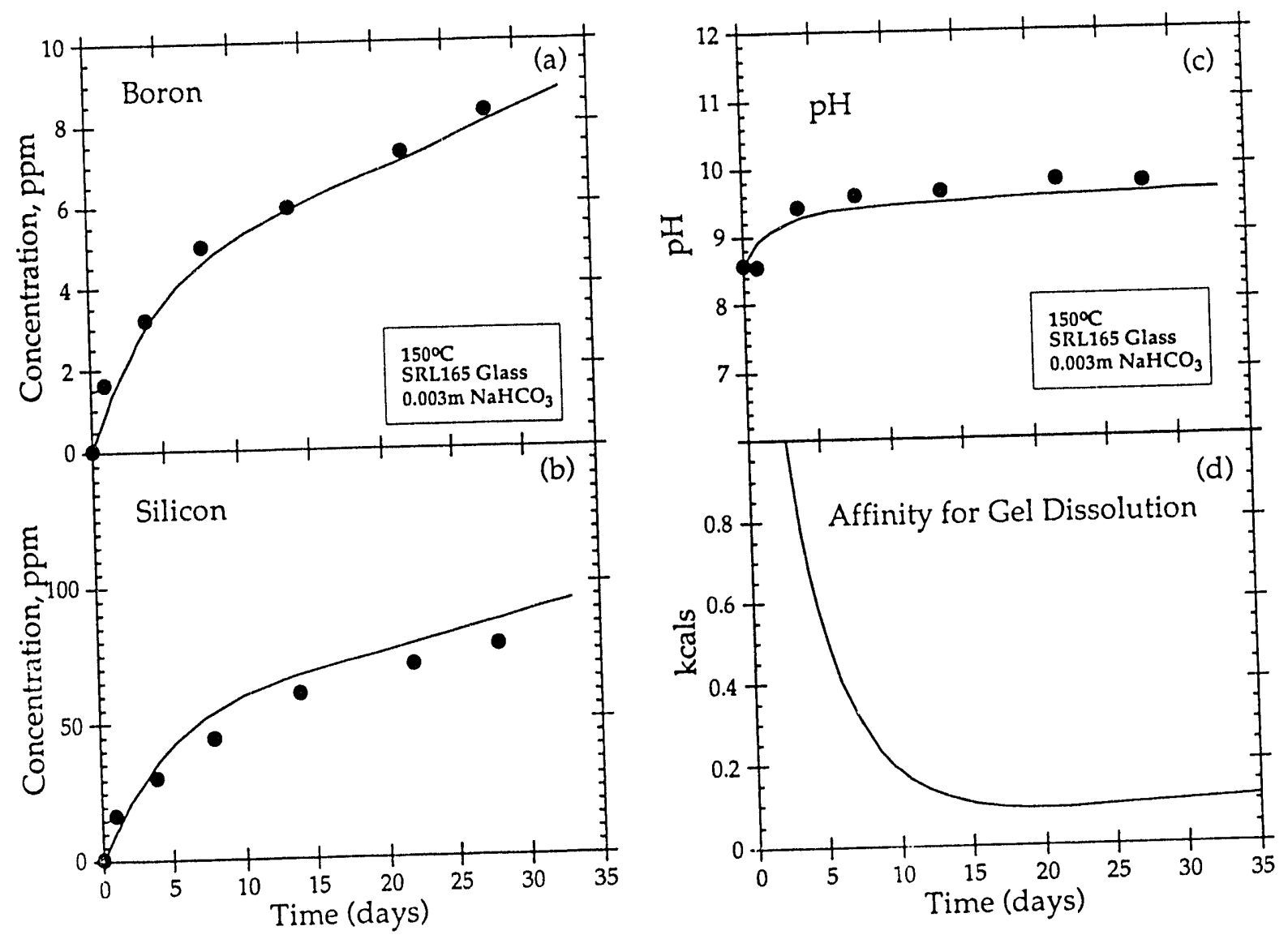

Fig. 8. Model Simulation Results and Experimental Data for Closed-System Dissolution Tests of SRL 165 Glass in 0.003 molal $\mathrm{NaHCO}_{3}$ Solution at $150^{\circ} \mathrm{C}$, with a Surface Area-to-Volume Ratio of $0.01 \mathrm{~cm}^{-1}$. Lines are concentrations predicted by gel layer glass dissolution model; symbols are experimental data. Predicted concentrations are generated from starting solution composition, surface gel layer composition, and a rate constant derived from the boron release data of this same test. Affinity in plot (d) is equal to $-R T \ln (Q / K)$, where $R$ is the gas constant, $T$ is temperature in kelvins, $Q$ is the activity product for the gel layer dissolution reaction, and $\mathrm{K}$ is the solubility product for the gel layer. Affinity remains nearly constant during steady-state conditions in which the rate of dissolution of the glass is approximately equal to the rate of precipitation of secondary phases [11]. 
Advocat et al. [59] describe the use of the DISSOL code in simulating RTT7 glass dissolution experiments carried out at $100^{\circ} \mathrm{C}$ for relatively short periods (up to $140 \mathrm{~h}$ ). Under these conditions, few secondary phases are likely to form that would complicate interpretation of the reaction kinetics. The purpose of this investigation was to determine which phase controls glass "saturation" and therefore the long-term dissolution rate.

Three models for the compositional dependence of the glass dissolution process were tried by Advocat et al. [59]: (1) hydration theory, used to estimate the free energy of the unreacted glass, (2) the gel model of Bourcier et al. [11] just discussed, and (3) the silica saturation model of Grambow [68]. Hydration theory predicts that saturation effects will not decrease the rate of glass dissolution. The thermodynamic stability of the glass as determined with hydration theory is so large that the value of $Q$ in the rate equation never approaches the value of $\mathrm{K}$, so the term $(1-\mathrm{Q} / \mathrm{K})$ remains approximately equal to one. The results from the gel model were similarly unsatisfactory in that dissolution rates higher than observed were predicted [65]. The DISSOL model predicts that very stable clay phases will maintain very low concentrations of dissolved iron and aluminum. If this is the case, the value of $Q$ in the gel model will be very small, and the affinity term will remain close to one. Experiments show, however, that the concentrations of dissolved iron and aluminum are much higher than the concentrations predicted by the clay thermodynamic model "CISSFIT" in DISSOL. If the DISSOL model were modified to better account for the observed concentrations of dissolved $\mathrm{Al}$ and $\mathrm{Fe}$, the agreement of the gel model results with experimental data would be improved.

Advocat and colleagues obtained satisfactory agreement between the experimental results for silicon, boron, and sodium and the model predictions by taking into account only dissolved silica in the affinity term (i.e., the Grambow model). As a result of the Advocat et al. analysis, however, it was found that the silica saturation value for the R7T7 glass ( $\mathrm{K}$ in Eqn. 7) varied with the SA/V for the test. $\mathrm{K}$ is therefore not a universal parameter related to the glass composition, hut varies with test conditions. Clearly, this result makes it problematic to use this model to extrapolate glass dissolution behavior to repository conditions. Also, the SA/V cannot be clearly defined for a repository.

The reason that $\mathrm{K}$ is a function of test conditions is that it is not an intrinsic parameter for the glass, but simply a fitting parameter that accounts for the decreased dissolution rate as silica increases in solution. The change in concentration of dissolved silica over time during a glass dissolution test results from the balance between the rate of release of silica from the glass and the rate of deposition of silica in secondary phases. The saturation level of silica is therefore a complex function of the types and rates of precipitation of secondary phases. It also will depend on factors that control the rate of release of silica from the glass surface, such as the concentrations of dissolved metals, solution $\mathrm{pH}$, and other factors. The concept saturation that applies to a simple, stable, crystalline phase like calcite does not apply to glasses. The incorporation of this concept in glass dissolution models leads to erroneous interpretations of the glass dissolution data. These models will never succeed in predicting glass performance in repositories because they cannot take into account the effects of coupled reactions between dissolution of glass and other repository materials. Parameters derived from fitting simple glass dissolution tests cannot be applied to repository conditions because these parameters will change under these differing conditions [91].

In a separate model, Delage et al. [61] have combined diffusional transport of silica and an affinity-based rate expression in the LIXIVER code. Their model is similar to Grambow's model, but in addition it has the capability to include the $\mathrm{pH}$ dependence of the rate coefficient and a more general treatment of secondary phase formation. In the LIXIVER model, the thickness of the gel layer and the rate of silica diffusion through it control the concentration of silica at the gel layer/solution interface, which they use for the value of $Q$ in Eqn. 7. This approach thus assumes that silica diffusion through the gel layer affects the concentration of 
dissolved silica at the gel/solution interface, thereby coupling the effects of silica transport and affinity rate control. Values of the diffusion constraint for silica through the gel layer and the "solubility constant" for the R7T7 glass were determined by applying the LIXIVER code to static leach tests in distilled water at $90^{\circ} \mathrm{C}$. Physically reasonable values for both of these parameters were obtained.

One of the problems with models that incorporate a mechanism of rate control by diffusion of aqueous silica through a gel layer is that neither a gel layer of the required thickness nor an observable gradient in silica saturation are commonly observed on reacted glasses [92]. Delage et al. [61] do not report any analysis of the surface alteration layers in their application of the LLXIVER model. They also do not report the layer thickness used in their model. Although the assumption of rate control by silica diffusion through a gel layer is consistent with some dissolution data, the model should be supported by experimental results consistent with model values for the thickness of the gel layer and for the silica concentration gradient. This information is needed to validate the model and is readily available through modern analytical electron microscopy and SIMS. LIXIVER is used only to interpret the results of short-term laboratory tests and is not meant for long-term prediction of glass performance.

\section{E. Hydration Theory for Estimating Glass Durahility}

Hydration theory is a theory of glass durability that relates thermodynamic properties of glasses to their dissolution rates as measured in short-term, closed-system tests [94-97]. Glasses are metastable solids, and therefore they dissolve irreversibly. They do not have measurable equilibrium solubilities. Therefore, the value of the solubility product $\left(\mathrm{K}_{\mathrm{sp}}\right)$ cannot be determined for glasses from simple solubility measurements as is done for thermodynamically stable solids. Instead, a thermodynamic model (hydration theory) has been developed and used to estimate the thermodynamic properties of glasses. Note that hydration theory in the context of this paper is not to be confused with the hydration theory of aqueous electrolytes incorporated into $E Q 3 / 6$.

Hydration theory treats glasses as solids composed of mechanical mixtures of silicate and oxide components. The free energy of hydration of the glass is calculated from the sum of the free energies of hydration of the components, each multiplied by the mole fraction of that component in the glass. The hydration reaction is simply the dissolution reaction of the oxide or silicate component written in terms of the dominant aqueous species. For example, the hydration reaction for the calcium component $\left(\mathrm{CaSiO}_{3}\right)$ is

$$
\mathrm{CaSiO}_{3}+2 \mathrm{H}^{+}=\mathrm{Ca}^{2+}+\mathrm{H}_{2} \mathrm{SiO}_{3} \text {. }
$$

Hydration theory has been successful in predicting the relative order of leach rates for a variety of silica-rich glasses (Fig. 9) $[95,97]$ with some qualifications [98]. Note that there is no unique way to divide the glass up into components and that the choice of components is arbitrary. The choice of components and the way the glass composition is divided up into those components will make a difference in the resulting hydration free energy of the glass. The best components will be those with elements whose coordination and bonding most closely match the coordination and bonding of the same element in the glass structure.

In essence, hydration theory predicts the stability of a glass on the basis of the relative differences between the basic set of components and constituent ions in solution. The hydration reactions for high field strength (and generally insoluble) cations such as $\mathrm{Si}, \mathrm{Al}$, and $\mathrm{Zr}$ have unfavorable hydration free energies of reaction (Table 2). Low field strength (and generally soluble) cations such as the alkalis $(\mathrm{Na}, \mathrm{Li}$, etc.) have relatively favorable hydration free energies of reaction. Therefore, glass compositions with large concentrations of soluble 


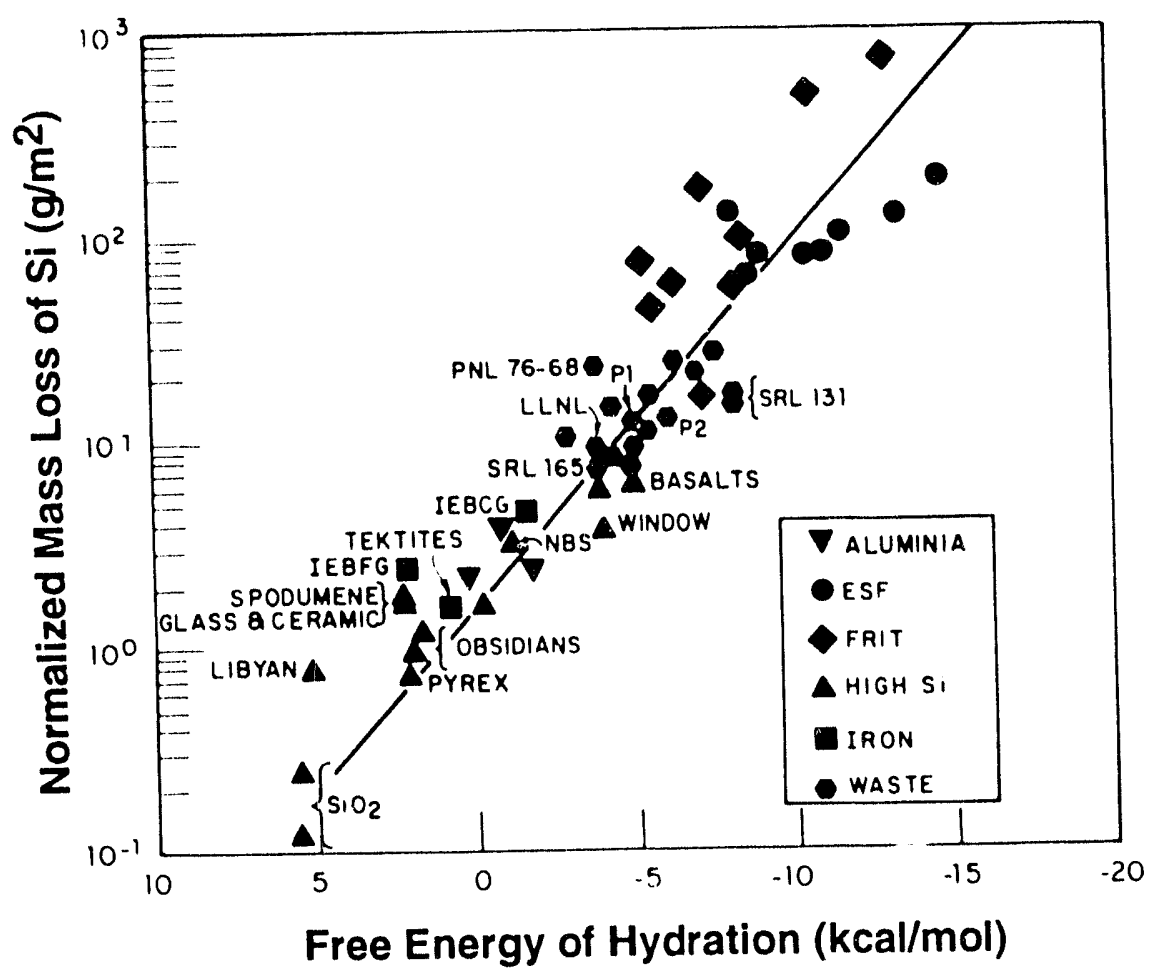

Fig. 9. Relation hetween the Normalized Mass Loss of Silicon Measured in an MCC-1 Test and the Calculated Free Energy of Hydration for a Variety of Glass Compositions. Data are corrected for the effect of $\mathrm{pH}$ on silica solubility (data from Jantzen and Plodinec [95]).

components have relatively low calculated values for hydration free energy, and glasses with high concentrations of insoluble components have high calculated values for hydration free energy. Therefore, glasses with high calculated hydration free energies are expected to be durable, and the opposite is expected for glasses with low hydration free energies. The model does not take into account the differences between the structure of the glass and the structures of the crystalline components used in the model to estimate the hydration free energy.

Although there is a gross correlation between glass dissolution rates and hydration free energy $[94,95,97]$, apparently the relationship is not sufficiently accurate to allow quantitative modeling of glass dissolution (see Section III.F.1). Note also that in Fig. 9, the data for the waste glass compositions SRL 165 and PNL 76-68 show nearly identical values for the hydration free energy, yet in short-term durability tests, the PNL 76-68 glass is much less durable. The hydration free energy model fails to predict this difference. Although rarely reported, plots of hydration free energy versus durability that are restricted to waste glass compositions show better correlations with restricted data bases. Data points often fall more than a log unit off the linear correlation. In other studies it has been shown that hydration theory cannot predict the relative durabilities of borosilicate glasses [99] and other simple glasses [100]. Simple empirical regression models of glass composition versus durability have been shown to provide correlations with experimental data that are equal to or better than those provided by hydration theory [98]. 
Table 2. Free Energies of Hydration for Glass Components (from [95])

\begin{tabular}{|c|c|c|c|c|c|}
\hline $\begin{array}{l}\text { Glass } \\
\text { Component }\end{array}$ & Hydrated Species & $\begin{array}{l}\text { Free Energy } \\
\text { of Hydration, } \\
\Delta \mathrm{G}(\mathrm{kcal} / \mathrm{mol})\end{array}$ & $\mathrm{F}=\mathrm{Z} / \mathrm{r}^{\mathrm{b}}$ & $\mathrm{Z} / \mathrm{r}^{\mathrm{b}}$ & $\begin{array}{l}\text { Coordination } \\
\text { Number }^{\mathrm{c}}\end{array}$ \\
\hline $\mathrm{Cs}_{2} \mathrm{SiO}_{3}$ & $\mathrm{Cs}^{+}, \mathrm{H}_{2} \mathrm{SiO}_{3}$ & -46.820 & 0.26 & 0.56 & VI \\
\hline $\mathrm{K}_{2} \mathrm{SiO}_{3}$ & $\mathrm{~K}^{+}, \mathrm{H}_{2} \mathrm{SiO}_{3}$ & -41.735 & 0.35 & 0.68 & VI \\
\hline $\mathrm{BaSiO}_{3}$ & $\mathrm{Ba}^{2+}, \mathrm{H}_{2} \mathrm{SiO}_{3}$ & $-3(0.570$ & $\begin{array}{l}0.88 \\
0.71\end{array}$ & $\begin{array}{l}1.32 \\
1.19\end{array}$ & $\begin{array}{l}\text { VIII } \\
\text { XII }\end{array}$ \\
\hline $\mathrm{Na}_{2} \mathrm{SiO}_{3}$ & $\mathrm{Na}^{+}, \mathrm{H}_{2} \mathrm{SiO}_{3}$ & -28.815 & 0.82 & 0.91 & $\mathrm{VI}$ \\
\hline $\mathrm{SrSiO}_{3}$ & $\mathrm{Sr}^{2+}, \mathrm{H}_{2} \mathrm{SiO}_{3}$ & -24.400 & $\begin{array}{l}1.13 \\
0.91\end{array}$ & $\begin{array}{l}1.50 \\
1.35\end{array}$ & $\begin{array}{l}\text { VIII } \\
\text { XII }\end{array}$ \\
\hline $\mathrm{Li}_{2} \mathrm{SiO}_{3}$ & $\mathrm{Li}^{+}, \mathrm{H}_{2} \mathrm{SiO}_{3}$ & -22.740 & 1.49 & 1.21 & VI \\
\hline $\mathrm{CaSiO}_{3}$ & $\mathrm{Ca}^{2+}, \mathrm{H}_{2} \mathrm{SiO}_{3}$ & -16.116 & $\begin{array}{l}1.39 \\
0.97\end{array}$ & $\begin{array}{l}1.67 \\
1.40\end{array}$ & $\begin{array}{l}\text { VIII } \\
\text { XII }\end{array}$ \\
\hline $\mathrm{MnSiO}_{3}$ & $\mathrm{Mn}^{2+}, \mathrm{H}_{2} \mathrm{SiO}_{3}$ & -14.871 & 3.75 & 2.19 & $\mathrm{VI}_{\mathrm{H}}$ \\
\hline $\mathrm{FeSiO}_{3}$ & $\mathrm{Fe}^{2+}, \mathrm{H}_{2} \mathrm{SiO}_{3}$ & -14.609 & $\begin{array}{l}2.70 \\
4.2\end{array}$ & $\begin{array}{l}2.32 \\
2.89\end{array}$ & $\begin{array}{l}\mathrm{VI}_{11} \\
\mathrm{VI}_{\mathrm{L}}\end{array}$ \\
\hline $\mathrm{NiSiO}_{3}$ & $\mathrm{Ni}^{2+}, \mathrm{H}_{2} \mathrm{SiO}_{3}$ & -14.347 & 4.88 & 2.59 & VI \\
\hline $\mathrm{MgSiO}_{3}$ & $\mathrm{Fe}^{2+}, \mathrm{H}_{2} \mathrm{SiO}_{3}$ & -13.888 & $\begin{array}{l}4.59 \\
3.12\end{array}$ & $\begin{array}{l}3.03 \\
2.50\end{array}$ & $\begin{array}{l}\text { IV } \\
\text { VI }\end{array}$ \\
\hline $\mathrm{B}_{2} \mathrm{O}_{3}$ & $\mathrm{H}_{3} \mathrm{BO}_{3}$ & -9.930 & 75.00 & 15.00 & IV \\
\hline $\mathrm{Al}_{2} \mathrm{O}_{3}$ & $\mathrm{Al}(\mathrm{OH})_{3}$ & -7.73 & 13.6 & 6.38 & IV \\
\hline $\mathrm{Al}_{2} \mathrm{O}_{3}$ & $\mathrm{AlO}(\mathrm{OH})$ & -1.63 & 8.06 & 4.92 & VI \\
\hline $\mathrm{Al}_{2} \mathrm{O}_{3}$ & $\mathrm{Al}(\mathrm{OH})_{3}(\mathrm{am})$ & $+3 .(040$ & & & \\
\hline $\mathrm{UO}_{3}$ & $\mathrm{UO}_{2}(\mathrm{OH})_{2} \mathrm{H}_{2} \mathrm{O}$ & -6.80 & 9.14 & 6.25 & VI \\
\hline $\mathrm{SiO}_{2}$ & $\mathrm{H}_{2} \mathrm{SiO}_{3}$ & +5.590 & 34.60 & 11.76 & IV \\
\hline $\mathrm{Fe}_{2} \mathrm{O}_{3}$ & $\mathrm{Fe}(\mathrm{OH})_{3}$ & +15.500 & 9.23 & 5.26 & $\mathrm{IV}_{\mathrm{H}}$ \\
\hline $\mathrm{TiO}_{2}$ & $\mathrm{TiO}(\mathrm{OH})_{2}$ & +15.990 & 8.40 & 5.79 & VI \\
\hline $\mathrm{ZrSiO}_{4}$ & $\mathrm{ZrO}(\mathrm{OH})^{+}, \mathrm{HSiO}_{3}^{-}$ & +45.100 & 4.72 & 5.0 & VI \\
\hline
\end{tabular}

aFor reactions written as $\mathrm{R}_{\mathrm{x}} \mathrm{O}_{\mathrm{y}}+\mathrm{H}_{2} \mathrm{O}=$ hydrated species.

$b_{F}=$ ionic field strength; $Z=$ ionic charge; $r=$ ionic radius.

$c " H "$ and "L" refer to high spin and low spin states.

Because the free energy of hydration theory treats glasses as mechanical mixtures of crystalline phases, the theory ignores both the enthalpy and entropy changes associated with glass-crystalline phase transitions. It also ignores any clustering or phase separation that may be present in the glass (see discussion of NMR results in Section II.A). Because the energy associated with the glass-crystalline phase transition is approximately equal for aluminosilicate glasses of variable composition [101], especially within the fairly narrow compositional range that comprises the glasses used to demonstrate the validity of hydration theory, that term cancels out and is not important for the purpose of generating correlation plots of hydration free energy versus normalized mass loss in leach tests. 
The energy difference between a glass and a corresponding set of crystalline phases having the same bulk composition is

$$
\Delta \mathrm{G}_{\text {glass-xtal }}=\Delta \mathrm{H}_{\text {glass }-\mathrm{xtal}}-\mathrm{T} \Delta \mathrm{S}_{\mathrm{glass}-\mathrm{xtal}},
$$

where $\Delta \mathrm{G}$ is the free energy of formation of the glass, $\Delta \mathrm{H}$ is the enthalpy of formation of the glass, $T$ is the temperature in kelvins, and $\Delta S$ is the entropy of formation of the glass; "glassxtal" refers to the glass-to-crystalline phase transition. The enthalpy term is related to bonding, bond distances, and ionic coordination and favors the crystalline phase. The entropy term corresponds to order-disorder in the solids and favors the glass phase. High-temperature calorimetric studies of aluminosilicate phases [101] indicate that enthalpies of vitrification contribute more to $\Delta \mathrm{G}_{\text {glass-xtal }}$ than the entropy differences between amorphous and crystalline phases. Thus the crystalline phases are more stable than the corresponding glass by a few kilocalories. The energetics of glass-crystalline phase transitions should be incorporated into hydration theory to improve the calculation of glass dissolution affinities.

Another improvement in hydration theory could be achieved by taking account of the clustering of boron into alkali-boron-oxygen enriched zones as observed in NMR investigations (see Section II.A). The boron and alkali in these zones are highly soluble and will readily leach out of the glass upon contact with water. If the zones occur as isolated patches in the glass, they will not affect overall glass durability, other than to slightly increase the effective surface area exposed to water. However, separation into boron-rich zones effectively modifies the composition of the glass matrix, which controls overall glass durability. The glass matrix becomes richer in silica and poorer in alkali and boron as a consequence of clustering. This modified composition should be used in the correlation with durability rather than the bulk composition, which is presently used. NMR data can be used to estimate the amount of boron concentrated in the alkali- and boron-rich clusters. These data can be used to directly calculate the composition of the matrix.

Finally, data from experimental determinations of glass durabilities show that there is no absolute measure of durability. The durability order of glass will change as the type of test used to measure durability changes (see Section II.A). Therefore, no single thermodynamic property of a glass, such as that provided by hydration theory, can be expected to provide more than a qualitative index of glass durability Glass durability is not an intrinsic parameter related to glass composition and structure alone. Improved hydration free energy models, or alternate models that could replace this theory, are therefore not a useful goal of further waste glass dissolution research. Efforts should instead be directed at developing mechanistically based models and conducting experimental work designed to support these models.

Note that the thermodynamic database for hydration theory given by Paul $[96,102]$ and used by others $[95,97]$ has a systematic error in the free energy data of about $12.3 \mathrm{kcal}$ for all silica and silica-containing solid phases and aqueous species when compared with the CODATA tables [103] and more recent critical compilations of thermodynamic data [104]. Because this error has been incorporated into the database in an internally consistent way, it does not affect hydration free energies. Reactions involving silica have the error on both sides of hydration reactions, so it cancels out. However, error would result if data from Paul's iatabase were mixed with any other data that have correct silica values. The source of Paul's thermodynamic data is not given, and the source of error therefore cannot be determined. A more detailed analysis of this model will be given in the critical review of glass composition. 


\section{F. Parametric Modeling Studies of Glass Dissolution}

Here we review the methods used in models to account for the effeets of glass composition, solution composition, $\mathrm{pH}$, temperature, and radiolysis on glass dissolution.

\section{Effects of Glass Composition}

To date, most studies directed at the effects of glass composition on glass durability have not clearly separated the effect of glass composition from that of other parameters, such as $\mathrm{pH}$ (see Section II.B). A few studies in which the compositional effect is clearly isolated show that this effect on dissolution rate is complex. Adding aluminum to alkali silicate glasses [105] increases glass durability by causing $\mathrm{Na}^{+}$ions to shift from nonbridging oxygen sites to charge balance at aluminum sites. This shift decreases the diffusion rate of water through the structure, which also enhances durability. The effects of alkaline earth ions on glass performance are particularly complex [106] and may increase or decrease the durability depending on $\mathrm{pH}$ and the cation added. Trotignon [107] looked at the dissolution behavior of a range of systematically more complex borosilicate glass compositions, with complex results.

In some cases, closed-system leach tests of powdered glasses show that relatively small empositional differences can give rise to large differences in glass durabilities $[108,109]$. A rapid increase in durability is observed in going from two to three weight percent of added silica. The effect is explained by Feng et al. [108] in terms of the influence of the added components on the glass structure. Clearly the types and amounts of metals added to the borosilicate framework of waste glasses will affect the structure and may cause increased transport rates through the glass, which will in turn affect dissolution rates.

An additional problem in relating glass composition to glass durability is that the relative durabilities of glasses in short-term experiments may not correlate with their long-term performance in a repository. For example, the SRL 165 glass is found to be more durable than PNL 76-68 glass when reacted in liquid water. However, the reverse is true in hydration tests in which the glasses are reacted in water vapor [110]. Apparently, the composition of SRL 165 glass is more amenable to forming stable secondary phases, which precipitate on the glass surface. The secondary phases act to keep the solution concentrations of silica and other species low and therefore help prevent the glass from approaching saturation where the reaction rate slows down. PNL 76-68 glass tends not to form abundant secondary phases in hydration tests. The PNL 76-68 glass therefore reacts more slowly than the SRL 165 glass in vapor hydration tests. Similar problems may arise in trying to relate short term glass dissolution tests in liquid water to long-term repository performance in episodically saturated and unsaturated environments.

The effect of glass composition on glass durability under repository conditions is therefore a complex issue. The way that glass composition affects the glass dissolution rate is difficult to isolate and quantify without the results of carefully designed experiments. Also, an answer to the question of how glass composition affects glass reaction rates depends on knowing what the rate-limiting reaction is and how it may change with environmental conditions.

Some attempts have been made to incorporate glass compositi, nal effects into mechanistic glass dissolution models. For glass dissolution models bused on the rate equation called for by transition state theory, glass composition can affect the rate of glass dissolution in three ways: (1) the rate constant $\left(\mathrm{k}_{\mathrm{r}}\right)$ may depend on glass composition; (2) glass composition determines the composition of the alteration layer, which in turn is used in the affinity term calculation and therefore affects the dissolution rate; and (3) the glass composition affects the 
types and amounts of secondary phases that precipitate, which in turn affect the concentrations of species in solution and therefore the size of the affinity term in the rate equation. Models hased on these three principles are described below.

For the first case, Grambow [68] used hydration theory to ealculate the glass compositional dependence of $k_{r}$, the rate coefficient (Eqn. 7). The hydration theory for determining glass durabilities had been used previously to correlate glass durability with an estimated free energy of formation of glass. Although hydration theory provides an estimate of the thermodynamic glass stability, hydration theory has not been directly used to predict glass dissolution rates. To do that, it must be combined with a rate law that relates thermodynamic stahility to a dissolution rate.

In this case, Grambow [68] used hydration theory to calculate the glass compositional dependence of $k_{r}$ by means of the expression

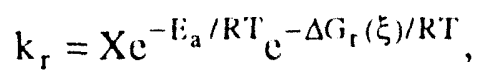

where $E_{a}$ is the activation energy for dissolution (determined experimentally), and $\Delta \mathrm{G}_{\mathrm{r}}$ is the hydration free energy for the glass dissolution reaction as a function of reaction progress $(\xi)$. The first term in Eqn. 13 (X exp(- $\left.E_{\mathrm{a}} / \mathrm{RT}\right)$ ) is an Arrhenius term that accounts for the effect of temperature on the rate constant. The second term $\left(\exp \left(-\Delta \mathrm{G}_{\mathrm{r}}(\xi) / \mathrm{RT}\right)\right)$ corrects the rate constant for the effect of glass composition. This approach has had limited suceess when dealing with the compositional range of real waste glasses. It was eventually dropped from the Grambow model and replaced with experimentally determined values for specific glass compositions [13].

For case two, an alternate approach to account for glass composition in the rate expression was used by other workers $[10,59)$. In this approach, the effect of glass composition was entered into the affinity term of Eqn. 7. With this approach, Q in Eqn. 7 corresponds to the activity product for the dissolution reaction of the entire glass, and $\mathrm{K}$ is the equilibrium constant for glass dissolution calculated using hydration free energy. Both Bourcier [10] and Advocat et al. [59] added a term to the hydration free energy to correct for the mixing entropy of the oxide components (see $[59$, p. 243] or [10, p. 12]. In both of these studies, it was found that the hydration free energy term did not improve the models' ahility to simulate experimental measurements. In hoth studies, the rate of dissolution was not predicted to slow down as is observed in experiments. The hydration free energy model predicts that the solution never approaches saturation, so the affinity term has a value of one throughout the duration of the simulation. The predicted reaction rate therefore remains approximately constant, in contrast with experimental results, in which the rates slow down. Concentration versus time curves for elements such as Si and B are predicted to be linear and increasing with time rather than concave downward, as is typical for experimental results. In hoth cases, the models failed to make accurate predictions of the effect of glass composition on glass dissolution rates.

It is clear that mechanistic dissolution/precipitation models have not yet matured to the point that they are useful for estimating glass durabilities as a function of glass composition. Although the theoretical foundations for the models $[57,111]$ are well established, uncertainties in our understanding of the dominant rate-controlling mechanisms as a function of glass composition and environmental eonditions make it impossible to rigorously incorporate glass compositional terms in the equations describing glass dissolution. It may also be necessary to include the effects of water content, glass structure (such as the existence of percolation pathways), secondary phases, and perhaps other effects of glass composition on glass reaction rates. Once the rate-limiting mechanisms are identified, and experiments are 
performed to quantify the effect of glass composition on the rate constant for glass dissolution, it should be possible for the models to quantitatively relate glass compositional variation to repository performance.

\section{Effects of Temperature}

Temperature affects dissolution rates in a complex way (see critical review of Mazer [112]). Temperature affects dissolution behavior by increasing the rates of surface reaction and diffusion to different extents $[113,114]$. The typical activation energies for diffusion of water in glasses of about $20 \mathrm{kcal} /$ mole [115] are greater than the activation energies for surface reactions of $10-20 \mathrm{kcal} / \mathrm{mole}[66,116,117]$. Therefore, higher temperatures will increase the rate of water diffusion faster than the rate of surface reaction. This shift will favor the formation of surface hydration layers in high-temperature dissolution tests [87].

A continuous spectrum of hehavior exists hetween (1) solids with fast surface dissolution rates relative to diffusion and (2) solids with slow surface dissolution rates relative to diffusion. Diffusion refers to the rate of diffusion of species out of the glass through the glass/water contact. Aluminosilicate phases leached in neutral to alkaline $\mathrm{pH}$ solutions fall into the first category. They seldom show thick reaction layers. However, bombardment by energetic ion beams serves to disrupt the crystallographic structure and increase diffusion rates through the surface layers [113]. When leached, these bombarded materials form thick diffusion layers much like those of waste glasses. Most waste glasses also fall into the second category because their surface dissolution rates are slow relative to their diffusion rates, and, consequently, they develop thick diffusion layers when leached. For any given material, therefore, dissolution may lead to variable thickness of surface hydration layers depending on the glass composition, leachant composition, and temperature. In all cases, the same fundamental processes take place, but coupling of these processes and changes in their relative rates gives rise to seemingly complex differences in dissolution hehavior.

Solution composition complicates the matter because the rate of surface layer dissolution depends on solution composition, especially $\mathrm{pH}$. At low $\mathrm{pH}$ values, high concentrations of $\mathrm{H}^{+}$increase the diffusion gradients and therefore diffusion rates of $\mathrm{H}^{+}$. Because silica solubilities are not affected by $\mathrm{pH}$ (at neutral to acidic $\mathrm{pH}$ conditions) the rate of surface reaction is not increased. Thus silicate phases such as silicate minerals and borosilicate glasses leached under acid conditions generate thick silica-rich leached layers depleted in soluble components [116]. For silicate phases leached at high $\mathrm{pH}$ values, surface reaction rates are high and surface layers are thin or nonexistent.

The temperature dependencies of kinetic processes are implicitly provided for in kinetic reaction path dissolution models. The codes account for the effects of temperature on mineral saturation states, glass dissolution rate coefficients, and changes in solution speciation. Codes that couple transport by diffusion with surface reaction rate control also account for the effects of temperature on the relative rates of the two processes. Temperature effects can be provided relatively easily in glass dissolution models. The more difficult problem is performing experiments that quantify these effects separately from other concurrent processes.

\section{Effects of $\mathrm{pH}$}

When glasses are dissolved under constant $\mathrm{pH}$ conditions [116], the dissolution rate as a function of $\mathrm{pH}$ appears as shown in Fig. 5. Rates are high at low and high $\mathrm{pH}$ values, and low at neutral $\mathrm{pH}$. Thus, in closed-system tests (such as MCC-1 [28]), although the 
dissolution rate slows as the pH rises, the intrinsic dissolution rate coefficient is increasing. The effect of aftinity (saturation) overeomes the faster intrinsic dissolution rate to slow the overall process of glass dissolution.

This effect is accounted for in dissolution models by incorporating a rate coefficient that is a function of pH [118]. The curve shown in Fig. 5 is regressed to an equation, and that equation is included in the kinetic model employed in the reaction path program. The effect of changing $\mathrm{pH}$ as a function of reaction progress is thus automatically accounted for in the modeling.

The $\mathrm{pH}$ will also affect which types of secondary phases are likely to precipitate. This effect is also accounted for in the reaction path programs. The programs automatically evaluate the saturation indices for phases at each step along the reaction path. The changing $\mathrm{pH}$ is therefore considered in predicting the sequence of secondary phase precipitates.

\section{Eliects of Secondary Phases}

It is not currently possible to predict which secondary phases will form in glass dissolution tests or to predict the rates at which they nucleate and grow. Although the most thermodynamically stable phases cau be predicted by running the reaction path programs, the results rarely match the phases actually observed in the tests. Current modeling is usually performed by using a restricted set of phases known to form in real systems [13].

One implication of the surface-reaction-controlled model is that precipitation of stable secondary phases at some future time may decrease concentrations of some elements in solution, such as silicon. A reduced silicon concentration should cause glass dissolution rates to rise [10]. Therefore, as early metastable phases convert to more stable phases (Ostwald Step Rule), glass dissolution rates may rise. Some experimental data exist that show such behavior $[56,82]$. Alternatively, some glass compositions rich in aluminum tend to react to form analcime as a secondary phase. Although the aluminum-rich glasses are intrinsically more durable, analcime saturation maintains a relatively low dissolved silica concentration, compared to tests of aluminum-poor glasses, which are not accompanied by analcime precipitates. Under these conditions, the aluminum-rich glasses dissolve faster than aluminum-poor glasses [119].

However, it may not be necessary to know the exact identities of the precipitating phases. Bourcier [27] compared results from two simulations, one that used secondary mineral phases observed in ests and one that allowed the thermodynamically most stable phases to form. The solution compositions were different in the two simulations, but the net effect on the rate of glass dissolution was relatively small. The Grambow model [13] predicts the dissolution rate will be two times faster for the stable phase assemblage as a result of the lower silica concentration. The model proposed by Bourcier et al. [11] predicts the rate will increase by only $20 \%$. The effect is smaller because that model assumes the dissolution rate is affected by all the components of the gel layer, including iron and magnesium, which are at higher concentrations in the stable-phase equilibrated solution. In both cases, the effect is not predicted to be very large, a factor of two greater in one case and $20 \%$ greater in the other case.

A more important issue concerning secondary phases is the question of how readily they incorporate radionuclides into their structures. Although some radionuclides are known to partition strongly into the surface layers $[20,120]$, do they remain incorporated into the structures after these initially amorphous phases crystallize into distinct phases with aging? More work on the solubilities of radionuclides in host mineral phases is needed to address this question. 


\section{Effects of Radiolysis}

Radiolysis of the local environment surrounding the glass waste form appears to have little effect on glass durability (see ANL-93/45). The major effect is the formation of nitric acid from gaseous nitrogen in the atmosphere [121]. Models for glass durability can readily account for the effect of nitric acid on the $\mathrm{pH}$ and Eh of the local environment by adding some flux of nitric acid and hydrogen peroxide into the system at a rate determined from theoretical or experimental data on nitric acid and oxidant production rates. The effect is likely to be small because of the much greater $\mathrm{pH}$ buffering capacity of other components in the system and, in particular, of the host rock and glass waste form itself.

Possible radiation-induced structural damage to the glass does not appear to significantly alter the leachability of the glass [122]. Any radiation damage induced the glass by a gamma radiation field is therefore not expected to affect the overall glass dissol: won rate or mechanisms as predicted by current models. Because glass is already a disordered phase, radiation-induced defects and dislocations are not important for glass durability. The effects of radiation on glass durability is discussed in more detail in ANL-93/45, Effects of Radionuclide

Behavior Decay on Waste Glass Behavior - A Critical Review, which is part of this critical review series.

\section{Effects of Surface Chemistry}

Current models of aluminosilicate dissolution have shown that interpretations of solid dissolution rates are simplified by incorporating surface chemistry in the analysis. However, few current glass dissolution models include surface chemistry [7]. These effects are specific to certain elements, such as the effect of dissolved $\mathrm{Mg}, \mathrm{Zn}$, and $\mathrm{Pb}$ to slow glass dissolution rates. Figure 10 shows a variety of surface complexes that may exist on an oxide surface and that may affect the kinetics of oxide dissolution.

Some attempts have heen made to understand and model deviations in dissolution behavior believed to be due to surface complex formation $[7,22,88,123]$. Explicit provision for surface interactions may be useful to account for the coupled effects of glass with other repository materials in performance assessment calculations. In addition, after thick assemblages of reaction products accumulate, it is likely that the local chemical environment at the glass surface will be different from that of the bulk solution [124]. It will be controlled by surface complexation reactions in potential restricted channel ways near the glass surface. Consequently, the rates of reaction will be influenced by the conditions of these localized environments. The types of secondary phases that form will also be affected by this chemistry. Surface chemistry clearly needs to be accounted for in our models.

When current kinetic parameters measured in the laboratory are extrapolated to natural systems, they predict rates of reactions up to several orders of magnitude faster than those observed in nature [125]. Several reasons for this discrepancy have been proposed: (1) the minerals do not remain in contact with water or are cut off from water flow, therefore affecting estimates of true reaction times; (2) the mineral surfaces are poisoned by adsorbed species (for example, phosphate adsorbed on calcite surfaces drastically reduces its dissolution rate); and (3) surface layers form on the mineral surfaces and protect the minerals from further reaction. It is important to understand these points so that we know whether a similar slowdown in dissolution rate is to be expected when comparing glass dissolution rates in the laboratory with those in nature. Studies of natural analogues for glass (such as basaltic glass [126]) may help in this regard. 


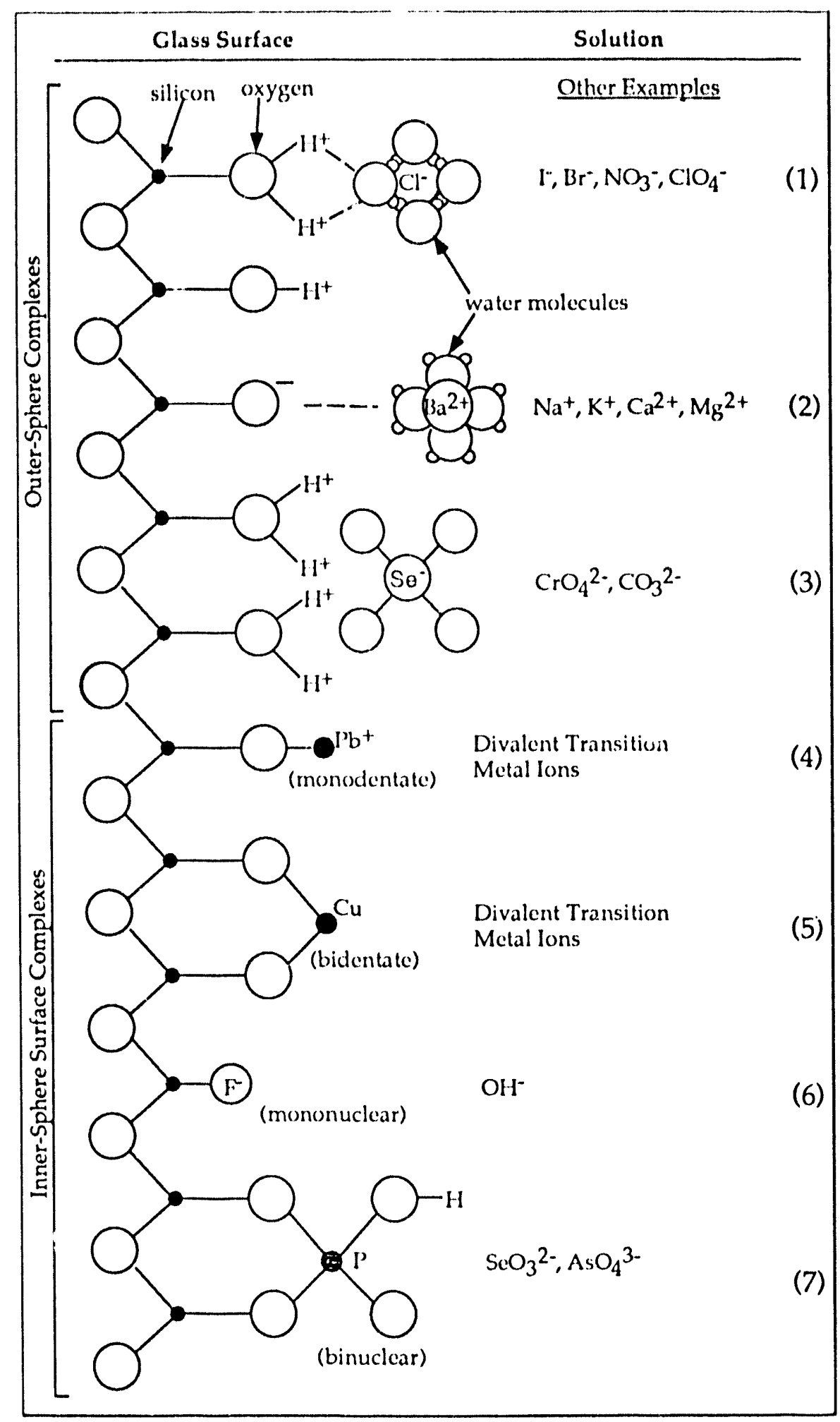

$\rightarrow$

Fig. 10. Types of Surface Complexes Potentially Present at Glass-Solution Interface (modified from Hayes (127]). 


\section{G. Model Applications}

In this section, we look at the results of applying glass dissolution models to experimental results and to data obtained from natural systems. The purpose of modeling is to make long-term predictions of glass dissolution rates under repository conditions. The first step in validating a model is testing the model's prediction of short-term experimental results. A higher degree of validation is achieved by demonstrating that the mudil is capable of accurately predicting the results of a large variety of glass dissolution experiments in which parameters such as temperature, $S A / V$, flow rate, leachate composition, and others are varied over the range expected for a nuclear waste repository. The development of a model is therefore an iterative process in which chemical and physical processes are added to the model or existing ones modified to better predict the results of glass tests. Validation tests and dissolution experiments continue until a satisfactory level of agreement is ohtained.

\section{Results from Applying the Grambow Model}

The most extensive validation test yet performed for a glass dissolution model is the application of the geochemical modeling code GLASSOL to experimental data for the glasses JSS-A, ABS-118, and R7T7 [88]. These glasses have been subjected to a variety of dissolution tests over a SA/V range of 10 to $10,0(0) \mathrm{m}^{-1}$; in distilled water, silica-doped water and granitic groundwater; under static and open-system condition;; with and without bentonite and magnetite; and for durations of up to one year. The GLASSOL code was used to simulate these tests results on the basis of the rate laws given by Eqns. 8 and 9 .

When using GLASSOL, model parameters are obtained from the set of test results that are also used to validate the model. The forward rate constant $\left(k_{r}\right)$ was obtained from the initial reaction rate from the low SA/V $\left(10 \mathrm{~m}^{-1}\right)$ tests because these are farthest from silica saturation and should therefore have the highest initial reaction rate. The silica saturation constant $(K)$ is obtained from the high SA/V tests, which are closest to silica saturation $\backslash$ when the reaction rate is slowest. The value of $\mathrm{K}$ regressed from the test data at 9()$^{\circ} \mathrm{C}(-2.93)$ is close to the solubility product of eristobalite $(-2.75)$, which is the silica polymorph most similar to silica glass in structure. Cristobalite is the silica phase on the liquidus at the glass transition temperature. The final rate $\left(r_{f i n}\right)$ is also obtained from the highest SAV tests. The diffusion constant for silica through the gel layer is obtained from regression to data from open-system tests. These are the four parameters GLASSOL needs to predict glass dissolution rates.

Figure 11 shows expermental data and model predictions of GLASSOL obtained by using this set of parameters for (a) closed-system tests and (b) open-system tests at $90^{\circ} \mathrm{C}$. The agreement is good, within about $40 \%$ for boron and $20 \%$ for silica.

\section{Modeling Unsaturated rest Results}

At the Yucca Mountain potential repository site, the waste forms would likely be exposed to dripping water. For that reaso., an unsaturated test methodology was developed so that the performance of glass waste forms could be predicted in this environment [110]. These tests had previously not been analyzed by using the models developed for saturated environments.

The results of using a reaction path kinetic glass dissolution model to sinulate the response of the SRL 202 glass to the unsaturated test conditions are reported in Bates et al. [128]. The test consists of dripping a single drop $(0.075 \mathrm{~mL})$ every 3.5 days on top of a glass wafer $\left(13.5 \mathrm{~cm}^{2}\right)$ secured in a stainless steel frame. If the water is assumed to contact the entire glass wafer, the test has an effective $\mathrm{SA} / \mathrm{V}$ ratio of about $18,000 \mathrm{~m}^{-1}$. In the modeling, it is assumed that each drip contacts the entire glass surface for 3.5 days, then is completely replaced 


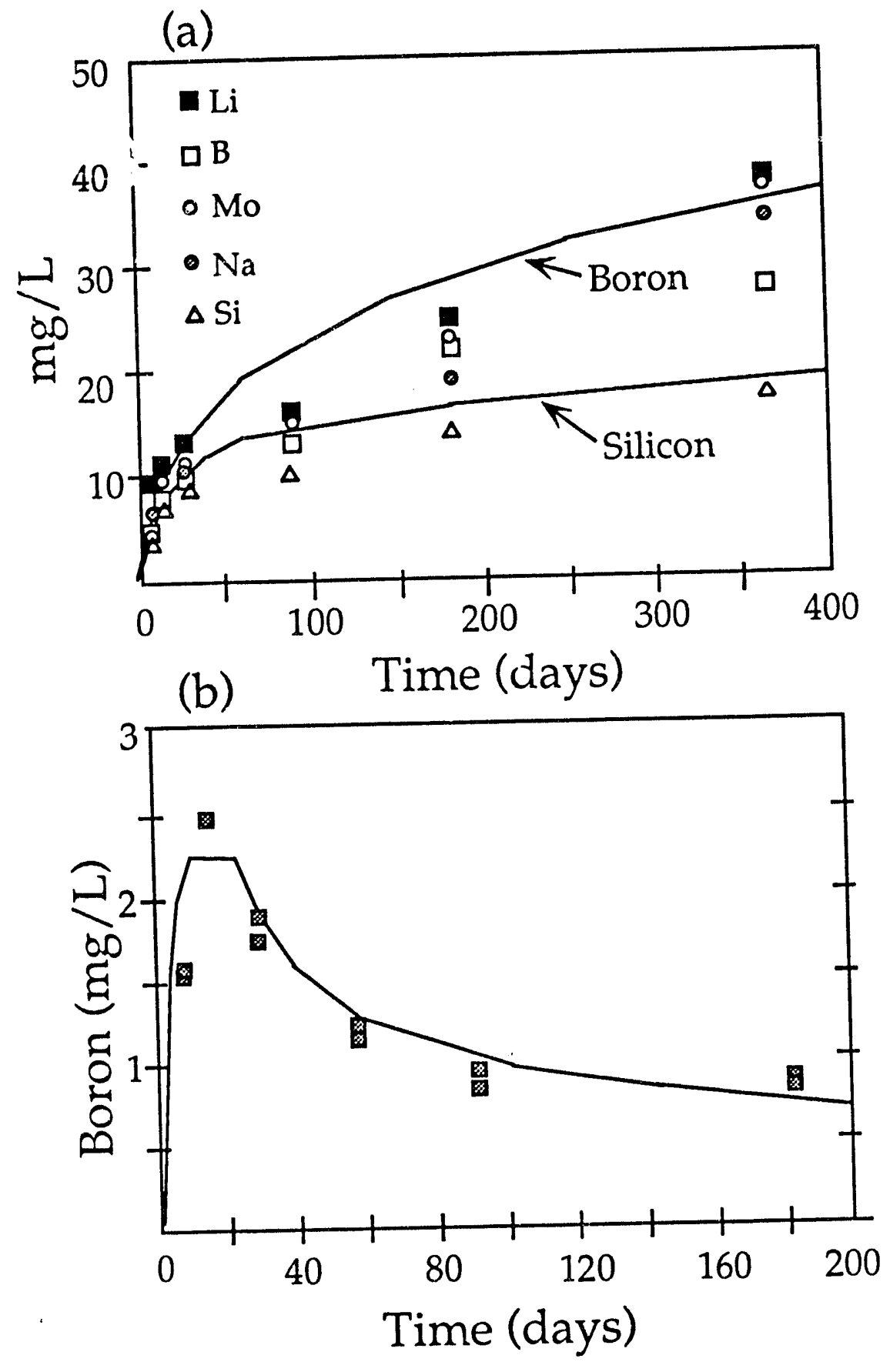

Fig. 11. Comparison of Experimental and Calculated Normalized Solution Data for Elements Released from R7T7 Glass at $90^{\circ} \mathrm{C}$ in (a) Deionized Water at $\mathrm{SA} / \mathrm{V}=10 \mathrm{~m}^{-1}$ and (b) Deionized Water Flowing at $2.9 \mathrm{~mL} /$ day [88]. 
with a new drop. In a real experiment, some of the water probably falls off the glass before the 3.5-day interval is over, and the new drop probably mixes to some extent with the previous drop on the glass surface.

The model predicts that after one year, about $3.5 \mathrm{mg}$ of glass will have reacted to form clays, zeolites, calcite, and uranophane (see Fig. 12). The predicted extent of reaction and types of secondary phases are in good agreement with experimental results [129]. The model also predicts that the $\mathrm{pH}$ of the drop, while on the glass surface, will initially rise to a value of about 9.25 (from the starting pH of EJ-13 water of 7.8), then fall with time to a value near 9 after one year (Fig. 12b). This pH drop occurs because the glass surface becomes less reactive with time as the glass reacts with successive drops. Note that the pH curve shown in Fig. $12 \mathrm{~b}$ is the $\mathrm{pH}$ of the drop after it has reacted for 3.5 days prior to being displaced by the next drop. Figure 12c shows the predicted elemental concentrations of species in the drop as a function of time. There is no way to compare these predictions with experimental data because the drop cannot be sampled while in contact with the glass surface. It may be possible to compare the integrated solution composition determined by adding up each predicted drop composition with the composition of the residual solution in the vessel bottom at the completion of the run. This has not yet been attempted.

\section{Modeling Accelerated Rates}

Data from static dissolution tests of horosilicate glasses have shown that after several months of reaction at a relatively slow rate, glasses will suddenly begin to dissolve at accelerated rates approaching the very high initial rate of reaction [56]. This effect occurs preferentially in high SA/V tests. High SA/V tests are used to simulate long-term conditions and to provide insight into glass dissolution rates and mechanisms expected over long periods. It is therefore important to understand the underlying mechanism responsible for the accelerated rates. Whether or not the observed rate acceleration process will affect glass in a repository depends on the underlying mechanism.

Ebert et al. [56] observed that the onset of the accelerated rate coincides with the precipitation of additional secondary phases such as the zeolite clinoptilolite. They suggest that these phases are supersaturated during the reaction until some point at which they nucleate and begin to grow. The growth of additional secondary phases will deplete the solution with respect to dissolved glass species such as silica. This decrease will increasc the value of the glass dissolution rate through the affinity effect.

Modeling can be used to determine whether or not this is a viable process [128]. A glass dissolution model can predict the glass reaction rate, given the solution composition. By giving the model the solution composition from both before and after the onset of the accelerated rate, we can determine whether the predicted change in reaction rate is similar to the measured one. As noted previously, no glass dissolution model is capable of predicting accelerated reaction conditions. However, moseling can be used to evaluate potential accelerating mechanisms. To evaluate the mechanism proposed by Ebert et al. [56], Bates et al. [128] used results from Ebert's SRL 202 glass dissolution tests in which accelerated reactions rates were observed.

The SRL 202 dissolution test results from Ebert et al. [56] are shown in Fig. 7. Up until 182 days, the glass is reacting slowly at what might appear to be its long-term rate. The rate then increases to a value about 13 times faster than the rate exhibited up to 182 days. The accelerated rate is nearly that of the initial rate measured in the first few hours of glass reaction in highly undersaturated solutions. 


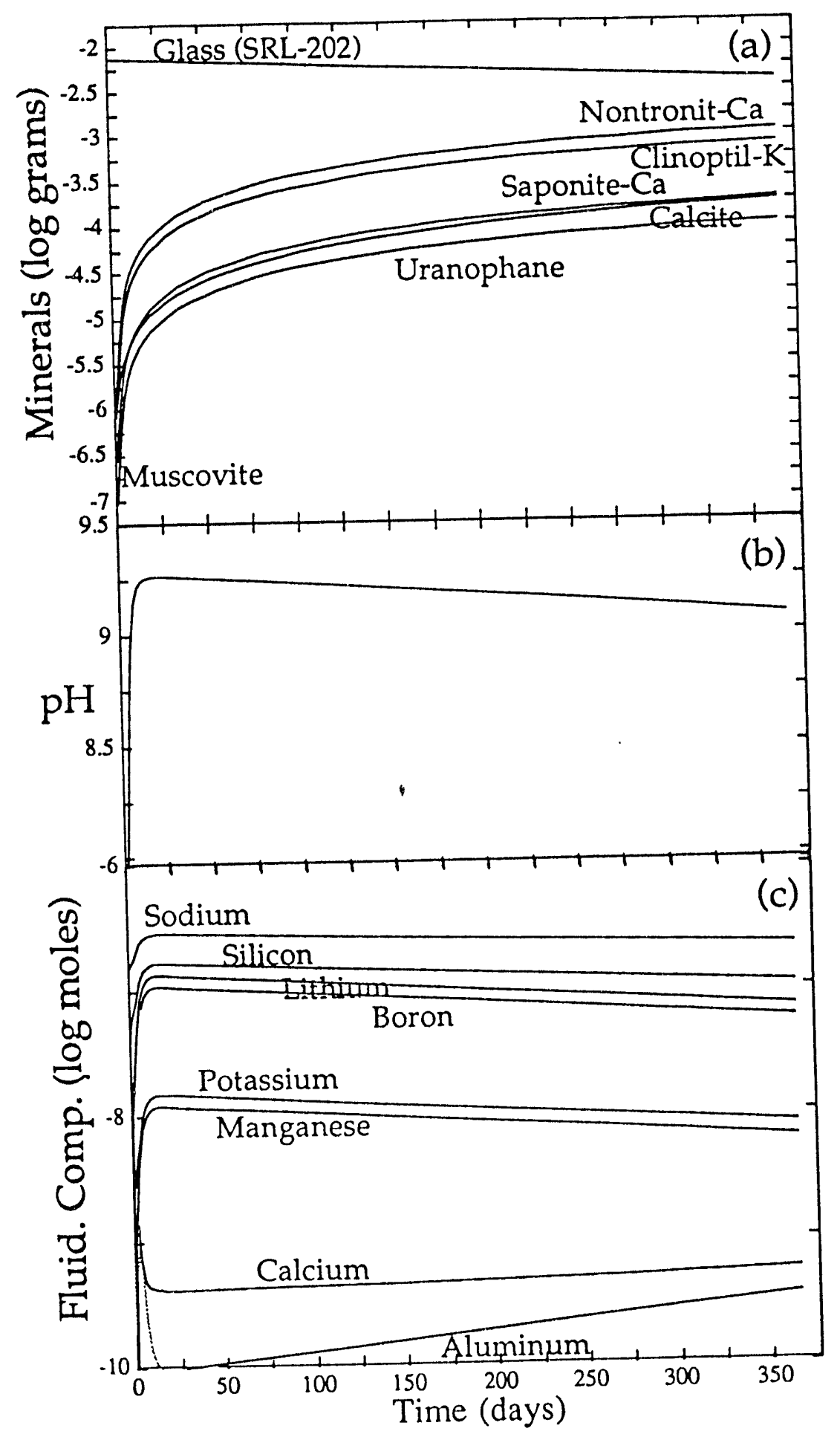

Fig. 12. Results of Simulations of Interactions of SRL 202 Glass with EJ-13 Water in Unsaturated Test (Drip Test) [128]: (a) Minerals Predicted to Precipitate during Reaction, (b) Predicted pH of Fluid, and (c) Predicted Composition of Fluid. 
The model was used to compare the ratio of predicted glass dissolution rates calculated by using measured solution data at day 91 (before acceleration) and day 504 (after acceleration). The rate of glass dissolution is predicted by the model to be a function of $\mathrm{pH}$ and dissolved silica concentrations. At day 91 , the $\mathrm{pH}$ is 11.3 and total dissolved silica is 0.019 molal. At day 504, the $\mathrm{pH}$ is 11.9 and total dissolved silica is 0.054 molal. The increase in $\mathrm{pH}$ from 11.3 to 11.9 causes the rate coefficient in the rate expression to increase by a factor of 1.5 (on the basis of open-system experiments). The affinity term in the rate expression increases by a factor of nine. Note that although there is more dissolved silica in the 504-day sample than in the 182-day sample, the saturation state $(\mathrm{Q} / \mathrm{K})$ actually decreases because silica becomes much more soluble at the higher $\mathrm{pH}$ values as a result of ionization and formation of polymeric $\mathrm{s}_{1}$ ecies. The two factors (rate coefficient and affinity term) combine to predict a rate about 11.5 times faster than the rate measured at 182 days (Fig. 7). This agrees well with the observed acceleration of 13 times.

Accelerated rates have been identified, and a potential mechanism underlying the accelerated rates has been identified. The accelerated rate phenomenon is clearly important for determining the suitability of the glass waste form for a high-level waste repository, considering that rates increases of over an order of magnitude have been observed after reaction periods of over a year. Most short-term tests have would not show this behavior because the reaction is terminated before the acceleration can be observed. Performance assessment calculations that are based on the long-term rate measured under "silica saturation" conditions would be seriously in error if they did not consider the potential for this accelerated rate.

\section{Interactions with Other Repository Materials}

Many experimental studies have looked at the effects of other repository materials on glass dissolution rates: i.e., with tuff present [130-134], with iron or stainless steel present [3,22,135-137], with bentonite present [137-139], with lead and other metals present $[21,131,140]$. Good reviews of interactions between repository material and glass are found in Werme et al. [84] and Bibler and Jantzen [134].

The modeling of these interactions has received much less attention. The Grambow model has been used to simulate the effect of iron dissolution products on glass performance [88]. They found that the increase in the dissolution rate of glass caused by adding iron to the system was probably due to the precipitation of iron silicate phases or colloids that effectively removed silica from solution. Alternatively, sorption of silica onto the iron oxides could have taken place. The relatively high dissolution rates were therefore caused by the lowering of silica in solution and the consequent increase in the affinity term in Eqn. 8. The relatively poor performance of glass with iron present was not improved when bentonite was added.

The effect of bentonite on glass performarce was modeled by Grambow et al. [141]. Bentonite can have either favorable or unfavorable effects on glass dissolution rates. Modeling results suggested that the early increase in leach rate observed in experiments occurs because it takes longer to approach to silica saturation when bentonite is present. Long-term effects should be less significant. The rate of glass dissolution also is closely linked with the amount of bentonite surface area available for ion exchange. Similar experimental and modeling results involving bentonite backfill were obtained by Curti and Smith [138].

\section{Application of Glass Dissolution Models to Natural Analogues}

Interpreting the chemical evolution of glasses in natural environments is inherently difficult because of the lack of key environmental data. For example, for naturally occurring glasses, it is not known how long the glass was exposed to water, what the 
composition of the water was, and what the values of physical parameters such as temperature and relative humidity were. Although in many cases, reasonable values can be assumed, these assumptions will necessarily restrict quantitative application of chemical models. The goodness of fit of a model is primarily constrained by the solution compositional data. These data are obviously not available for natural analog sites. As a consequence, most applications of chemical models to natural glasses are restricted to attempts to predict the identities of secondary phases found in association with the glass. The exceptions are modeling simulations of natural glasses such as basalts in laboratory leach experiments [67,71,142].

Attempts to model glasses in natural environments include use of the GLASSOL code [143,144], EQ3/6 [145], and DISSOL [146]. In most cases, reasonable agreement is found between observed and predicted secondary phase assemblages, as long as some thermodynamically stable phases are suppressed so that metastable precipitates can form. The modeling of Crovisier et al. [146] also provided estimates of mass balances for altered basalt glasses in Iceland and showed good agreement between model predictions and field observations.

\section{Modeling the Release of Actinides}

Most modeling efforts to date have been applied to the overall rate of glass dissolution and have not dealt explicitly with the rates of release of radionuclides from the glass waste form. The overall rate of glass dissolution provides a conservative maximum for the rate of release of radionuclides; they can be released no faster than the glass itself breaks down. Although there are numerous experimental studies of the rates of release of radionuclides from glass [85,147-151], including comparisons with actinide solubilities as discrete phases [152-153], there have been few attempts to incorporate these results into mechanistic models of glass dissolution. For any such attempt to succeed, better quantified information is needed, particularly in the areas of (1) solubilities of actinides as trace and minor components in the common clay, zeolite, and oxide alteration phases; (2) stabilities and formation rates of colloids; (3) stabilities of actinide complexes; and (4) the sorption behavior of radionuclides onto mineral surfaces including both colloids and alteration phases. Present geochemical computer codes used to model glass dissolution are being enhanced to include provisions for these chemical processes. Both better and more quantitative experimental data and computer code enhancements are needed to allow quantitative predictions of specific radionuclide release rates from the glass waste form. For many important radionuclides, however, this refinement of the modeling capability may not be necessary. This would be the case if simple bulk dissolution rates are within the Nuclear Regulatory Commission limits. 


\title{
IV. REPOSITORY PERFORMANCE ASSESSMENT CALCULATIONS FOR GLASS
}

\begin{abstract}
Most current repository performance assessment models do not link a mechanistically based glass dissolution model with mechanistically based durability models for other repository materials. The one exception is the work reported by McGrail $[93,154]$, which is discussed below. Current performance assessment strategies are probabilistically based $[155,156]$ and do not rigorously take into account chemical and physical processes that will govern repository behavior. Efforts to perform deterministic performance assessments are presently far from being applicable [157-159]. Most calculations to date have assumed some simple glass dissolution rates that are either constant $[119,160]$, a function of temperature [161], solubilitycontrolled [119,162], or controlled by exterior field mass transfer (diffusion-limited) [163]. Solubility-controlled release rates are not conservative. Experimental data for spent fuel dissolution show that measured actinide concentrations can be orders of magnitude higher than calculated values [153], a result possibly due to precipitation of amorphous and disordered actinide phases or formation of colloids containing actinides.
\end{abstract}

None of these calculations mechanistically link chemical processes involving multiple repository materials. There is no feedback to submodels for glass behavior that affects subsequent glass dissolution rates. For example, as dissolution of stainless steel canisters takes place, affecting solution $\mathrm{pH}$ and iron concentrations, no account is taken of how these changes affect glass dissolution rates. Likewise, the response of glass to environmental changes induced by dissolution processes will affect subsequent dissolution rates and mechanisms. Presently, we have made minimal progress in quantifying glass performance under repository conditions because in the United States these conditions still have not been completed defined. However, the mechanistically based glass dissolution models can readily be interfaced to total repository models once data and submodels for other repository processes become available.

Some recent work in this area has been reported by McGrail $[93,154]$. These studies report the linking of a mechanistically based glass dissolution model with mass transport (advective and diffusive) and probabilistic container failure models of the waste package. When fully implemented, the modified AREST code [155] will be able to link chemical dissolution of the waste package materials with dissolution of the glass waste form. This linkage is essential for the calculation of meaningful estimates of radionuclide release rates for a repository.

Application of the coupled AREST code to potential repository scenarios [93] shows that simpler models that assume solubility-controlled release of radionuclides are not always conservative. Changes in solution $\mathrm{pH}$ and oxidation state in the vicinity of the waste form are highly dependent on coupled chemical interactions between components of the waste package. Calculated release rates of uranium from a glass waste form predicted using the coupled chemical model may be higher than supposedly conservative solubility-limited release rates, depending on the value chosen for the effective diffusion constant of uranium in the backfill material. More work in this area is needed. On the basis of our current knowledge of the glass dissolution mechanism, if a performance assessment model does not take into account chemical parameters describing groundwater composition, such as $\mathrm{pH}$ and silica concentration, and their changes due to reactions with repository materials, it cannot be used to make meaningful predictions of radionuclide release rates from a repository. 


\section{SUMMARY AND CONCLUSIONS}

The major processes that take place during glass dissolution have been incorporated into current glass dissolution models. These models provide reasonable agreement with experimental observations under a limited range of test conditions. However, given the limited number of tests that have been designed to isolate and quantify these processes, several questions concerning a mechanistic model of glass dissolution remain to be answered.

\section{A. Qutstanding Problems}

The most important problems of current models arise from three situations: (1) the empirical nature of current glass dissolution models and the practice of obtaining model parameters from the very experiments being modeled, (2) the lack of a precise definition of the concept of "silica saturation," and (3) the poor definition and quantification of long-term release rate. These areas need to be addressed with additional experimental and modeling work and are discussed in more detail below.

In current models, the same experiments are used both to regress model parameters (such as rate constants and silica saturation values) and to validate the final model. A defensible model must use parameters derived from experiments different from those used to test the model. If similar experiments are used both to derive model parameters and test the model, it follows only that the model is consistent with the data, not that the data prove the correctness of the model. The more varied the set of experiments the model can correctly simulate, the more confidence one can have in the model. Current modeling work can only predict a narrow range of experimental results that are similar to the experiments used to generate model parameters. This does not constitute validation of the models.

The ultimate chemical process responsible for controlling the long-term dissolution rate has not been identified. The Grambow model includes the concept of "residual affinity," which is used to explain why dissolution continues even after "silica saturation." This mechanism has no physical basis and therefore cannot be quantified in the model, except as a fitting parameter to short-term test results. The model proposed by Bourcier et al. [11] predicts the long-term rate on the basis of the saturation state of the solution with respect to the surface alteration layer. The model avoids the concept of residual affinity by making the implicit assumption that the affinity effect (caused by the depletion of elements in solution due to secondary phase formation) will always be much greater than any effect that arises because glass is an inherently thermo-dynamically metastable solid. In other words, the solution will never become saturated with respect to the gel layer, so there is no need to try to describe how fast glass will dissolve under conditions where the solution is approaching saturation. More work is needed to more carefully define a long-term rate-controlling mechanism.

Actinides are assumed to be released congruently with glass matrix dissolution. In reality, the actinide release rates may be lower because of solubility limits or because of the incorporation of actinides into secondary phases that remain as part of the gel layer. The ability to apply current models is limited mainly by the lack of good thermodynamic data for the relevant phases and the identification of these phases. These data need to be incorporated into existing geochemical reaction codes and used in model simulations.

Both nucleation and growth kinetics need to be added to the simulations. Present modeling work assumes that secondary phases precipitate immediately upon reaching saturation in solution. It is commonly observed that phases do not begin to precipitate until they are sufficiently supersaturated that they can overcome any nucleation barrier to precipitation. Also, precipitation rates are sometimes slower than the buildup in concentration of species, and 
precipitation kinetics must be added to the simulations to account for this. Although for some long-term simulations it can be assumed that nucleation and precipitation kinetics barriers may be overcome and that the system will equilibrate, it will be necessary to include these features in a kinetic model to accurately simulate short-term experimental results.

Finally, experimental and modeling investigations of glass dissolution have ignored biological effects. The effects of microbes on the dissolution of natural glasses is significant [164] and may affect not only the dissolution rate of the glass, but also the oxidation states and therefore solubilities of radionuclides as they are released [165]. Microbial activity will also increase the local abundance of organic acids [166] which are known to increase the dissolution rates of silicate glasses [167]. Microbes have been identified in repository environments [168] and are likely to remain active even in the most extreme conditions following waste emplacement [169]. Future work must address important questions regarding the ability of microorganisms to affect glass waste form durability under repository conditions.

\section{B. Recommended Future Experimental and Modeling Work}

\section{Issues Needing Investigation}

Simple, well-constrained, and interpretable experiments designed to isolate individual mechanisms taking place during glass dissolution are needed as the foundation for further model development. The vast majority of tests performed to date, while useful for identifying and prioritizing important factors affecting glass dissolution, cannot be used directly in developing a quantitative glass dissolution model. Additional experimental approaches are needed to isolate individual processes taking place during glass dissolution. It would be desirable to design experiments to investigate each of the following issues.

The Rate Coefficient as a Function of Temperature and Solution Composition. Recent work has shown that the dissolution rates of solids depend on their surface chemistry [170]. The overall rate of dissolution depends on the population of surface species adsorbed at the solid-solution interface. Explicit provision for surface complexation should account for the effects of $\mathrm{pH}$, ionic strength, and solution composition on the rate constant.

The Nature of the Affinity Effect. One example of the affinity effect is the observation that increasing the concentration of dissolved silica slows the glass dissolution rate. Recent data show that dissolved aluminum has a similar effect but to a lesser degree [24]. The form of the aftinity expression in the rate law needs to be determined from experimental data for which the affinity term can be calculated from available solution data. This information is critical for predicting long-term glass leaching rates, when the affinity term dominates the rate law. Other recent work has shown that an alternate numerical expression for the affinity term is more appropriate for some glasses [171], although the mechanistic basis for this change has yet to be established. More work is needed to further investigate the general applicability of this revised form of the affinity expression.

The Effect of Glass Composition on Glass Durability. Leach experiments should be combined with studies to obtain glass structural information from studies of unreacted and reacted glasses [12]. Previous work has shown that glass durability is determined primarily by the major glass components and is not measurably sensitive to substitution of minor and trace components [24]. However, an exception to this general trend is the observation that small amounts of zirconia can greatly increase durability [172]. Related to this topic is the known tendency for some glasses to precipitate specific secondary phases in leach tests. For example, high alumina glasses will alter to form analcime and maintain lower levels of dissolved silica than glasses with lower alumina contents [119]. The lowered dissolved silica concentrations 
will increase glass dissolution rates. Although increased aluminum in the glass increases the durability as measured in open-system tests, the precipitation of analcime (or other zeoliies) has the opposite effect and may decrease glass durability in a repository environment.

Accelerated Tests. To predict long-term dissolution rates, it is clearly desirable to have available experiments that validate predicted long-term performance. However, there are no experiments that can faithfully simulate long-term behavior over short time intervals. The best available methods are (a) to do tests at elevated temperatures, which accelerate intrinsic reaction rates and (b) to do tests at high surface area-to-volume ratios, which increase solution concentrations in proportion to the exposed glass surface area. For a variety of reasons (see next section), neither technique can be assumed to faithfully simulate long-term behavior. Likewise, natural analogues such as basaltic glass, althoug,h not tested under accelerated conditions, provide information on glass reaction rates or er repository-relevant periods, but this information is limited by the lack of complete characteri zation of the system over time.

Understanding the Mechanism Respons, ble for Delayed Onset of Accelerated Dissolution Rates. As mentioned in Section III.G.3, experimental investigations by Ebert et al. [56] show that after over a year of reaction, glass diss olution rates abruptly rise by over an order of magnitude. The mechanism responsible for this increase must be identified. It also must be determined whether or not the mechanism will cause a similar rise in reaction rate under repository conditions.

\section{Types of Experiments Needed}

On the basis of these five areas of need, we have identified the following classes of experiments as those most critical for improving our current glass dissolution models.

Open-System Tests of Glasses in Continuously Stirred Reactors with Controlled $\mathrm{pH}$ Levels. These tests should be designed to measure the rate constant for glass dissolution over a range of temperatures, $\mathrm{pHs}$, and glass compositions. These tests will provide the rate constant as a function of $\mathrm{pH}$ and temperature under controlled conditions where no secondary phase precipitation takes place that could complicate the interpretation of results. The measured rate as a function of temperature can be used to determine the activation erergy for dissolution. Similar tests should be performed in $\mathrm{pH}$ buffer solutions doped with relevant cations and anions to systematically determine the effects of dissolved species on dissolution rate. These tests should be combined with surface titrations to characterize glass surface speciation. Surface titrations should be a routine procedure in all glass dissolution experiments. The glass-solution interface and the types of surface complexes present can be determined with these methods (Fig. 10). Oxide dissolution rates are known to be affected by the types of surface complexes present [173]. Additional tests should be performed in high-temperature circulating systems to provide accelerated rate data and better constrain the rate coefficient as a function of temperature.

\section{Closed-System Tests of a Matrix of Glass Compositions with Controlled oH}

( $\mathrm{nH}$ Stat). These tests should be designed to investigate the effect of glass composition on glass dissolution rate under conditions where secondary phases are able to form (unlike the opensystem tests above). These tests should be combined with nuclear magnetic resonance (NMR) analysis of unreacted glasses to correlate glass structure and coordination with glass durability as measured in both the open-system and closed-system tests. These tests should cover a wide range of surface area-to-volume ratios (SA/V). By using the $\mathrm{pH}$ stat technique, high SA/V tests should scale with low SA/V tests when normalized using SA/V•t. High SA/V tests in closedsystem tests with free-drift $\mathrm{pH}$ do not scale because of early rapid ion exchange that causes high $\mathrm{SA} / \mathrm{V}$ solutions to react at higher $\mathrm{pH}$ values than low SA/V solutions [119]. Using high SA/V as an accelerated test procedure is justified if all system parameteters are measured and the 
reaction mechanism does not change. The closed-system tests should be extended to high temperatures in pressurized autoclaves. These test results will provide accelerated test data and will also allow the formation of larger and more crystalline alteration phases for characterization.

Closed-System Tests with Controlled Solution Composition. Additional closedsystem tests should be performed in which stable secondary phases such as calcite, quartz, and clays are added to control solution composition. Glass dissolution rates should change by a predictable amount based on the imposed change in the affinity term in the glass dissolution rate expression. The added mineral phases should control the solution composition to values different than the concentrations measured in tests without added phases. The data from these tests should help to define and quantify the affinity term in the rate expression. The predicted effect of analcime on glass dissolution rate could be validated by tests having added analcime.

Molecular Simulation of Glass Dissolution. Finally, modern molecular simulation methods should be applied to all aspects of the glass dissolution process. Molecular dynamics simulations of glass structures may provide insight to maximize durability of glass compositions. The effects on structure and bonding in the glass of adding specific oxides can be calculated. Monte Carlo simulations of the type described by Dran et al. [174] may also help to quantify the effect of glass composition on structure and durability. Other studies that should be performed include simple molecular orbital investigations of glass surface speciation using methods such as those presented by Lee et al. [175] and molecular dynamics calculations of surface transport processes [176]. The results of these types of studies can be used to evaluate various proposed rate-limiting mechanisms such as that shown in Fig. 13. These studies can help constrain macroscopic glass dissolution models and support validation of proposed dissolution mechanisms. The form of the aftinity term in the rate equation can also potentially be calculated from molecular orbtial theory [177].

In all cases, glass dissolution experiments should include a complete analysis of both solid and aqueous phases. Too many experiments have been performed in which incomplete characterization of either solids or solution phases has made interpretation of the results ambiguous, both for mechanistic analysis of the results and for use of the results in model validation. Future work to improve and validate glass dissolution models must include experiments such as those described above, along with refinement and quantification of current models. This work will be most effective if modeling and experimental work are closely coupled. 


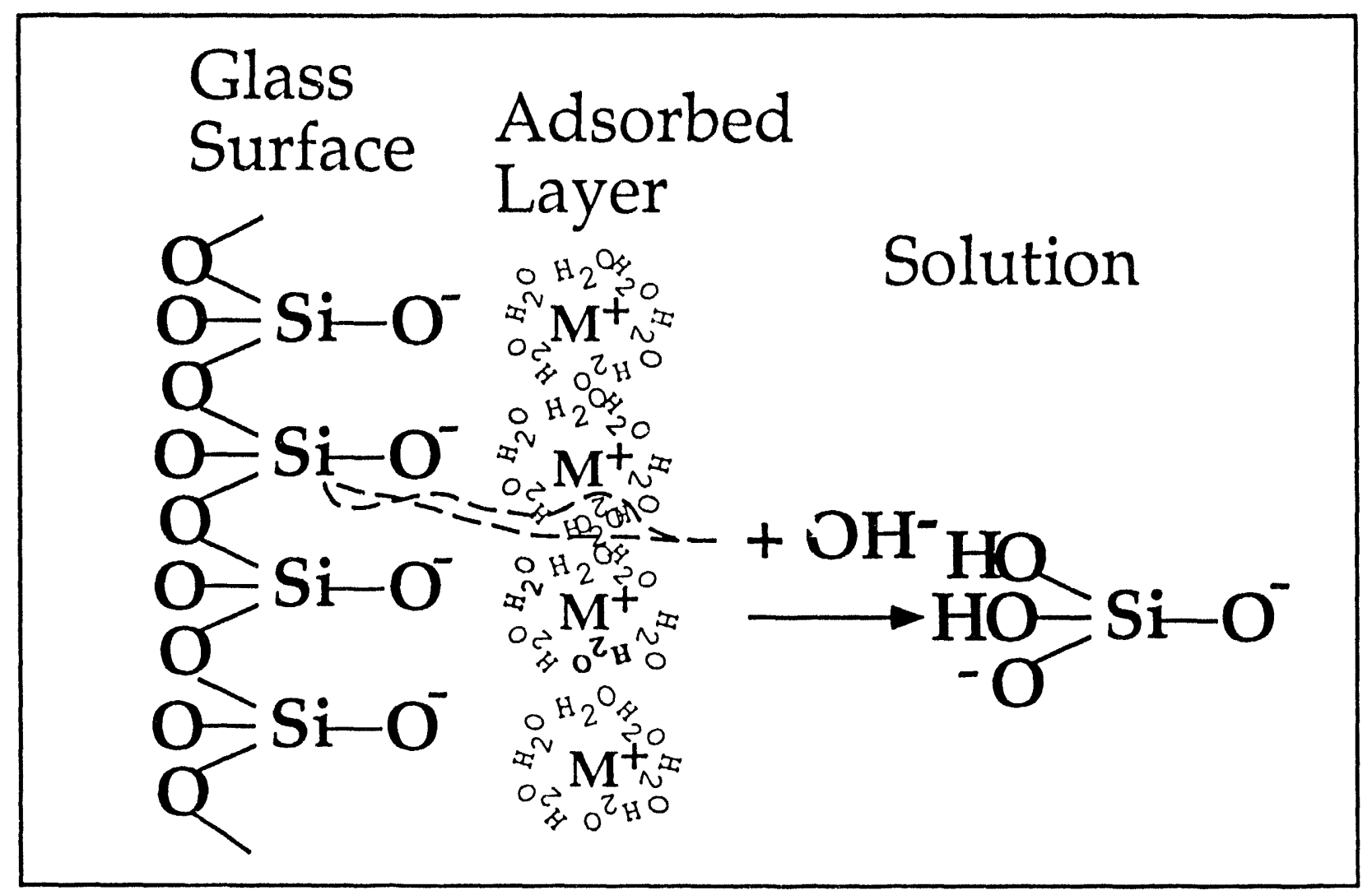

Fig. 13. Proposed Microscopic Structure of Glass-Solution Interface. According to this model, the dissolution rate is controlled by the diffusion of $\mathrm{OH}^{-}$through the layer of adsorbed cations [177]. 


\section{ACKNOWLEDGMENTS}

The author wishes to acknowledge reviews of this manuscript by John Bates and William Ebert. Financial support was provided to Lawrence Livermore National Laboratory by Argonne National Laboratory, through the U.S. Department of Energy, Office of Environmental Restoration and Waste Management, under contract W-31-1(19-ENG-38. 


\section{REFERENCES}

1. T. A. Abrajano and J. K. Bates, "Transport and Reaction Kinetics at the Glass:Solution Interface Region: Results of Repository-Oriented Leaching Experiments," Mat. Res. Soc. Symp. Proc. 84, 533-546 (1987).

2. V. M. Oversby and D. L. Phinney, "The Development of Surface Alteration Layers on SRL-165 Nuclear Waste Glasses," J. Nucl. Mater. 190, 247-268 (1992).

3. J. E. Mendel, Final Report on the Defense High Level Waste Leaching Mechanisms Program, Pacific Northwest Laboratory Report PNL-5157 (1984).

4. J. K. Bates, W. L. Ebert, J. J. Mazer, J. P. Bradley, C. R. Bradley, and N. L. Dietz, "The Role of Surface Layers in Glass Leaching Performance," Mat. Res. Soc. Symp. Proc. 212. 77-87 (1991).

5. L. C. Klein, "Natural Glasses in Howardites and Chondrites (Meteorites)," Adv. Ceram. 20, 693-698 (1986).

6. H. C. Palmer, K. Tazaki, W. S. Fyfe, and Z. Zhou, "Precambrian Glass," Cu ology 16 , $221-224$ (1988).

7. C. T. Lee and D. E. Clark, "Effects of Solution Cations on Waste Glass Leaching," Adv. Ceram. 20), 541-550 (1986).

8. B. K. Zoitos, R. L. Schulz, and D. E. Clark, "A Marker Study of Surface Layer Formation and Partial Dissolution," Nuclear Waste Mgmt. III, 297-306 (1991).

9. T. Abrajano, J. K. Bates, W. L. Ebert, and T. J. Gerding, The Effect of Gamma Radiation on Groundwater Chemistry and Glass Leaching as Related to the NNW'S: Repository Site, Lawrence Livermore National Laboratory Report UCRL-15825 (1986).

10. W. L. Bourcier, Geochemical Modeling of Radioactive Wasteglass Dissolution Using EQ3/6: Preliminary Results and Data Needs, Lawrence Livermore National Laboratory Report UCID-21869 (1990).

11. W. L. Bourcier, D. Peiffer, K. Knauss, K. McKeegan, and D. Smith, "A Kinetic Model for Borosilicate Glass Dissolution Based on the Dissolution Affinity of a Surface Reaction Layer," Mat. Res. Soc. Symp. Proc. 176, 209-216 (1990).

12. B. C. Bunker, D. R. Tallant, T. J. Headley, G. L. Turner, and R. J. Kirkpatrick, "The Structure of Leached Sodium Borosilicate Glass," Phys. Chem. Glasses 29, 106-120 (1988).

13. B. Grambow, Nuclear Waste Glass Dissolution: Mechanism, Model and Application, Swedish Nuclear Fuel and Waste Management Co., JSS Project Report JSS-87-02 (1987).

14. T. A. Abrajano, J. K. Bates, A. B. Woodland, J. K. Bradley, and W. L. Bourcier, "Secondary Phase Formation during Nuclear Waste-Glass Dissolution," Clays and Clay Miner. 38(5), 537-548 (1990). 
15. L. A. Chick and L. R. Pederson, "The Relationship between Layer Thickness and Leach Rate for Nuclear Waste Glasses," Mat. Res. Soc. Symp. Proc. 20, 63.5-642 (1984).

16. T. Murakami, R. C. Ewing, and B. C. Bunker, "Analytical Electron Microscony of Leached Layers on Synthetic Basalt Gilass," Mat. Res. Soc. Symp. Proc. 112, 737-748 (1988).

17. S.-B. Xing, A. C. Buechele, and I. L. Pegg, "Effect of Surlace Layers on the Dissolution of Nuclear Waste Glasses," Mat. Res. Soc. Symp. Proc. 333, $541-548$ (1994).

18. B. L. Phillip:s, "Preliminary NMR Investigation of Sodium Borosilicate and Analogue SRL Waste Glasses," in Technical Support Program for DOE Environmental Restoration and Waste Management, Anmual Re'port, October 1991-September 1992, Argonne National Laboratory Report ANL-93/13, pp. 153-164 (1993).

19. A. Barkatt, E. E. Saad, R. Adiga, W. Sousampour, A. Barkatt, and M. A. Adel-lladadi, "Leaching of Natural and Nuclear Waste Glasses in Sea Water," Appl. Geochem. 4. $593-6(1) 3(1989)$.

2(). C. Q. Buckwalter, L. R. Pederson, and G. L. Mc Vay, "The Eflects of Surface Area to Volume Ratio and Surface Roughness on Glass Leaching," J. Non-Cryst. Solids 49, $397-412(1982)$.

21. R. L. Lehman and F. A. Kuchinski, "The Eflect of Various Lead Species on the leaching Behavior of Borosilicate Waste Glass," Mat. Res. Soc. Symp. Proc. 44 , 179-186(1985).

22. G. L. McVay and C. Q. Buckwalter, "Eflect of Iron on Waste-Glass Leaching," J. Am. Cor. Soc. 66(3), 17()-174(1982).

23. L. Michaux, E. Mouche, and J. C. Petit, "Geochemical Modeling of the Long-Term Dissolution Behavior of the French Nuclear Glass R7T7," Appl. Geochem. Special Issuc 1, 41-54 (1992).

24. W. L. Bourcier, H. C. Weed, S. N. Nguyen, J. K. Nielsen, L. Morgan, L. Newton, and K. G. Knatuss, "Solution Compositional Effects on Dissolution Kinetics of Borosilicate Glass," Proc. Seventh Annual Water-Rock Conference, eds. Y. Khat aka and A. Maest, A. A. Balkema, publisher, pp. $81-84$ (1992).

25. X. Feng and A. Barkalt, "Eflects of Ayueous Phase Composition on the Leach Behavior of Nuclear Waste Glasses," Mat. Res. Soc. Symp. Proc. 84, 519-531 (1987).

26. W. B. White, "Dissolution Mechanisms of Nuclear Waste Glasses: A Critical Review," Adv. Ceram. 201, 431-442 (1986).

27. W. L. Bourcier, "Overview of Chemical Modeling of Nuclear Waste Glass Dissolution," Mat. Res. Soc. Symp. Proc. 212, 3-18 (1991).

28. MCC-IP Static Leach Test Method, Materials Characterization Center, Pacific Northwest Laboratory Report D()E/TIC-1140() (1985).

29. D. M. Strachan, L. R. Pederson, and R. (). Lokken, Results from Long-Term Interaction and Modeling of SRL-1.3I Glass with Aqueous. Solution, Pacific Northwest Laboratory Report PNL-5654 (1985). 
30. W. L. Bourcier and H. L. Barnes, "Rocking Autoclaves for Hydrothermal Experiments. I. Fixed Volume Systems," in Hydrothermal Experimental Methods, ed. G. C. Ulmer and H. L. Barnes, John Wiley \& Sons, New York, pp. 189-215 (1987).

31. R. H. Doremus, "Diffusion Controlled Reaction of Water with Glass," J. Non-Cryst. Solids 25, 143-147 (1983).

32. K. B. Harvey and C. A. Boase, "The Dissolution of a Simple Glass. Part 2. Behavior in Closed Glass/Water Systems," Phys. Chem. Glasses 28, 11-16 (1987).

33. K. B. Harvey and C. A. B. Larocque, "The Dissolution of a Simple Glass. Part 3. Behavior in Replenished or Flowing Systems," Phys. Chem. Glasses 30(4), 123-129 (1989).

34. K. B. Harvey, C. D. Litke, and C. A. Boase, "The Dissolution of a Simple Glass. Part 1. Initial Model and Application to an Open Glass/Water System," Phys. Chem. Glasses 27, 15-21 (1986).

35. R. Conradt, H. Roggendorf, and H. Scholze, "A Contribution to the Modeling of the Corrosion Process for HLW Glasses," Mat. Res. Soc. Symp. Proc. 44, 155-162 (1985).

36. R. H. Doremus, "Interdiffusion of Hydrogen and Alkali Ions in a Glass Surface," J. Non-Cryst. Solids 19, 137-144 (1975).

37. J. O. Isard, A. R. Allnatt, and P. J. Melling, "An Improved Model of Glass Dissolution," Phys. Chem. Glasses 23(6), 185-189 (1982).

38. B. M. J. Smets, "The Role of Molecular Water in the Leaching of Glass," Phys. Chem. Glasses 24(1), 35-36 (1983).

39. T. Banba and T. Murakami, "The Leaching Behavior of a Glass Waste Form - Part 2: The Leaching Mechanisms," Nucl. Technol. 70, 243-248 (1985).

40. T. Banba, T. Murakami, and H. Kimura, "The Leaching Behavior of a Glass Waste Form - Part 3: The Mathematical Leaching Model," Nucl. Technol. 76, 84-90 (1987).

4i. T. Murakami and T. Banba, "The Leaching Behavior of a Glass Waste Form - Part 1: The Characteristics of the Surface Layers," Nucl. Technol. 67, 419-428 (1984).

42. R. M. Wallace and G. G. Wicks, "Leaching Chemistry of Defense Borosilicate Glass," Mat. Res. Soc. Symp. Proc. 15, 23-28 (1983).

43. K. B. Harvey, C. D. Litke, and C. A. Boase, "Diffusion Based Leaching Models for Glassy Waste Forms," Adv. Ceram. ㅇ, 496-507 (1984).

44. A. J. Machiels and C. Pescatore, "The Influence of Surface Processes in Waste Form Leaching," Mat. Res. Soc. Symp. Proc. 3, 371-378 (1981).

45. C. Pescatore and A. J. Machiels, "Effects of Surfaces on Glass Waste Form Leaching," J. Non-Cryst. Solids $\underline{49}$, 379-388 (1982).

46. L. R. Pederson, C. Q. Buckwalter, G. L. McVay, and B. L. Riddle, "Glass Surface Area to Volume Ratio and Its Implications to Accelerated Leach Testing," Mat. Res. Soc. Symp. Proc. 15, 47-54 (1983). 
47. T. J. Wolery, EQ3/6, A Software Package for Geochemical Modeling of Aqueous Systems: Package Overview and Installation Guide, Lawrence Livermore National Laboratory Report UCRL-MA-110662 PT 1 (1992).

48. T. J. Wolery, EQ3NR, A Computer Program for Geochemical Aqueous SpeciationSolubility Calculations: Theoretical Manual, User's Guide, and Related Documentation, Lawrence Livermore National Laboratory Report UCRL-MA-110662 PT III (1992).

49. T. J. Wolery and S.A. Daveler, EQ6, A Computer Program for Reaction-Path Modeling of Aqueous Geochemical Systems: Theoretical Manual, User's Guide, and Documentation, Lawrence Livermore National Laboratory Report UCRL-MA-110662 PT IV (1992).

50. D. L. Parkhurst, D. C. Thorstenson, and L. N. Plummer, PHREEQE-A Computer Program for Geochemical Calculations, United States Geological Survey Report USGS-WRI-80-96 (1980).

51. Y. K. Kharaka, W. D. Gunter, P. K. Aggarwal, E. H. Perkins, and J. D. DeBraal, SOLMNEQ: Solution Mineral Equilibria Computations, United States Geological Survey Report USGS-CCP-215-899 (1973).

52. C. J. Bruton, "Geochemical Simulation of Dissolution of West Valley and DWPF Glasses in J-13 Water at $90^{\circ} \mathrm{C}$," Mat. Res. Soc. Symp. Proc. 112, 607-619 (1988).

53. W. L. Ebert, J. K. Bates, and W. L. Bourcier, "The Hydration of Borosilicate Waste Glass in Liquid Water and Steam at $200^{\circ} \mathrm{C}$," Waste Mgmt. 11, 205-221 (1991).

54. D. Savage, "The Geochemical Interactions of Simulated Borosilicate Waste Glass, Granite, and Water at $100-350^{\circ} \mathrm{C}$ and $50 \mathrm{MPa}$," Nucl. Chem. Waste Mgmt. $\underline{6}, 15-39$ (1986).

55. D. M. Strachan, K. M. Krupka, and B. Grambow, "Solubility Interpretations of Leach Tests on Nuclear Waste Glass," Nucl. Chem. Waste Mgmt. ㅁ, 87-99 (1984).

56. W. L. Ehert, J. K. Bates, E. C. Buck, and C. R. Bradley, "Accelerated Glass Reaction under PCT Conditions," Mat. Res. Soc. Symp. Proc. 294, 569-576 (1993).

57. P. Aagaard and H. C. Helgeson, "Thermodynamic and Kinetic Constraints on Reaction Rates Among Minerals and Aqueous Solutions I. Theoretical Considerations," Am. J. Sci. $\underline{282}, 237-285$ (1982).

58. A. C. Lasaga, "Chemical Kinetics of Water-Rock Interactions," J. Geophys. Res. 89(B6), 4009-4025 (1984).

59. T. Advocat, J. L. Crovisier, B. Fritz, and E. Vernaz, "Thermokinetic Model of Borosilicate Glass Dissolution: Contextural Affinity, "Mat. Res. Soc. Symp. Proc. 176, 241-248 (1990).

60. C. M. Bethke, The Geochemist's Workbench: A Users Guide to Rxn, Act2, Tact, React, and Gtplot, University of Illinois Press, Urbana, Illinois (1992).

61. F. Delage, D. Ghaleb, J. L. Dussossoy, O. Chevallier, and E. Vernaz, "A Mechanistic Model for Understanding Nuclear Waste," J. Nucl. Mater. 190, 191-197 (1992). 
62. W. L. Ebert and J. K. Bates, "The Effects of Leachate $\mathrm{pH}$ and the Ratio of Glass Surface Area to Leachant Volume on Glass Reactions," Phys. Chem. Glasses 34(2), 58-65 (1993).

63. W. L. Bourcier, K. G. Knauss, and C. I. Merzbacher, "A Kinetic Model for Borosilicate Glass Dissolution," Proc. Sixth Internat. Symp. on Water-Rock Interactions, ed. D. L. Miles, A. A. Balkema, publisher, pp. 107-110(1989).

64. T. Advocat, J. L. Crovisier, E. Vernaz, G. Ehret, and H. Charpertier, "Hydrolysis of R7T7 Nuclear Waste Glass in Dilute Media: Mechanisms and Rate as a Function of pH," Mat. Res. Soc. Symp. Proc. 212, 57-64 (1991).

65. E. Y. Vernaz and J. L. Dussossoy, "Current State of Knowledge of Nuclear Waste Glass Corrosion Mechanisms: The Case of R7T7 Glass," Appl. Geochem. Special Issue 1, 13-22 (1992).

66. W. M. Murphy and H. C. Helgeson, "Thermodynamic and Kinetic Constraints on Reaction Rates Among Minerals and Aqueous Solutions. IV. Retrieval of Rate Constants and Activation Parameters for the Hydrolysis of Pyroxene, Wollastonite, Olivine, Andalusite, Quartz, and Nepheline," Am. J. Sci. 289, 17-101 (1989).

67. J. J. Mazer, "Kinetics of Glass Dissolution as a Function of Temperature, Glass Composition, and Solution pHs," Ph.D. Thesis, Northwestern University, Evanston, Illinois (1987).

68. B. Grambow, "Ein Physikalische-Chemisches Modell für den Mechanismus der Laskorrosion - Unter Besonderer Berücksichtigung Simulierter Radioaktiver Abfallgläser," Ph.D. Thesis, Freien Universität, Berlin, Germany (1984).

69. B. Grambow, "A General Rate Equation for Nuclear Waste Glass Corrosion," Mat. Res. Soc. Symp. Proc. 44, 16-27 (1985).

70. B. Grambow and D. M. Strachan, A Comparison of the Performance of Nuclear Waste Glasses by Modeling, Pacific Northwest Laboratory Report PNL-6698 (1988).

71. J. L. Crovisier, B. Grambow, and J. P. Eherhart, "Dissolution of Basaltic Glass in Seawater: Experiments and Thermodynamic Modeling," Mat. Res. Soc. Symp. Proc. 5(), 273-280 (1985).

72. E. Curti, Modelling the Dissolution of Borosilicate Glasses for Radioactive Waste Disposal with the PHREEQE/GLASSOL Code: Theory and Practice, Paul Scherrer Institute Report PSI-Bericht Nr. 86, Würlingen, Switzerland (1991).

73. E. Freude, B. Grambow, W. Lutze, H. Rabe, and R. Ewing, "Long-Term Release from High-Level Waste Glass - Part IV: The Effect of Leaching Mechanism, "Mat. Res. Soc. Symp. Proc. 44, 99-106 (1985).

74. B. Grambow, "Geochemical Modeling of the Reaction between Glass and Aqueous Solution," Adv. Ceram. $\underline{8}, 474-481$ (1984).

75. B. Grambow, "Geochemical Approach to Glass Dissolution," in Corrosion of Glass, Ceramics, and Ceramic Superconductors, eds. D. E. Clark and B. K. Zoitos, Noyes Publications, Park Ridge, New Jersey, pp. 124-152 (1992). 
76. B. Grambow and W. Lutze, "Performance Assessment of Glass as a Long-Term Barrier to the Release of Radionuclides into the Environment," Mat. Res. Soc. Symp. Proc. 112, $531-541$ (1988).

77. B. Grambow, W. Lutze, and R. Müller, "Empirical Dissolution Rate Law for the Glass R7T7 Contacting Halite- and Silica-Saturated Brines," Mat. Res. Soc. Symp. Proc. 257, 143-150 (1992).

78. B. Grambow and R. Muller, "Chemistry of Glass Corrosion in High Saline Brines," Mat. Res. Soc. Symp. Proc. 176, 229-240 (1990).

79. B. Grambow and D. Strachan, "Leach Testing of Waste Glasses under Near-Saturation Conditions," Mat. Res. Soc. Symp. Proc. 26, 623-634 (1984).

80. B. Grambow and D. M. Strachan, A Comparison of the Performance of Nuclear Waste Glasses by Modeling, Pacific Northwest Laboratory Report PNL-6698 (1988).

81. Experimental and Modeling Studies of HLW Glass Dissolution in Repository Environments, Swedish Nuclear Fuel and Waste Management Co., Stockholm, Sweden, JSS Project Report 87-()1 (1987).

82. J. Patyn, P. Van Iseghem, and W. Timmermans, "The Long-Term Corrosion and Modeling of Two Simulated Belgian Reference High-Level Waste Glasses - Part II," Mat. Res. Soc. Symp. Proc. 176, 299-3(17 (1990).

83. P. Van Iseghem and B. Grambow, "The Long-Term Corrosion and Modelling of Two Simulated Belgian High-Level Reference Waste Glasses," Mat. Res. Soc. Symp. Proc. $112,631-639$ (1988).

84. L. Werme, I. K. Bjorner, G. Bart, H. U. Zwicky, B. Grambow, W. Lutze, R. Ewing, and C. Magrabi, "Chemical Corrosion of Highly Radioactive Borosilicate Waste Glass under Simulated Repository Conditions," J. Mater. Res. 5(5), 1130-1146 (199()).

85. B. Grambow, H. U. Zwicky, G. Bart, I. K. Björner, and L. O. Werme, "Modeling the Effect of Iron Corrosion Products on Nuclear Glass Performance," Mat. Res. Soc. Symp. Proc. 84, 471-481 (1987).

86. B. Grambow, R. Muller, A. Rother, and W. Lutze, "Release of Rare Earth Elements and Uranium from Glass in Low pH Brines," Radiochim. Acta 52/53, 501-5()6 (1991).

87. K. J. Jackson, "Extension of the EQ3/6 Computer Codes to Geochemical Modeling of Brines," Mat. Res. Soc. Symp. Proc. 44, 507-514 (1985).

88. J. C. Petit, M. C. Magonthier, J. C. Dran, and G. Della Mea, "Long-Term Dissolution Rate of Nuclear Glasses in Confined Environments: Does a Residual Chemical Affinity Exist?" J. Mater. Sci. 25, 3048-3052 (1990).

89. B. Fritz, "Etude Thermodynamique et Modelisation des Reactions Hydrothermales et Diagenetiques," Sci. Geologique Memoir 65 (1981).

90. Y. Tardy and B. Fritz, "An Ideal Solid Solution Model for Calculating Soluhility of Clay Minerals," Clay Miner. 16, 361-373 (1981). 
91. E. Vernaz, T. Advocat, and J. L. Dussossoy, "Effects of the SA/V Ratio on the LongTerm Corrosion Kinetics of R7-T7 Glass," Nuclear Waste Mgmt. III, 175-185 (1991).

92. J. K. Bates, W. I.. Ebert, J. P. Bradley, and W. L. Bourcier, "Mechanistic Interpretation of Glass Reaction: Input to Kinetic Model Development," Proc. of the 2nd Annual International High-Level Radioactive Waste Management Topical Meeting, American Nuclear Society, Las Vegas, NV, Vol. 1, pp. 72()$-727$ (1991).

93. C. M. Jantzen, "Thermodynamic Approach to Glass Corrosion," in Corrosion of Glass, Ceramics, and Ceramic Superconductors, eds. D. E. Clark and B. K. Zoitos, Noyes Publications, Park Ridge, New Jersey, pp. 153-215 (1992).

94. C. M. Jantzen and M. J. Plodinec, "Thermodynamic Model of Natural, Medieval, and Nuclear Waste Glass Durability," J. Non-Cryst. Solids 67, 2(17-223 (1984).

95. A. Paul, Chemistry of Glasses, 2nd ed., Chapman and Hall, London (199()).

96. M. J. Plodinec, C. M. Jantzen, and G. G. Wicks, "Stability of Radioactive Waste Glasses Assessed from Hydration Thermodynamics," Mat. Res. Soc. Symp. Proc. 26, 755-762 (1984).

97. C. M. Jantzen and W. G. Ramsey, "Prediction of Radioactive Waste Glass Durability by the Hydration Thermodynamic Model: Application to Saturated Repository Environments," Mat. Res. Soc. Symp. Proc. 176, 217-228(1990)).

98. T. A. Abrajano, J. K. Bates, and J. K. Bohlke, "Linear Free Energy Relationships in Glass Corrosion," Mat. Res. Soc. Symp. Proc. 125, 383-392 (1988).

99. B. C. Bunker, "Waste Glass Leaching: Chemistry and Kinetics," Mat. Res. Soc. Symp. Proc. 84, 493-507 (1987).

100. G. Perera and R. H. Doremus, "Dissolution Rates of Silicate Glases in Water at pH 7," J. Am. Cer. Soc. 74(6), 1269-1274 (1991).

101. P. Richet and Y. Bottinga, "Thermochemical Properties of Silicate Glasses and Liquids: A Review," Rev. Geophys. 24 (1), 1-25 (1986).

102. A. Paul, "Chemical Durahility of Glasses: A Thermodynamic Approach," J. Mater. Sci. $12,2246-2268$ (1977).

103. J. D. Cox, D. D. Wagman, and V. A. Medvedev, CODATA Key Values for Thermodynamics, Hemisphere Publishing Corporation, New York (1989).

104. H. C. Helgeson, J. M. Delany, H. W. Nesbitt, and D. M. Bird, "Summary and Critique of the Thermodynamic Properties of Rock-Forming Minerals," Am. J. Sci. 278, 1-229 (1978).

105. B. M. J. Smets and T. P. A. Lommen, "The Leaching of Sodium Aluminosilicate Glasses Studied by Secondary Ion Mass Spectroscony," Phys. Chem. Glasses 23, 83-87 (1982).

106. J. O. Isard and W. Muller, "The Influence of Alkaline Earth Ions on the Corrosion of Glasses," Phys. Chem. Glasses 27, 55-58 (1986). 
107. L. Trotignon, "Aqueous Corrosion of Borosilicate Glasses: Nature and Properties of Alteration Layers," Ph.D. Thesis, Paul Sabatier University, Toulouse, France (1990).

108. X. Feng, I. L. Pegg, A. Barkatt, P. B. Macedo, S. J. Cucinell, and S. Lai, "Correlation between Composition Effects on Glass Durability and the Structural Role of the Constituent Oxides," Nucl. Technol. 토, 334-345 (1989).

109. M. Kinoshita, M. Harada, Y. Sato, and Y. Hariguchi, "Percolation Phenomenon for Dissolution of Sodium Borosilicate Glasses in Aqueous Solutions," J. Am. Cer. Soc. 74 , 783-787 (1991).

110. J. K. Bates, W. L. Ehert, X. Feng, and W. L. Bourcier, "Issues Affecting the Prediction of Glass Reactivity in an Unsaturated Environment," J. Nucl. Mater. 190, 198-227 (1992).

111. J. D. Rimstidt and H. L. Barnes, "The Kinetics of Silica-Water Reactions," Geochim. Cosmochim. Acta 44(11), 1683-1699 (1980).

112. J. J. Mazer, Temperature Effects on Waste Glass Performance, Argonne National Laboratory Report ANL-91/17 (1991).

113. J. C. Petit, J. C. Dran, G. Della Mea, and A. Paccagnella, "Dissolution Mechanisms of Silicate Minerals Yielded by Intercomparison with Glasses and Radiation Damage Studies," Chem. Geol. 78, 219-227 (1989).

114. E. Y. Vernaz, J. L. Dussossoy, and S. Fillet, "Temperature Dependence of R7T7 Nuclear Waste Glass Alteration Mechanism," Mat. Res. Soc. Symp. Proc. 112, 555-563 (1988).

115. B. M. J. Smets and M. G. W. Tholen, "The pH Dependence of the Aqueous Corrosion of Glass," Phys. Chem. Glasses 26(3), 60-63 (1985).

116. K. G. Knauss, W. L. Bourcier, K. D. McKeegan, C. I. Merzbacher, S. N. Nguyen, F. J. Ryerson, D. K. Smith, H. C. Weed, and L. Newton, "Dissolution Kinetics of a Simple Nuclear Waste Glass as a Function of $\mathrm{pH}$, Time, and Temperature," Mat. Res. Soc. Symp. Proc. 176, 371-381 (1990)).

117. B. J. Wood and J. V. Walther, "Rates of Hydrothermal Reactions," Science 222, 413-415 (1983).

118. W. L. Bourcier, W. L. Ebert, and X. Feng, "Modeling Surface Area to Volume Effects on Borosilicate Glass Dissolution," Mat. Res. Soc. Symp. Proc. (in press) (1994).

119. D. M. Strachan, B. P. McGrail, M. J. Apted, D. W. Engel, and P. W. Eslinger, Preliminary Assessment of the Controlled Release of Radionuclides from Waste

- Packages Containing Borosilicate Waste Glass, Pacific Northwest Laboratory Report PNL-7591 (1990).

120. J. C. Petit, J. C. Dran, L. Trotignon, J. M. Casabonne, A. Paccagnella, and G. Della Mea, "Mechanism of Heavy Element Retention in Hydrated Layers Formed on Leached Silicate Glasses," Mat. Res. Soc. Symp. Proc. 127, 33-40 (1989).

121. R. A. Van Konynenburg, Radiation Chemical Effects in Experiments to Study the Reaction of Glass in an Environment of Gamma-Irradiated Air, Groundwater, and Tuff, Lawrence Livermore National Laboratory Report UCRL-53719 (1986). 
122. G. L. McVay and L. R. Pederson, "Effect of Gamma Radiation on Glass Leaching," J. Am. Cer. Soc. 64, 154-158 (1981).

123. Z. Andriambololona, N. Godon, and E. Vernaz, "R7T7 Glass Alteration in the Presence of Mortar: Effect of the Cement Grade," Mat. Res. Soc. Symp. Proc. 257, 151-158 (1992).

124. W. H. Casey and B. C. Bunker, "Leaching of Mineral and Glass Surfaces during Dissolution," in Mineral-Water Interface Geochemistry, eds. M. F. Hochella and A. F. White, Vol. 23, 1st ed., Mineralogical Society of America, Washington, D.C., pp. $397-424$ (1990).

125. M. A. Velbel, "Influence of Surface Area, Surface Characteristics, and Solution Composition on Feldspar Weathering Rates, " in Geochemical Processes at Mineral Surfaces, eds. J. Davis and K. Hayes, American Chemical Society, Washington, DC, pp. 613-634 (1986).

126. R. C. Ewing and G. Roed, "Natural Analogues: Their Application to the Prediction of the Long-Term Behavior of Nuclear Waste Glasses," Mat. Res. Soc. Symp. Proc. $\underline{84}$, $67-83$ (1987).

127. K. F. Hayes, "Equilibrium, Spectroscopic, and Kinetic Studies of Ion Adsorption at the Oxide/Aqueous Interface," Ph.D. Thesis, Stanford University, Stanford, California (1987).

128. J. K. Bates, W. L. Bourcier, C. R. Bradley, N. R. Brown, E. C. Buck, S. A. Carroll, J. C. Cunnane, N. L. Dietz, T. DiSanto, W. L. Ebert, J. W. Emery, X. Feng, T. J. Gerding, M. Gong, L. D. Hafenrichter, J. C. Hoh, J. J. Mazer, L. Newton, B. L. Phillips, R. Pletcher, and D. J. Wronkiewicz, Technical Support Program for DOE Environmental Restoration and Waste Management, Annual Report, October 1992. September 1993, Argonne National Laboratory Report ANL-94/19 (1994).

129. A. B. Woodland, J. K. Bates, and T. J. Gerding, Parametric Effects on Glass Reaction in the Unsaturated Test Method, Argonne National Laboratory Report ANL-91/36 (1991).

130. T. A. Abrajano, J. K. Bates, T. J. Gerding, and W. L. Ebert, The Reaction of Glass during Gamma-Irradiation in a Saturated Tuff Environment. Part 3. Long-Term Experiments at $1 \times 10^{4}$ Rad/Hour, Argonne National Laboratory Report ANL-88-14 (1988).

131. J. K. Bates and T. J. Gerding, NNWSI Waste Form Test Method for Unsaturated Disposal Conditions, Lawrence Livermore National Laboratory Report UCRL-15723 (1989).

132. J. K. Bates, T. J. Gerding, W. L. Ebert, J. J. Mazer, and B. M. Biwer, NNWSI Waste Form Testing at Argonne National Laboratory, Semiannual Report, July-December 1987, Lawrence Livermore National Laboratory Report UCRL-21060-87-2 (1988).

133. J. K. Bates, T. J. Gerding, D. F. Fisher, and W. L. Ebert, The Reaction of Glass in a Gamma-Irradiated Saturated Tuff Environment, Part II: Data Package for ATM-1c and ATM-8 Glasses, Lawrence Livermore National Laboratory Report UCRL-15991 (1987). 
134. N. E. Bibler and C. M. Jantzen, "Materials Interactions Relating to Long-Term Geologic Disposal of Nuclear Waste Glass," Mat. Res. Soc. Symp. Proc. 84, 47-66 (1987).

135. G. Bart, H. U. Zwicky, E. T. Aerne, Th. Graber, D. Z'Berg, and M. Tokiwai, "Borosilicate Glass Corrosion in the Presence of Steel Corrosion Products," Mat. Res. Soc. Symp. Proc. 84 , 459-470 (1987).

136. D. B. Burns, B. H. Upton, and G. G. Wicks, "Interactions of SRP Waste Glass with Potential Overpack Materials," J. Non-Cryst. Solids $\underline{84}$, 258-267 (1986).

137. H. P. Hermansson, H. Christensen, I. K. Bjorner, L. Werme, and D. E. Clark, "Variables Affecting the Leaching of Swedish Nuclear Waste Glasses," Nucl. Chem. Waste Mgmt. 5, 315-332 (1985).

138. E. Curti and P. A. Smith, "Enhancement of Borosilicate Glass Dissolution by Silica Sorption and Diffusion in Compacted Bentonite: A Model Study," Mat. Res. Soc. Symp. Proc. 212, 31-39 (1991).

139. H Wanner, "Modeling Interactions of Deep Groundwaters with Bentonite," in Proc. Workshop on Geochemical Modeling, Fallenleaf Lab, California, eds. K. J. Jackson and W. L. Bourcier, pp. 120-129 (1986).

140. C. Q. Buckwalter and L. R. Pederson, "Inhibition of Nuclear Waste Glass Leaching by Chemisorption," J. Am. Cer. Soc. 65, 431-436 (1982).

141. B. Grambow, H. P. Hermansson, I. K. Bjorner, and L. Werme, "Glass/Water Reaction with and without Bentonite Present," Mat. Res. Soc. Symp. Proc. 50, 263-272 (1986).

142. C. M. Jantzen, "Prediction of Nuclear Waste Glass Durability from Natural Analogs," Adv. Ceram. 20, 703-712 (1986).

143. B. Grambow, M. J. Jercinovic, R. C. Ewing, and C. D. Byers, "Weathered Basalt Glass: A Natural Analogue for the Effects of Reaction Progress on Nuclear Waste Glass Alteration," Mat. Res. Soc. Symp. Proc. 50), 263-272 (1985).

144. B. P. McGrail, L. R. Pederson, D. M. Strachan, R. C. Ewing, and L. C. Cordell, "Obsidian Hydration Dating - Field, Laboratory, and Modeling Results," Mat. Res. Soc. Symp. Proc. 125, 393-399 (1988).

145. G. Berger, J. Schott, and M. Loubet, "Fundamental Processes Controlling the First Stage of Alteration of a Basalt Glass by Seawater: An Experimental Study between 200 and $320^{\circ} \mathrm{C}$," Earth and Planet. Sci. Lett. 84, 431-445 (1987).

146. J. L. Crovisier, J. Honnorez, and B. Fritz, "Dissolution of Subglacial Volcanic Glasses from Iceland: Laboratory Study and Modeling," Appl. Geochem. Suppl. Issue No. 1, 55-81 (1992).

147. D. J. Bradley, C. O. Harvey, and R. P. Turcotte, Leaching of Actinides and Technicium from Simulated High-Level Waste Glass, Pacific Northwest Laboratory Report PNL-3152 (1979).

148. S. Fillet, J. L. Nogues, E. Vernaz, and N. Jacquet-Francillon, "Leaching Actinides from the French LWR Reference Glass," Mat. Res. Soc. Symp. Proc. 50, 11-22 (1985). 
149. J. A. Schramke, S. A. Simonson, and D. G. Coles, "Np-237 and Pu-239 Solution Behavior during Hydrothermal Testing of Simulated Nuclear Waste Glass with Basalt and Steel," Mat. Res. Soc. Symp. Proc. 44, 343-350)(1985).

150. E. Y. Vernaz and N. Godon, "Leaching of Actinides from Nuclear Waste Glass: French Experience," Mat. Res. Soc. Symp. Proc. 257, 37-48 (1992).

151. J. F. Kerrisk, "Solubility Limits and Radionuclide Dissolution," Mat. Res. Soc. Symp. Proc. 44, 237-244 (1985).

152. B. P. McGrail and D. W. Engel, "Coupled Process Modeling and Waste-Package Performance," Mat. Res. Soc. Symp. Proc. 294, 215-223 (1993).

153. C. N. Wilson and C. J. Bruton, "Studies on Spent Fuel Behavior under Yucca Mountain Repository Conditions," Ceram. Trans. 9, 423-441 (1991).

154. B. P. McGrail, M. J. Apted, D. W. Engel, and A. M. Licbetrau, "A Coupled ChemicalMass Transport Submodel for Predicting Radionuclide Release from an Engineered Barrier System Containing High-Level Waste Glass," Mat. Res. Soc. Symp. Proc. 176, 785-792 (1990).

155. A. M. Liehetrau, M. A. Apted, D. W. Engel, M. K. Altenhofen, C. R. Reid, D. M. Strachan, R. L. Erikson, and D. H. Alexander, "AREST: A Probabilistic SourceTerm Code for Waste Package Performance Analysis," Proc. of Waste Mgmt. '87, Vol. 2, ed. R. G. Post, University of Arizona, Tucson, Arizona (1987).

156. R. A. Shaw and R. K. McGuire, Demonstration of a Risk-Based Approach to HighLevel Waste Repository Evaluation, Electric Power Research Institute Report EPRI NP-7057 (1989).

157. E. Mouche, P. Lovera, and M. Jorda, "Near-Field Modeling for the Safety Assessment of French High-Level Waste Repositories," High-Level Radioactive Waste Management, American Nuclear Society, pp. 691-698 (1990).

158. E. Mouche and E. Vernaz, "Aqueous Corrosion of the French LWR Solution Reference Glass: First Generation Model," Mat. Res. Soc. Symp. Proc. 112, 703-712 (1988).

159. W. J. O'Connell and R. S. Drach, Waste Package Performance Assessment: Deterministic System Model Program Scope and Specification, Lawrence Livermore National Laboratory Report UCRL-53761 (1986).

160. H. Umeki, A. Suzuki, and R. Kiyose, "A Leach Model for Safety Assessment," Adv. Ceram. 20, 523-529 (1986).

161. P. L. Chambre, C. H. Kang, W. W. Lee, and T. H. Pigford, "The Role of Chemical Reaction in Waste-Form Performance," Mat. Res. Soc. Symp. Proc. 112, 285-291 (1988).

162. National Academy of Sciences, A Study of the Isolation System for Geologic Disposal of Radioactive Waste, National Academy Press (1983).

163. T. H. Pigford and P. L. Chambre, Reliable Predictions of Waste Performance in a Geologic Disposal of Radioactive Wastes, Lawrence Berkeley Laboratory Report LBL-20166 (1985). 
164. I. H. Thorseth, H. Furnes, and M. Heldal, "The Importance of Microbiological Activity in the Alteration of Basaltic Glass," Geochim. Cosmochim. Acta 56, 845-850 (1992).

165. D. Lovley, E. J. P. Phillips, Y. A. Gorby, and E. R. Landa, "Microbial Reduction of Uranium," Nature 350, 413-415 (1991).

166. F. Hiebert and P. C. Bennett, "Microbial Control of Silicate Weathering in Organic-Rich Groundwater," Science 258, 278-281 (1992).

167. S. Gin, N. Godon, J. P. Mestre, E. Y. Vernaz, and D. Beaufort, "Experimental Investigation of Aqueous Corrosion of R7T7 Nuclear Glass at $90{ }^{\circ} \mathrm{C}$ in the Presence of Organic Species," Appl. Geochem. (in press) (1994).

168. H. Spor, M. Trescinski, and M. F. Libert, "Microbial Effects on the Radionuclide Transport in a Deep Nuclear Waste Repository," Mat. Res. Soc. Symp. Proc. 294, $771-776$ (1993).

169. J. M. West, I. G. McKinley, H. A. Grogan, and S. C. Arme, "Laboratory and Modeling Studies of Microbial Activity in the Near Field of a High-Level Waste Repository," Mat. Res. Soc. Symp. Proc. 50, 533-539 (1985).

170. W. Stumm and E. Wieland, "Dissolution of Oxide and Silicate Minerals: Rates Depend on Surface Speciation," in Aquatic Chemical Kinetics, ed. W. Stumm, Wiley Intersciences, New York, pp. 36T-400) (1990).

171. W. L. Bourcier, S. A. Carroll, and B. L. Phillips, "Constraints on the Affinity Term for Modeling Long-Term Glass Dissolution Rates," Mat. Res. Soc. Symp. Proc. (in press) (1994).

172. W. Lutze and R. C. Ewing, "Silicate Glasses," in Radioactive Waste Forms for the Future, eds. W. Lutze and R. C. Ewing, North Holland, Amsterdam, pp. 1-159 (1988).

173. P. M. Dove and S. F. Elston, "Dissolution Kinetics of Quartz in Sodium Chloride Solutions: Analysis of Existing Data and a Rate Model for $25^{\circ} \mathrm{C}$," Geochim. Cosmochim. Acta 56, 4147-4156 (1992).

174. J. C. Dran, Y. Langevin, E. Doorhyee, and J. C. Petit, "Modeling the Dissolution of Silicate Glasses by a Monte-Carlo Code (Etch)," Mai. Res. Soc. Symp. Proc. $\underline{84}$, 559-569 (1987).

175. M. A. Lee, N. W. Winter, and W. H. Casey, "Investigation of the Ligand Exchange Reaction for the Aqueous Be ${ }^{2+}$ Ion," J. Phys. Chem. (in press) (1994).

176. A. C. Lasaga and J. Gibbs, "Ab Initio Quanturn-Mechanical Calculations of Surface Reactions - A New Era?" in Aquatic Chemical Kinetics, ed. W. Stumm, Wiley Intersciences, New York, pp. 259-289 (1990).

177. A. C. Lasaga, "Ab Initio Methods in Mineral Surface Reactions," Rev. Geophys. 30(3), 269-303 (1992). 
This page intentionally left blank. 
Distribution for ANL-94/1/

Internal:

J. K. Bates (35)

J. E. Harmon

J. J. Laidler

J. E. Battles

J. E. Helt

TIS Files

J. C. Cunnane

T. R. Johnson

\section{External:}

DOE-OSTI (2)

ANL-E Library (2)

ANL-W Library

Manager, Chicago Operations Office, DOE

A. Bindokas, DOE-CH

J. Haugen, DOE-CH

Chemical Technology Division Review Committee Members:

E. R. Beaver, Monsanto Company, St. Louis, MO

D. L. Douglas, Consultant, Bloomington, $\mathrm{MN}$

R. K. Genung, Oak Ridge National Laboratory, Oak Ridge, TN

J. G. Kay, Drexel University, Philadelphia, PA

G. R. St. Pierre, Ohio State University, Columbus, $\mathrm{OH}$

J. Stringer, Electric Power Research Institute, Palo Alto, CA

J. B. Wagner, Arizona State University, Tempe, AZ

T. Ahn, U. S. Nuclear Regulatory Commission, Washington, DC

D. H. Alexander, USDOE, Civilian Radioactive Waste Management, Washington, DC

J. Allison, USDOE, Office of Waste Operations, Germantown, MD

S. Bates, Idaho Falls, ID

H. Benton, B\&W Fuel Company, Las Vegas, NV

A. Berusch, USDOE, Office of Civilian Radioactive Waste Management, Washington, DC

N. E. Bibler, Westinghouse Savannah River Company, Aiken, SC

J. M. Boak, USDOE, Yucca Mountain Site, Las Vegas, NV

K. Boomer, Westinghouse Hanford Company, Richland, WA

W. Bourcier, Lawrence Livermore National Laboratory, Livermore, CA

E. Bramlitt, Defense Nuclear Ager sy, Kirtland Air Force Base, Kirtland, NM

A. Brandstetter, Science Applications, International Corporation, Las Vegas, NV

J. Bucher, Lawrence Berkeley Laboratory, Berkeley, CA

J. Canepa, Los Alamos National Laboratory, Los Alamos, NM

K. A. Chacey, USDOE, Office of Waste Management, Germantown, MD

D. Chestnut, Lawrence Livermore National Laboratory, Livermore, CA

G. R. Choppin, Florida State University, Tallahassee, FL

S. Clark, University of Georgia, Savannah River Ecology Laboratory, Aiken, SC

P. Cloke, Science Applications International Corp., Las Vegas, NV

M. O. Cloninger, Mac Technical Services, Inc., Richland, WA

D. Codell, U. S. Nuclear Regulatory Commission, Washington, DC 
G. Colten-Bradley, U. S. Nuclear Regulatory Commission, Rockville, MD

C. Colter, Los Alamos National Laboratory, Los Alamos, NM

S. Coplan, U. S. Nuclear Regulatory Commission, Washington, DC

S. P. Cowan, USDOE, Office of Waste Management, Germantown, MD

J. Davidson, U. S. Environmental Protection Agency, Washington, DC

J. Docka, Roy F. Weston, Inc., Washington, DC

R. Dresser, Roy F. Weston, Inc., Washington, DC

R. S. Dyer, Yucca Mountain Project Office, Las Vegas, NV

R. E. Erickson, USDOE, Office of Waste Operations, Germantown, MD

E. Essington, Los Alamos National Laboratory, Los Alamos, NM

F. M. Estes, Idaho State University, Pocatello, ID

R. C. Ewing, Department of Geology, University of New Mexico, Albuquerque, NM

D. Farr, Los Alamos National Laboratory, Los Alamos, NM

R. Fish, B\&W Fuel Company, Las Vegas, NV

J. Gauthier, Sandia National Lab ratories, Albuquerque, NM

F. Gelbard, Sandia National Laboratories, Albuquerque, NM

C. P. Gertz, USDOE, Yucca Mountain Project Office, Las Vegas, NV

S. E. Gomberg, USDOE, Office of Civilian Radioactive Waste Management, Washington, DC

W. Gray, Battelle Pacific Northwest Laboratory, Richland, WA

P. W. Hart, USDOE, Office of Technology Development, Germantown, MD

J. Hennessey, USDOE, Office of Waste Operations, Germantown, MD

D. Hobart, LANL-TTSO/USDOE Headquarters, Germantown, MD

J. Hunt, University of California, Berkeley, Berkeley, CA

D. Hutchins, Martin Marietta Systems, Inc., Oak Ridge, TN

C. Interrante, U. S. Nuclear Regulatory Commission, Washington, DC

C. Jantzen, Westinghouse Savannah River Company, Aiken, SC

L. J. Jardine, Lawrence Livermore National Laboratory, Livermore, CA

P. Kearl, Oak Ridge National Laboratory, Grand Junction, CO

J. Keith, Daniel B. Stephens \& Associates, Albuquerque, NM

J. Kerrisk, Los Alamos National Laboratory, Los Alamos, NM

W. S. Ketola, USDOE, West Valley Project Office, W'est Valley, NY

D. A. Knecht, Westinghouse Idaho Nuclear Company, Idaho Falls, ID

W. L. Kuhn, Battelle Pacific Northwest Laboratory, Richland, WA

K. S. Kung, Los Alamos National Laboratory, Los Alamos, NM

W. Lee, Environmental Evaluation Group, Albuquerque, NM

W. W. Lee, University of California, Berkeley, CA

J. C. Lehr, USDOE, Office of Environmental Restoration, Germantown, MD

H. Leider, Lawrence Livermore National Laboratory, Livermore, CA

R. A. Lemons, Los Alamos National Laboratory, Los Alamos, NM

S. Levy, Los Alamos National Laboratory, Los Alamos, NM

D. Livingston, USDOE, Yucca Mountain Site, Las Vegas, NV

R. Lopez, Los Alamos National Laboratory, Los Alamos, NM

J. J. Lorenz, USDOE, Yucca Mountain Site, Las Vegas, NV

R. Luce, Nuclear Waste Technical Review Board, Arlington, VA

W. Lutze, University of New Mexico, Albuqueque, NM

H. Manaktala, Southwest Research Institute, San Antonio, TX 
S. Martin, Lawrence Livermore National Laboratory, Live: is, CA

J. M. Matuszek, JMM Consulting, Del Mar, NY

J. McCarthy, Oak Ridge National Laboratory, Oak Ridge, TN

L. McDowell-Boyer, Oak Ridge National Laboratory, Grand Junction, CO

T. W. Mcintosh, USDOE, Office of Waste Management, Germantown, MD

A. Meijer, Jacobs Engineering, Albuquerque, NM

J. Meldrum, University of Nevada - Las Vegas, Las Vegas, NV

A. Mitchell, Los Alamos National Laboratory, Los Alamos, NM

R. Morissette, Science Applications International Corp., Las Vegas, NV

D. Morris, Los Alamos National Laboratory, Los Alamos, NM

P. K. Nair, Southwest Research Institute, San Antonio, TX

S. Nelson, Las Vegas, NV

B. Newman, Los Alamos National Laboratory, Los Alamos, NM

C. Novak, Sand ^ National Laboratories, Albuquerque, NM

E. Nultall, University of New Mexico, Albuquerque, NM

W. O'Connell, Lawrence Livermore National Laboratory, Livermore, CA

G. C. S. Ordaz, USDOE, Office of Technology Development, Germantown, MD

C. Palmer, Lawrence Livermore National Laboratory, Livermore, CA

R. Palmer, West Valley Nuclear Services, West Valley, NY

H. Papenguth, Sandia National Laboratories, Albuquerque, NM

U-Sun Park, Science Applications International Corp., Las Vegas, NV

W. D. Pearson, Westinghouse Savannah River Company, Aiken, SC

C. Peterson, U. S. Nuclear Regulatory Commission, Washington, DC

T. H. Pigford, University of California, Berkeley, CA

M. J. Plodinec, Westinghouse Savannah River Company, Aiken, SC

W. Polzer, Los Alamos National Laboratory, Los Alamos, NM

W. G. Ramsey, Westinghouse Savannah River Company, Aiken, SC

P. Reimus, Los Alamos National Laboratory, Los Alamos, NM

B. Robinson, Los Alamos National Laboratory, Los Alamos, NM

P. Rogers, Los Alamos National Laboratory, Los Alamos, NM

R. Rundberg, Los Alamos National Laboratory, Los Alamos, NM

C. G. Russomanno, USDOE, Civilian Radioactive Waste Management, Washington, DC

J. Ryan, University of Colorado, Boulder, CO

R. Schulze, Los Alamos National Laboratory, Los Alamos, NM

W. C. Schutte, USDOE, Office of Technology Development, Germantown, MD

R. Sherman, Los Alamos National Laboratory, Los Alamos, NM

M. Siegel, Sandia National Laboratories, Albuquerque, NM

M. Silva, Environmental Evaluation Group, Albuquerque, NM

R. Silva, Lawrence Livermore National Laboratory, Livermore, CA

A. Simmons, USDOE, Las Vegas, NV

E. Springer, Los Alamos National Laboratory, Los Alamos, NM

J. Sproull, Westinghouse Savannah River Company, Aiken, SC

D. Stahl, M\&O/B\&W Fuel Company, Las Vegas, NV

W. Steinkampf, U.S. Geological Survey, Lakewood, CO

L. Stetzenbach, University of Nevada - Las Vegas, Las Vegas, NV

R. B. Stout, Lawrence Livermore National Laboratory, Livermore, CA 
D. Strachan, Battelle Pacific Northwest Laboratories, Richland, WA

M. Tomozawa, Rensselaer Polytechnic Institute, Troy, NY

I. Triay, Los Alamos National Laboratory, Los Alamos, NM

V. Trice, USDOE, Office of Waste Management, Germantown, MD

D. Turner, Southwest Research Institute, San Antonio, TN

B. Viani, Lawrence Livermore National Laboratory, Livermore, CA

J. Wan, New Mexico Tech, Socorro, NM

L. Wang, University of New Mexico, Albuquerque, NM

R. Weiner, Environmental Evaluation Group, Albuquerque, NM

M. Whitbeck, Desert Research Institute, University of Nevada, Reno, NV

C. N. Wilson, Westinghouse Hanford Company, Richland, WA

J. Wilson, New Mexico Tech, Socorro, NM

M. Wilson, Sandia National Laboratories, Albuquerque, NM

A. Wistrom, Los Alamos National Laboratory, Los Alamos, NM

J. H. Wolfram, Biotechnology-INTEL, Montana State University, Bozeman, MT

K. Wolfsberg, Los Alamos National Laboratory, Los Alamos, NM

A. Wollerman, Science Applications International Corp., Germantown, MD

A. Yang, U.S. Geological Survey, Denver, CO

M. P. Gardiner, Harwell Laboratory, Didcot, Oxon, UNITED KINGDOM

N. C. Garisto, Atomic Energy of Canada, Pinawa, Manitoba, CANADA

B. Grambow, Kernforschungszentrum Karlsruhe, GmbH, GERMANY

J. Kim, Kernforschungszentrum Karlsruhe, GERMANY

H. Nitsche, Forschungszentrum Rossendorf e.V., Institut fur Radiochemie, GERMANY

T. Payne, Australian Nuclear Science and Technology Organization, AUSTRALIA

P. Van Isegham, Boerecamp, BELGIUM

E. Vernaz, Centre d'Etudes Nucleares de la Valle du Rhone, Marcoule, FRANCE

P. Vilks, Atomic Energy of Canada, Whiteshell Laboratories, Pinawa, Manitoba, CANADA

L. Werme, Svensk Karnbranslehantering AB, Stockholm, SWEDEN 

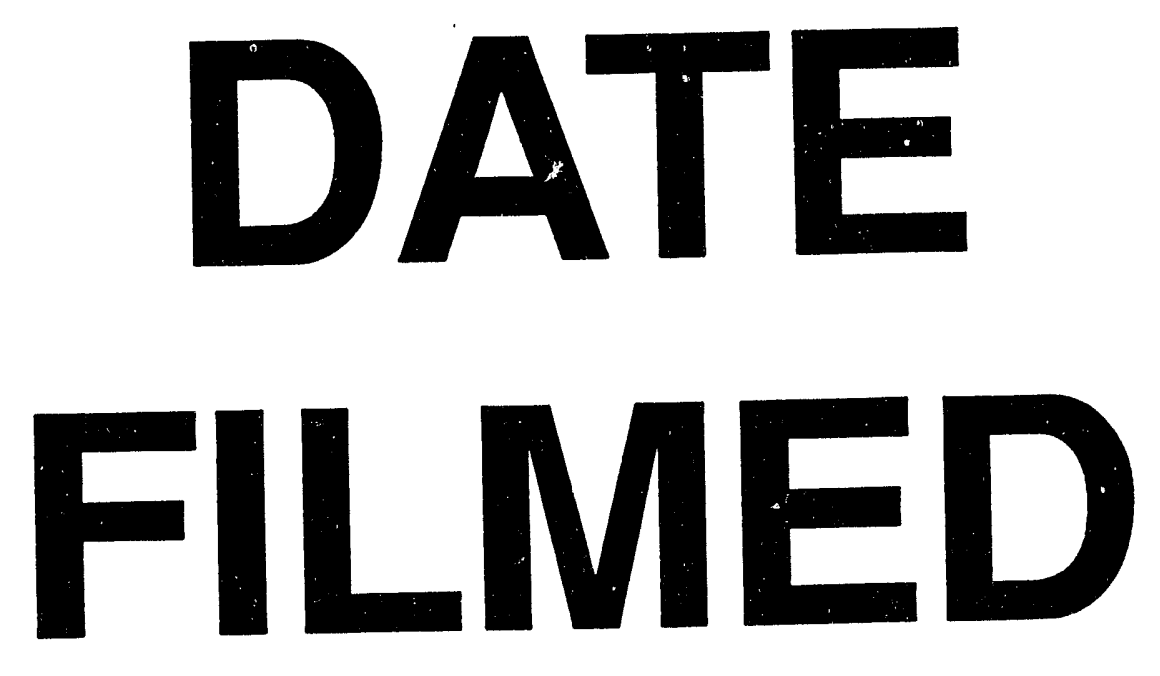

$9 / 29 / 94$
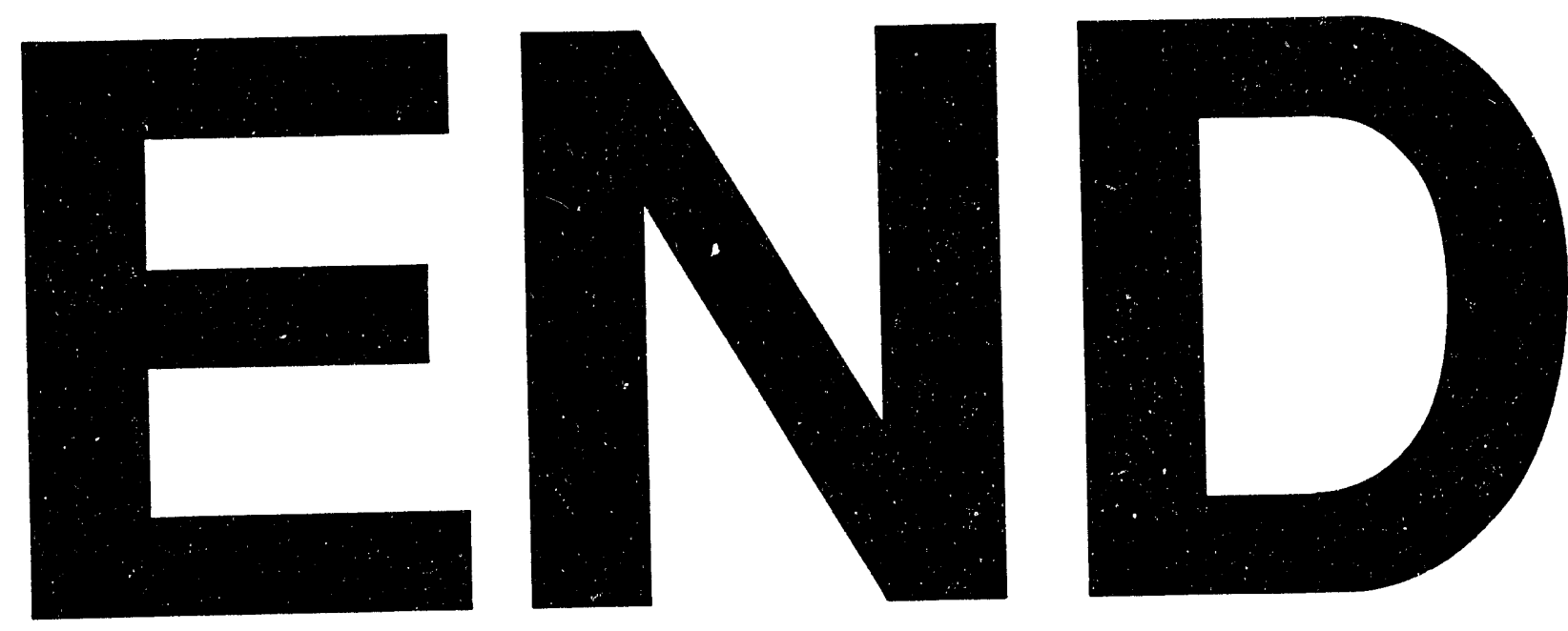
